Um simulador para modelos de larga escala baseado no padrão scalable simulation framework (ssf) 



\title{
Um simulador para modelos de larga escala baseado no padrão scalable simulation framework (ssf)
}

\author{
Alexandre Nogueira Jahnecke
}

Orientador: Profa. Dra. Sarita Mazzini Bruschi

Dissertação apresentada ao Instituto de Ciências Matemáticas e de Computação - ICMC-USP como parte dos requisitos para obtenção do título de Mestre em Ciências de Computação e Matemática Computacional.

\section{USP - São Carlos}

Junho de 2007 
“Os verdadeiros sábios, são aqueles que criam;

Os verdadeiros alunos, aqueles que aprendem.

Os que decoram, são falsos profetas..."

(autor desconhecido) 
Agradeço do fundo do meu coração, à minha família, que sempre me incentivou e lutou para me permitir uma educação da melhor qualidade. Agradeço ao meu irmão César Augusto, pessoa a qual tenho a mais profunda admiração, pelo seu esforço diante às adversidades e pela honrada luta em busca de seus sonhos. E agradeço aos meus pais, que sempre lutaram para que nós, seus filhos, não fôssemos iguais a eles, e sim, melhores que eles, nunca nos deixando faltar nada e muitas vezes, abdicando de seus sonhos para realizar os nossos. Muito obrigado "mama e papa"!

Agradeço à minha amada esposa Maria Cristina que, com muita paciência, me incentivou, me ajudou e me deu forças para concluir o mestrado.

Agradeço à empresa LHS Américas Sistemas de Comunicação e ao meu gerente Marcos Ribeiro, por permitirem a minha vinda à Universidade para a defesa, deixando de trabalhar por um dia.

E, por fim, agradeço à minha orientadora Sarita Mazzini Bruschi, pelo apoio, pelo fornecimento de informações imprescindíveis para a conclusão do programa de mestrado e, principalmente, por orientar um aluno que desde o início não podia se dedicar de forma integral ao programa. 



\section{Sumário}

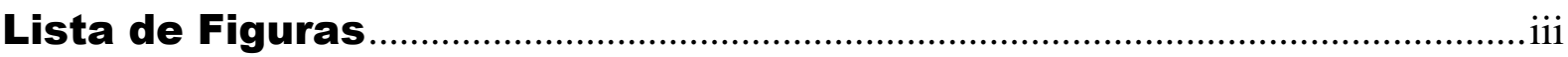

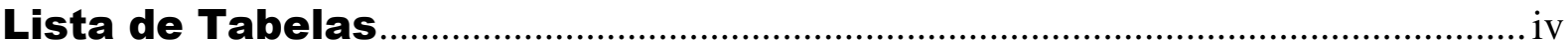

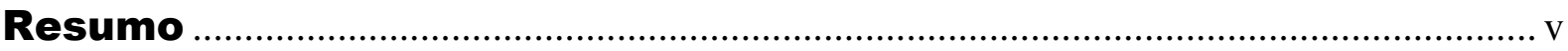

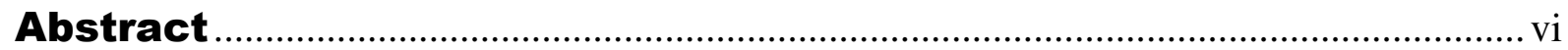

1. Introdução

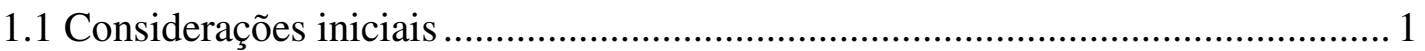

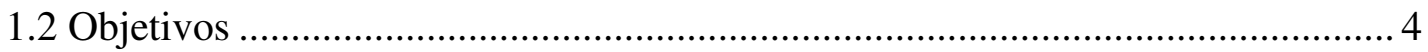

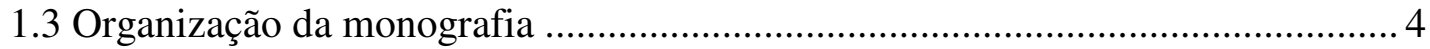

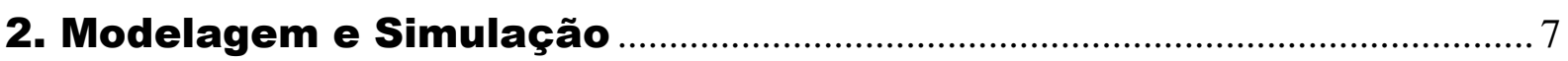

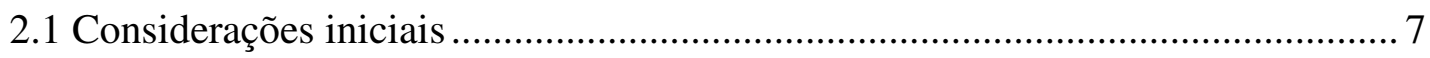

2.2 A modelagem e simulação de sistemas discretos ............................................... 8

2.3 Modelos baseados em redes de filas ............................................................... 11

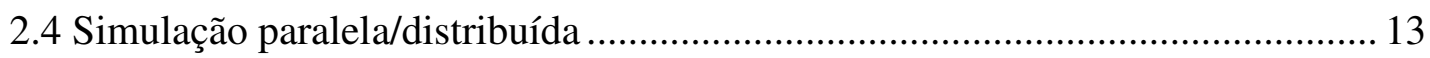

2.4.1 Protocolos de sincronismo conservativos ............................................. 15

2.4.2 Protocolos de sincronismo otimistas ...................................................... 16

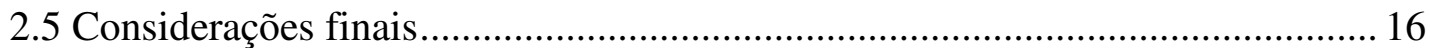

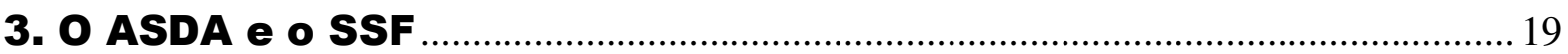

3.1 Considerações iniciais ....................................................................................... 19

3.2 O Ambiente de Simulação Distribuída Automático............................................ 21

3.3 O Scalable Simulation Framework ……........................................................ 24

3.4 Domain Modeling Language (DML) ............................................................ 28

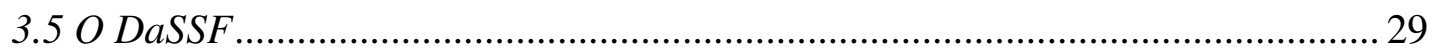

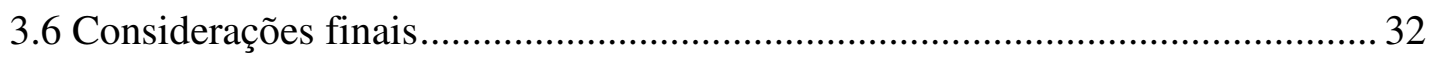

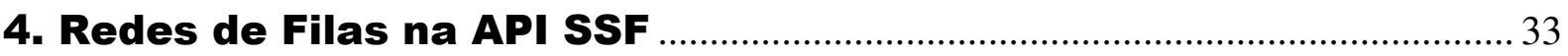

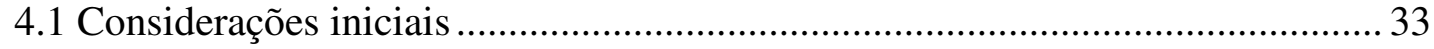

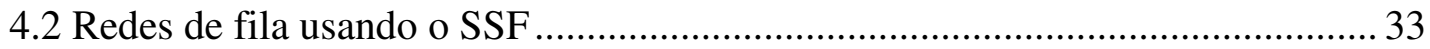

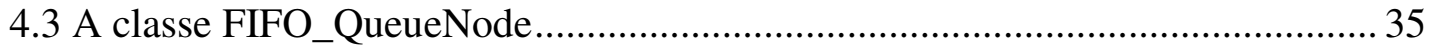

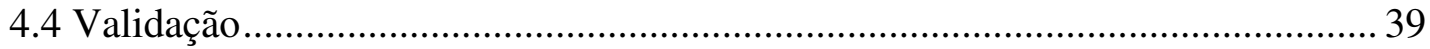

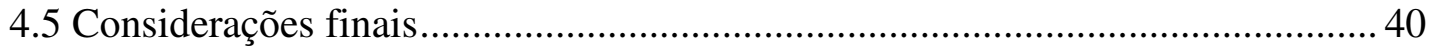

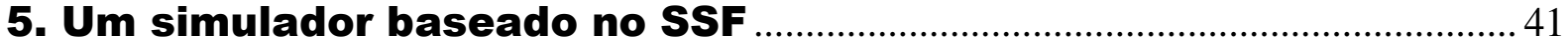

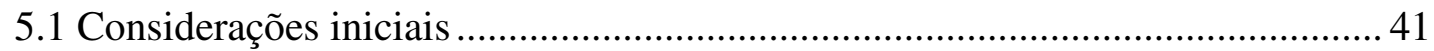

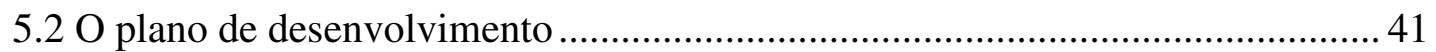

5.3 O módulo GUI: a interface com o usuário ....................................................... 45 
5.4 O módulo processador de modelos: ModelProcessor ........................................ 47

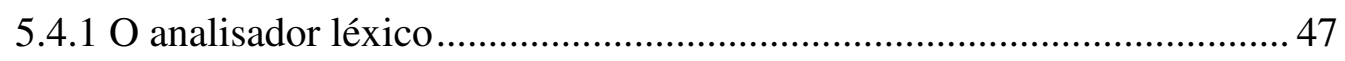

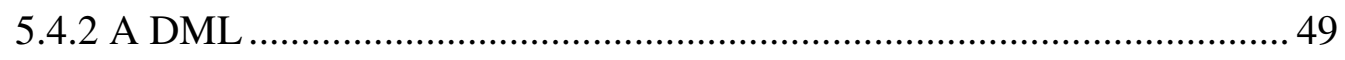

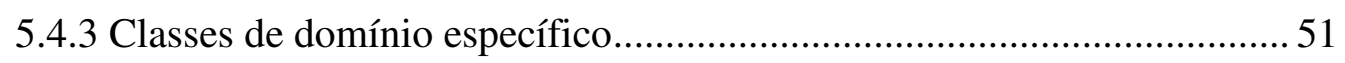

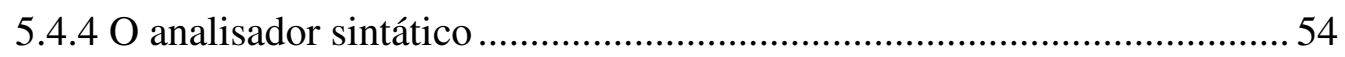

5.4.4.1 A árvore de sintaxe abstrata (ASA) .............................................. 56

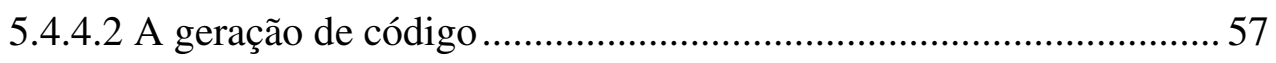

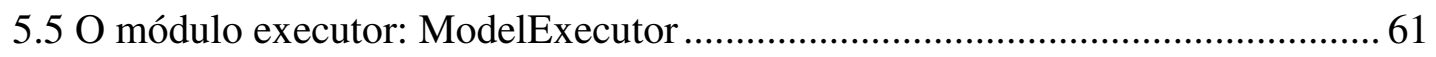

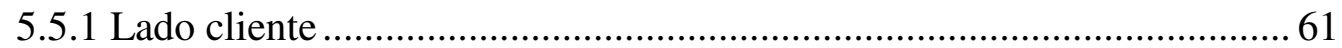

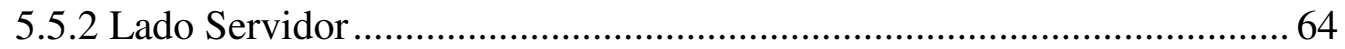

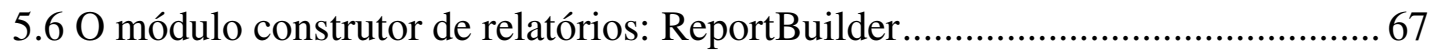

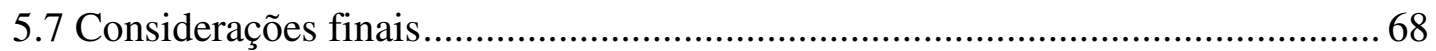

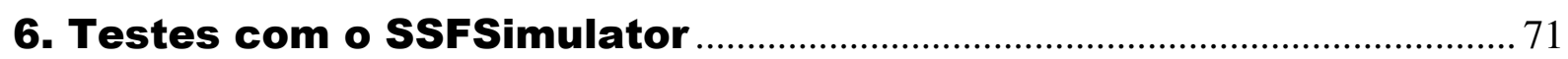

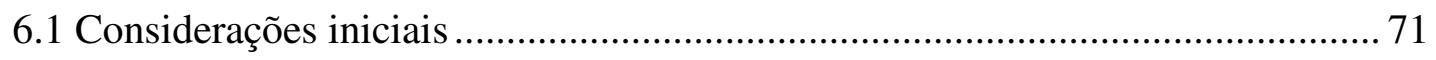

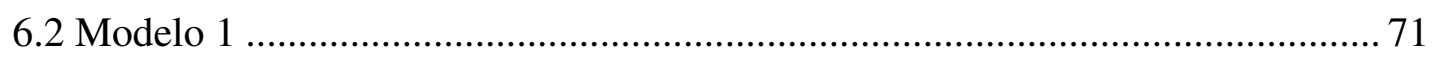

6.2.1 Geração do programa de simulação ..................................................... 74

6.2.2 Execução do programa de simulação ...................................................... 75

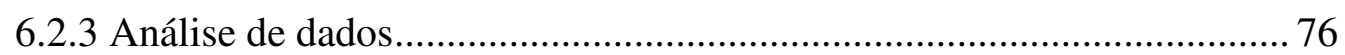

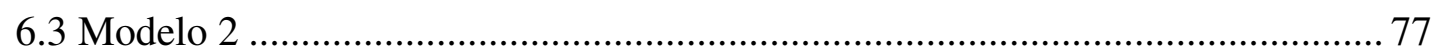

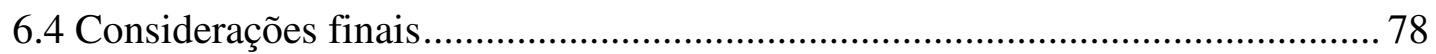

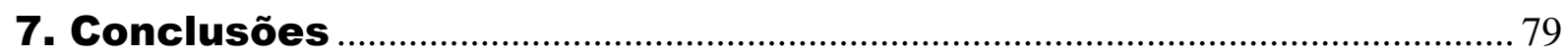

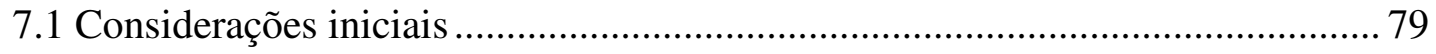

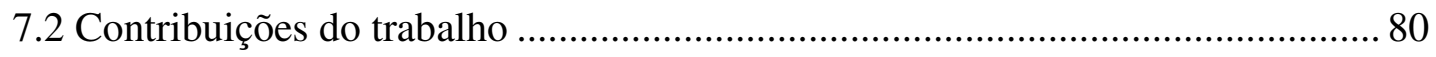

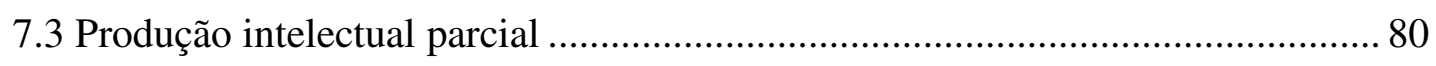

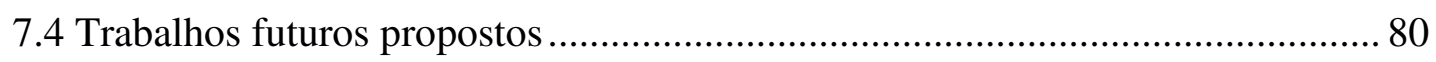

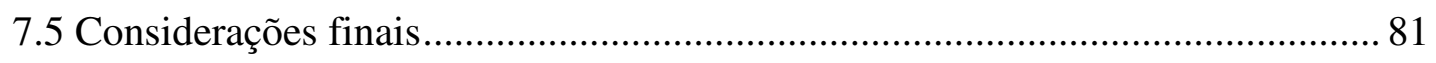

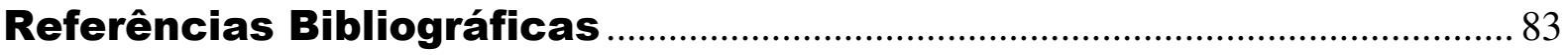

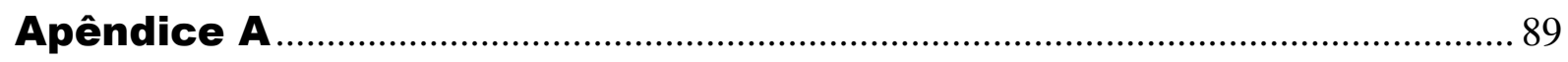

Apêndice B

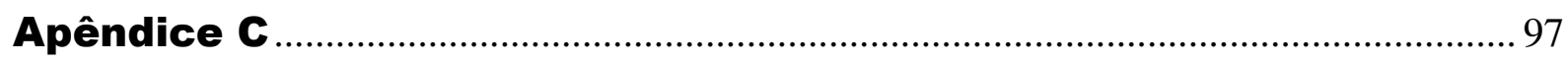

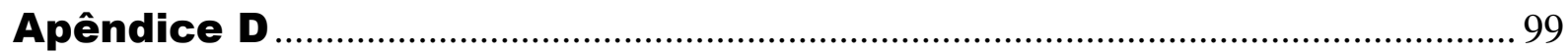




\section{Lista de Figuras}

Figura 3.1. Diagrama Modular do ASDA (Bruschi, 2002)................................................... 23

Figura 3.2. Organização dos processos no DaSSF (Liu \& Nicol, 2001)............................... 30

Figura 4.1. Visão conceitual de um centro de serviço ......................................................... 34

Figura 4.2. Modelo de redes de filas e mapeamento dos canais de saída para canais de

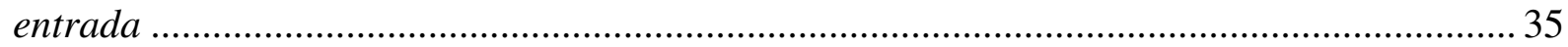

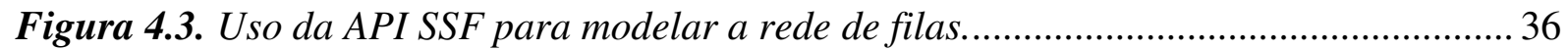

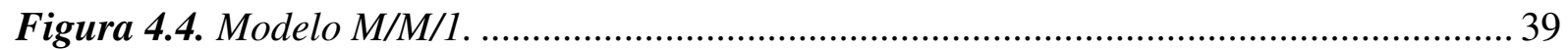

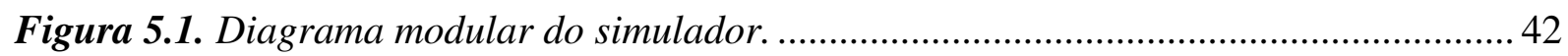

Figura 5.2. Fluxograma exibindo as atividades desempenhadas pelos componentes do

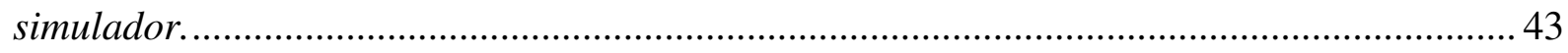

Figura 5.3. Associação entre os módulos do simulador e do ASDA. ...................................... 43

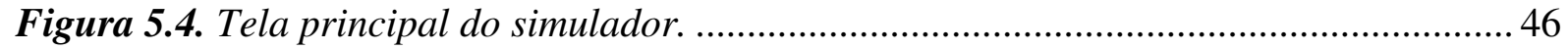

Figura 5.5. Diagrama de classes do analisador léxico do sistema. ....................................... 48

Figura 5.6. Especificação da gramática aceita pelo compilador. ............................................50

Figura 5.7. Código da função genC() da classe FIFO_Queue. ............................................52

Figura 5.8. Corpo da função genC() da classe FIFO_QueueNode. .................................... 53

Figura 5.9. Diagrama de classes do analisador sintático do SSFSimulator. ......................... 55

Figura 5.10. Visão conceitual da árvore de sintaxe abstrata. ...............................................56

Figura 5.11. Esqueleto da função main(), do programa de simulação................................... 58

Figura 5.12. Estrutura de diretórios (pacotes) do SSFSimulator. ........................................... 60

Figura 5.13. Diagrama de classes do lado cliente do módulo executor. ................................. 62

Figura 5.14. Diagrama de classes do SSFSimulatorServer. ..................................................6 65

Figura 5.15. Estrutura de diretórios do SSFSimulatorServer dentro da pasta do DaSSF .... 67

Figura 5.16. Relatório de execução formatado pelo ReportBuilder. ...................................... 68

Figura 6.1. Modelo visual de redes de filas que o modelo em DML representa..................... 72

Figura 6.2. Modelo em DML usado como exemplo. ............................................................ 72

Figura 6.3. Tela de exibição dos arquivos gerados do programa de simulação. ................... 73

Figura 6.4. Relatório básico de execução do programa de simulação, sem qualquer tipo de

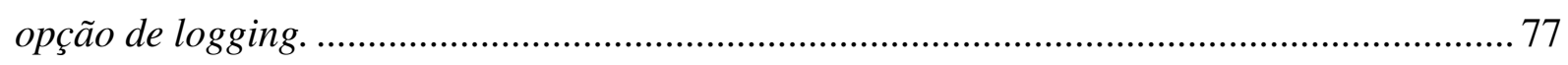

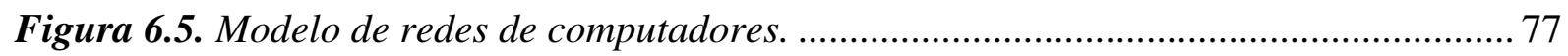




\section{Lista de Tabelas}

Tabela 3.1. Pseudo-código que ilustra a diferença entre as abordagens de simulação ......... 27

Tabela 4.1. Métodos e Funções da FIFO_QueueNode........................................................ 37

Tabela 4.2. Resultados dos testes efetuados com a classe FIFO_QueueNode........................ 40 


\section{Resumo}

Esta dissertação apresenta uma proposta de um simulador de modelos de larga escala para o Ambiente de Simulação Distribuída Automático (ASDA), uma ferramenta que facilita a utilização e o desenvolvimento de simulação distribuída e que vem sendo objeto de pesquisas e estudos no Laboratório de Sistemas Distribuídos e Programação Concorrente (LaSDPC) do ICMC-USP. Tal simulador permite ao ASDA a construção de modelos e programas que simulam modelos de redes de filas de larga escala, operações estas que tornam a ferramenta ainda mais completa. O simulador é baseado no padrão público para simulação distribuída de larga escala denominado Scalable Simulation Framework (SSF).

O protótipo do simulador desenvolvido é constituído de um programa cliente-servidor, mas podem ser observados três componentes principais: um compilador, que traduz os modelos escritos em linguagem de modelagem para linguagem $\mathrm{C}++$; o módulo SSF que define a API utilizada pelos programas de simulação; e um módulo de execução, que executa os programas de simulação, analisa os resultados e os repassa para um gerador de relatórios.

O simulador contribui ainda com mais estudos acerca de simulação, simulação distribuída e modelagem de sistemas utilizando as ferramentas desenvolvidas pelo grupo. 


\section{Abstract}

This dissertation presents a proposal for a large-scale model simulator, that is integrated into the Automatic Distributed Simulation Environment (ASDA), a tool that supports the development of distributed simulation, and that has been under studies and investigations in the Laboratory of Distributed Systems and Concurrent Programming at ICMC-USP. The proposed simulator allows ASDA to support the development of models and programs that simulates large-scale queuing models, making ASDA more complete and efficient. The simulator is based on a public standard for large-scale distributed simulation named Scalable Simulation Framework (SSF).

The simulator prototype that was developed is a client-server program in which we can observe three main components: one compiler, that translates the models written in a modeling language to a simulation program, written in $\mathrm{C}++$ programming language; the SSF library, that defines the API that is used by the simulation programs; and a runtime environment, which runs the simulation programs, analyzes the results and sends the information to a report builder.

The simulator prototype also aggregates to the simulation community more studies regarding simulation, distributed simulation, systems modelling using the internal tools developed by our group. 


\section{Introdução}

\subsection{Considerações iniciais}

A validação de sistemas computacionais através da medição e avaliação de desempenho é um grande desafio encontrado na área de Ciência da Computação. Os sistemas distribuídos têm uma rápida evolução e a cada momento exigem novas propostas, arquiteturas, topologias e uma melhor e mais eficiente comunicação entre as entidades envolvidas no sistema. Isso requer o uso das mais variadas ferramentas de apoio, uma vez que a construção de protótipos destes sistemas se torna cada vez mais difícil, tanto por dificuldades durante o desenvolvimento quanto pela inviabilidade devido a altos investimentos a serem realizados em protótipos de sistemas.

A modelagem e simulação de sistemas computacionais são técnicas de validação que podem ser utilizadas tanto em projetos a serem desenvolvidos quanto em sistemas já em funcionamento, a fim de promover melhorias e correções críticas. As características essenciais de um sistema são abstraídas em um modelo o qual representa com certo grau de identidade. Uma maneira de avaliar o desempenho do sistema é através da resolução analítica de tal modelo. Outra maneira é o desenvolvimento de um programa de simulação de acordo com o modelo especificado. A simulação tem sido largamente adotada na indústria, não se restringindo apenas aos sistemas computacionais, devido a sua versatilidade (pode ser utilizada em diferentes situações), flexibilidade (é adaptável a novas e diferentes situações) e baixo custo (com um mesmo programa diferentes situações podem ser simuladas sem alterar o custo da simulação).

Para o desenvolvimento de um projeto de simulação é necessário passar por vários estágios, dentre eles a descrição e abstração do sistema, a descrição do modelo, coleta de dados, o desenvolvimento do programa de simulação, depuração, testes para verificação e validação e análise dos resultados da simulação. Para ajudar o usuário neste processo, o conceito de ambiente de simulação foi desenvolvido (Tanir \& Sevinc, 1994). Esses ambientes são ferramentas que oferecem ao usuário uma série de recursos para a elaboração de uma simulação. Por exemplo, o programa de simulação pode ser gerado e executado 
automaticamente a partir de uma representação gráfica (ou em outra linguagem de mais alto nível e intuitiva) do sistema a ser avaliado. Para isto, faz-se necessária a inclusão de editores gráficos, interpretadores, compiladores e otimizadores. O ambiente de simulação é definido então como um ambiente de simulação automático.

Apesar dos ambientes automáticos de simulação acelerarem bastante o processo de construção de modelos, esbarra-se ainda no problema da velocidade de execução do programa de simulação gerado. Com o objetivo de diminuir o tempo de processamento de uma simulação, duas abordagens foram propostas e têm sido estudadas: simulação distribuída ou SRIP (Single Replication in Parallel) (Jefferson, 1985; Misra, 1986; Fujimoto, 1990) e MRIP (Multiple Replication in Parallel) (Heidelberger, 1988; Ewing et al., 1999). Tanto uma como a outra abordagem fazem uso dos benefícios de uma outra área que vem apresentando grandes avanços: a Computação Paralela. O objetivo principal da Computação Paralela é aumentar o desempenho, diminuindo o tempo para se obter um resultado (Kumar et al., 2001). O que diferencia as abordagens SRIP e MRIP é o modo como o modelo será distribuído nos vários processadores disponíveis para a simulação.

$\mathrm{Na}$ abordagem SRIP, o sistema é particionado em processos lógicos e cada processo lógico é mapeado em um processador. Estes processos se comunicam através da troca de mensagens. Para garantir que os eventos sejam simulados na devida ordem, diversos protocolos de sincronização foram desenvolvidos. O objetivo dos protocolos é sincronizar os tempos da simulação uma vez que a evolução de cada processo lógico depende dos eventos que podem ocorrer em outros processos lógicos.

Na abordagem MRIP o sistema não é particionado. Replicações independentes de um mesmo programa de simulação seqüencial são executadas em paralelo. Cada replicação envia seus resultados (variáveis estimadas) para um analisador global, onde as médias finais são calculadas. Quando a precisão requerida é atingida, a simulação é encerrada.

No sentido de facilitar a elaboração de uma simulação, no que se refere ao tempo de desenvolvimento do programa de simulação e nas tomadas de decisão necessárias para esse desenvolvimento, foi desenvolvido no Laboratório de Sistemas Distribuídos e Programação Concorrente do ICMC-USP, o ASDA - Ambiente de Simulação Distribuída Automático. O ASDA foi especificado no trabalho de doutorado de Sarita Mazzini Bruschi (Bruschi, 2002). Atualmente, o ASDA vem sendo alvo de constantes estudos com o propósito de tornar a ferramenta o mais completa possível, com várias abordagens de modelagem (Aiza, 2005, Rodrigues, 2006), escolha de abordagens de sincronismo em tempo de execução do programa 
de simulação (Silva, 2006; Kawabata, 2005), e para este trabalho de mestrado, a simulação de modelos de larga escala.

A simulação de modelos de larga escala também vem sendo alvo de estudos e pesquisas em diversas partes do mundo. A simulação é uma ferramenta indispensável para o estudo do comportamento da comunicação de redes compostas de milhares de computadores, podendo ser aplicada na validação de protocolos de rede, obtenção de medidas de segurança contra ataques e na análise de infra-estruturas críticas de redes. $\mathrm{O}$ desenvolvimento de software para tais tipos de sistemas é uma tarefa de grande complexidade. Os testes e a validação destes softwares são ainda mais complicados, devido a dois fatores principais: as condições do experimento não são capazes de serem repetidas nem controladas; e o número de nós (máquinas, processadores, unidades de processamento) na rede é potencialmente grande. Por estas razões, experimentos reais com tais tipos de sistemas são restritos a um número pequeno de entidades envolvidas, isto é, um número que permita o sistema ser gerenciado. Porém, geralmente, essa atividade não retrata nem imita de forma alguma a situação do mundo real.

O ASDA utiliza para a modelagem de sistemas duas abordagens: Queueing Statecharts, a qual foi um dos resultados da tese do aluno Carlos Renato Lisboa Francês (Francês, 2001; Francês et al. 2005) do Laboratório de Sistemas Distribuídos e Programação Concorrente (LaSDPC) do ICMC-USP, e Rede de filas (Jain, 1991). Após a conclusão da descrição do modelo do sistema, o usuário pode gerar o código de um programa que simulará o sistema desejado. Porém, as atuais funcionalidades do ASDA não permitem a modelagem de sistemas maiores, mais complexos, com milhares de entidades envolvidas, como uma rede ad-hoc com dezenas de sensores ou uma grade computacional composta por milhares de máquinas presentes no mundo todo. É nesse contexto que é apresentado o Scalable Simulation Framework.

O Scalable Simulation Framework (SSF) é um padrão público, relativamente novo, para simulações discretas de sistemas grandes e complexos, e foi desenvolvido no projeto Scalable Self-organizing Simulations (S3) (Ogielski, 1998; Cowie et al., 1999) por um conjunto de pesquisadores de redes, simulações paralelas e engenharia de software ligados a diversas instituições, dentre elas a Universidade de Dartmouth, nos Estados Unidos. O SSF se tornou um padrão para a construção de ambientes de simulação distribuída. Os modelos do SSF são compactos, flexíveis, portáteis e paralelisáveis de uma maneira transparente, assim como os modelos que podem ser gerados pelo ASDA. A API (Application Programming Interface) do SSF é encontrada atualmente desenvolvida tanto em Java quanto em C++. 


\subsection{Objetivos}

O foco deste trabalho de Mestrado está na especificação e na criação de uma extensão para o ASDA, que permita à ferramenta a construção de modelos e programas que simulem modelos de larga escala. Com esta abordagem de modelagem, onde características e comportamentos das entidades são consideradas na construção do modelo, a ferramenta se tornará ainda mais completa.

A extensão será desenvolvida na forma de um simulador, composto basicamente por três módulos: a API SSF que será utilizada pelos programas de simulação, de forma a separar o kernel de simulação (gerenciamento de memória, distribuição de carga, timelines) do modelo a ser simulado; um compilador que transformará o modelo escrito em uma linguagem de modelagem de alto nível em um programa de simulação em linguagem C++ e que utilizará a API SSF; e um módulo executor que executará os programas de simulação e armazenará os resultados em relatórios. Além disso, será especificada uma camada de componentes de domínios de modelagem de sistemas baseados em filas. Esta camada será desenvolvida sobre a API SSF e será bastante útil para minimizar o tamanho e a complexidade do programa de simulação gerado.

O ASDA foi desenvolvido para permitir a utilização de simulação distribuída. De modo a atender a este princípio, a extensão também é voltada para a simulação de modelos de forma distribuída utilizando as funcionalidades fornecidas pelo núcleo de simulação utilizada (DaSSF).

De modo a viabilizar a utilização do simulador como uma ferramenta consistente na simulação de sistemas de larga escala, foi desenvolvido um protótipo. Ele foi testado e validado e está pronto para a integração ao ASDA.

\subsection{Organização da monografia}

De forma a relatar o desenvolvimento deste trabalho, esta monografia está dividida em sete capítulos: um capítulo de introdução, dois capítulos de revisão bibliográfica, três capítulos que relatam o desenvolvimento do trabalho e um capítulo com as conclusões. Além disso, um apêndice é utilizado para expor listagens de código dos programas ilustrados.

Para a caracterização do contexto no qual a extensão proposta está inserida, a princípio foram estudados os conceitos referentes à simulação e computação paralela, os quais se unem 
para a definição de simulação distribuída. O capítulo 2 discute aspectos da utilização de simulação como técnica de avaliação de desempenho. Dentre os tópicos revisados salienta-se as fases para o desenvolvimento de uma simulação, destacando-se a fase de modelagem de sistemas (através de redes de filas, redes de petri, statecharts e queueing statecharts). São apresentados, ainda, alguns conceitos de Simulação Distribuída.

O capítulo 3 apresenta o Ambiente de Simulação Distribuída Automático (ASDA), objeto para o qual a extensão está sendo proposta. Feito isso, o outro objeto de estudo deste trabalho de mestrado é apresentado: o Scalable Simulation Framework (SSF), padrão para simulação paralela para modelos grandes e complexos, no qual a extensão é baseada. $\mathrm{O}$ capítulo ainda apresenta uma ferramenta voltada para a simulação de sistemas de larga escala já baseada no SSF, porém sem a relação com um ambiente de simulação automático, e mostra também como o SSF pode ser utilizado para a construção de modelos utilizando a abordagem de Rede de filas.

O capítulo 4 descreve a criação de classes de domínio específico (rede de filas) utilizando a API SSF e à execução de testes com essas classes. Essas classes são utilizadas como templates, auxiliando a geração de código por parte do simulador.

No capítulo 5, a extensão ao ASDA é especificada em detalhes. Inicialmente os objetivos gerais a serem alcançados são traçados, tendo por base todos os conceitos já apresentados nesta monografia. Posteriormente, passa-se a analisar e especificar o simulador proposto e sua relação com o ASDA. O simulador foi dividido em módulos distintos a fim de facilitar o desenvolvimento, manutenção, extensibilidade e legibilidade do seu código. No protótipo tem-se desenvolvidos o compilador, o módulo executor e o mecanismo de integração ao ASDA. O simulador em si foi desenvolvido utilizando a linguagem JAVA, porém a API SSF e os componentes de rede foram escritos na linguagem $\mathrm{C}++$. O ambiente, apesar de ser multi-plataforma por estar escrito em JAVA, será executado apenas na plataforma Linux uma vez que os programas de simulação utilizarão bibliotecas próprias e nativas deste sistema.

O capítulo 6 apresenta um estudo de caso do simulador proposto. Esse estudo de caso consiste na execução de uma simulação desde a definição de um modelo até a coleta dos resultados.

Por fim, o capítulo 7 apresenta as conclusões obtidas a partir desta dissertação. Discutem-se também algumas contribuições importantes que este trabalho forneceu à comunidade de pesquisa na área e as propostas de trabalho futuro. 


\section{Modelagem e Simulação}

\subsection{Considerações iniciais}

O projeto e a construção de sistemas computacionais se tornaram atividades críticas atualmente. De um lado, temos usuários demandando por sistemas cada vez mais potentes, com maior capacidade de armazenamento de dados, maior poder de processamento, cada vez menores em tamanho físico e uma melhor e mais eficiente comunicação entre as entidades envolvidas no sistema. Do outro, temos projetistas e construtores que necessitam de mais flexibilidade durante a construção de sistemas complexos e para a realização de modificações que melhorem o desempenho do sistema. Os custos para projeto e desenvolvimento desses sistemas podem ser significativamente reduzidos se houver uma técnica para a análise de desempenho que possa predizer o comportamento futuro de um projeto ou mesmo de algumas alterações em um sistema existente (Bagrodia et al., 1998).

Simulação é a imitação da operação de um sistema ou um processo real durante determinado tempo (Banks et al., 2001). É uma técnica efetiva não apenas na prototipagem de novos sistemas, mas também para avaliar e testar sistemas já existentes (Liu, 2003). Esta técnica se tornou atrativa e hoje se mostra atuante nas mais diversas áreas de aplicação devido à sua versatilidade (pode ser usada em diferentes ocasiões), flexibilidade (é adaptável a novas e diferentes situações) e baixo custo (com um mesmo programa pode-se simular diferentes situações) (Pegden et al., 1995).

Como exemplo da utilização de simulação, pode-se citar: aplicações militares (simulações de guerra e ambientes de treinamento), projetos aeroespaciais, sistemas urbanos, meteorologia, projetos de engenharia, sistemas de manufatura, sistemas ecológicos e ambientais e sistemas de computação (hardware, redes de comunicação, arquiteturas, etc.) (Pegden et al., 1995; Banks, 1998; Meng, 1999; Fujimoto, 2000).

Segundo Fujimoto (2000), duas classes de aplicações de simulação vêm atualmente recebendo maior atenção: as simulações analíticas e os ambientes virtuais. A simulação analítica é a visão clássica de simulação. O objetivo desse tipo de simulação é a análise de desempenho dos sistemas complexos, possuindo pouca interferência do usuário durante a 
execução da simulação, sendo este um observador externo. O tempo da simulação pode avançar mais rápido ou mais lentamente do que o tempo de execução, porém esse tempo de execução deve ser “o menor possível”. Já os ambientes virtuais são caracterizados pela total interferência do usuário no decorrer da execução da simulação. Essa classe possui como objetivo criar uma representação realista do ambiente a ser simulado. Eles diferem das simulações analíticas nos seguintes pontos: primeiramente no que se refere à interação com o usuário, onde é criada uma impressão de "look and feel”, que faz com que o usuário se sinta inserido no sistema e participante das decisões; em segundo lugar, o tempo da simulação deve acompanhar a mesma taxa de avanço de tempo percebida pelo usuário (Bruschi, 2002).

A adoção da computação paralela/distribuída nessas duas classes visa a objetivos distintos. Para o caso da simulação analítica, a simulação seqüencial apresenta uma desvantagem quando se deseja simular modelos mais complexos, com maiores detalhes: o tempo de simulação. Em modelos probabilísticos, devido à aleatoriedade das variáveis de entrada, o programa de simulação deve ser executado diversas vezes de modo a garantir que esta aleatoriedade não interfira nos resultados da simulação.

A simulação analítica fornece resultados quantitativos que facilitam o estudo do sistema nas mais variadas e complexas situações. Quando se tem em mente modelos e sistemas grandes e complexos, com muitas entidades envolvidas, a simulação detalhada de tais modelos requer quantidades enormes de memória e espaço em disco, além de que, como citado anteriormente, o tempo de execução do programa de simulação será grande. Com a utilização de técnicas de simulação distribuída e paralela, tais problemas podem ser contornados e pode-se partir, definitivamente, para a simulação de sistemas grandes e complexos, avaliando o desempenho dos sistemas já existentes, propondo melhorias e até novos sistemas.

Este capítulo tem por objetivo discutir com detalhes aspectos da utilização de simulação como técnica de avaliação de desempenho. Dentre os tópicos revisados salientamse as fases para o desenvolvimento de uma simulação, destacando a fase de modelagem de sistemas.

\subsection{A modelagem e simulação de sistemas discretos}

Vários são os objetos de estudo quando o tema "Simulação" é abordado. Um dos mais importantes é a modelagem de sistemas, o qual envolve técnicas de construção e análise de modelos. O modelo é o objeto a ser simulado. Portanto, é necessário construir e analisar um 
modelo para que possamos utilizar a simulação como técnica de avaliação de desempenho. $\mathrm{O}$ principal passo em um processo de modelagem é abstrair as características do sistema em um modelo (MacDougall, 1987).

Os modelos podem ser classificados de diferentes formas (Pegden et al., 1995). Uma possível classificação pode ser com relação à quantidade de detalhes inseridos: existem os que são uma réplica precisa do sistema a ser simulado (também conhecidos como simuladores, como por exemplo, simuladores de vôo e de carro) e os que podem ter suas principais características abstraídas. Nesse caso, a inclusão de muitos detalhes pode introduzir complicações desnecessárias enquanto que a exclusão de características importantes pode invalidar o modelo (Soares, 1992).

Classificando os modelos com relação ao tempo têm-se os modelos dinâmicos, os quais descrevem o comportamento do sistema através do tempo, e os modelos estáticos, os quais simplesmente fornecem um retrato do sistema em um ponto específico do tempo. Os modelos dinâmicos podem ainda ser contínuos ou discretos no tempo. Os modelos dinâmicos e discretos no tempo representam sistemas onde as mudanças no estado do sistema ocorrem em pontos específicos e descontínuos do tempo simulado, alterando o estado do sistema espontaneamente. Nos modelos dinâmicos e contínuos no tempo, o estado do sistema varia continuamente ao longo do tempo de simulação e normalmente são descritos através de equações diferenciais.

Temos ainda que os sistemas podem ser classificados pela maneira pela qual os estados sofrem mudanças: discretos ou contínuos. $\mathrm{Na}$ prática poucos sistemas são completamente discretos ou contínuos, mas uma vez que uma dessas classificações é predominante para a maioria dos sistemas, normalmente é possível classificar um sistema como sendo ou discreto ou continuo. (Law \& Kelton, 1991). Um sistema contínuo é aquele em que as variáveis de estado mudam de maneira continua durante o tempo. Já um sistema discreto é aquele em que as variáveis de estado mudam apenas em pontos discretos do tempo. Um banco é um exemplo de sistema discreto já que a variável de estado "número de clientes no banco" muda o valor apenas quando o cliente chega ou o serviço fornecido a um cliente é completado.

Uma das possíveis maneiras de resolver um modelo é através da simulação. A seguir tem-se um conjunto de passos a serem seguidos para a definição de uma simulação (Banks et al., 2001):

1. Formulação do problema; 
2. Definição de objetivos e planejamento geral de projeto;

3. Construção do modelo;

4. Coleta de dados;

5. Codificação do modelo (programa de simulação);

6. Verificação;

7. Validação;

8. Desenvolvimentos experimentais;

9. Execução e análise;

10. Execuções subseqüentes;

11. Documentação de programa e relato de resultados;

12. Implementação do sistema.

Este processo pode ser agrupado em quatro fases. A primeira fase, a qual consiste dos passos 1 e 2, é um período de descobertas ou orientações. O aspecto inicial do problema é normalmente bem confuso, os objetivos iniciais possivelmente terão de ser revistos e o plano original do projeto deverá ser refinado. A segunda fase está relacionada com a construção do modelo e a coleta de dados e inclui os passos 3, 4, 5, 6 e 7 . A terceira fase se preocupa com a execução do modelo (programa de simulação). Ela envolve os passos 8, 9 e 10. Esta fase deve conter um plano bem definido para a realização de experimentos com este modelo. Uma simulação estocástica discreta é de fato um experimento estatístico. As variáveis de saída são estimativas que contêm erros aleatórios e, posteriormente, uma análise estatística é requerida. A quarta e última fase, implementação, envolve os passos 11 e 12. A documentação (passo 11) é extremamente importante, pois o programa de simulação pode ser utilizado novamente por diversos outros analistas e assim faz-se necessário o conhecimento da estrutura do programa e como alterar no programa as variáveis do modelo. A implementação correta de um sistema que foi modelado e simulado depende de um desenvolvimento contínuo do profissional e do completo sucesso de cada passo do processo. Provavelmente o ponto crucial de todo processo, o qual é relacionado ao processo de modelagem, é o passo 7, validação, pois um modelo não validado irá resultar em erros, podendo gerar efeitos perigosos e custosos. 


\subsection{Modelos baseados em redes de filas}

A simulação é geralmente usada na análise de modelos baseados em redes de filas (White et al., 1975; Banks \& Daí, 1997; Fracchia et al., 2003). Tais modelos fornecem ao analista uma ferramenta poderosa para o desenvolvimento e avaliação de desempenho de sistemas baseados em filas. Métricas típicas do desempenho destes sistemas incluem a utilização do servidor (porcentagem do tempo em que o servidor está ocupado), comprimento das filas e tempo gasto pelos clientes. Geralmente, quando o analista deseja desenvolver ou aperfeiçoar um sistema baseado em filas, ele deve balancear a utilização do servidor e a satisfação dos clientes em termos de comprimentos da fila e tempos de atendimentos.

Os elementos chave de um sistema baseado em filas são os clientes e os servidores. O termo "clientes" pode se referir a pessoas, máquinas, caminhões, pacientes ou aviões (qualquer elemento que chega a uma entidade e requisita um serviço). O termo "servidor" se refere a recepcionistas, mecânicos, pistas em um aeroporto ou máquinas de lavagens automáticas (qualquer pessoa ou máquina que fornece o serviço requisitado).

A população de potenciais clientes pode ser finita ou infinita. Em sistemas que a população de clientes é muito grande, é assumido um caráter infinito de clientes. Para tais sistemas, assumir a população desta maneira simplifica o modelo. A principal diferença entre população finita e infinita está em como a taxa de chegada é definida. Em um modelo de população infinita a taxa de chegada (o número médio de chegada por unidade de tempo) não é afetada pelo número de clientes que ingressaram nos sistemas de filas. Quando o processo de chegada é homogêneo, geralmente assume-se que a taxa de chegada é constante. Por outro lado, para modelos cuja população de potenciais clientes é finita, a taxa de chegada dos sistemas de filas depende do número de clientes que estão sendo servidos e que estão esperando.

O processo de chegada para modelos de população infinita é normalmente caracterizado em termos do tempo de chegada entre sucessivos clientes. As chegadas podem ocorrer em tempos agendados ou aleatórios. Quando os tempos são aleatórios, os tempos entre as chegadas são normalmente caracterizados por uma distribuição de probabilidade. Os clientes podem ainda chegar individualmente ou em lotes. Os lotes podem ser de tamanhos constantes ou aleatórios.

O modelo mais importante para chegadas aleatórias é o processo de chegada de Poisson (Banks et al., 2001). Se $A_{n}$ representa o tempo entre-chegadas do cliente N-1 e o cliente $\mathrm{N}$ ( $\mathrm{A}_{1}$ é o tempo de chegada do primeiro cliente), então para um processo de chegada de Poisson, $A_{n}$ é exponencialmente distribuído com intervalos de $1 / \lambda$ unidades de tempo. A 
taxa de chegada é $\lambda$ clientes por unidade de tempo. O número de chegadas em um intervalo de tempo $\mathrm{T}$ tem a distribuição de Poisson com intervalos $\lambda \mathrm{T}$ clientes. $\mathrm{O}$ processo de chegada de Poisson foi empregado com sucesso como modelo de chegada de pessoas em restaurantes, bancos, a chegada de chamadas de telefones a uma telefonista entre outros.

A segunda e importante classe de processos de chegadas é a chegada agendada. Neste caso, os tempos entre chegadas devem ser constantes ou constantes mais ou menos uma pequena quantidade aleatória de tempo para representar chegadas adiantadas ou atrasadas (Banks et al., 2001).

Para modelos de população finita o processo de chegada é caracterizado de uma maneira completamente diferente. Um cliente é definido como "em execução" quando este cliente está fora dos sistemas de filas e é membro da população de clientes em potencial. $\mathrm{O}$ tempo de execução de um dado cliente é definido como o intervalo de tempo passado da partida deste cliente dos sistemas de filas até a chegada de outro cliente à fila.

Uma aplicação importante de modelos de população finita é o problema de reparos em máquinas. As máquinas são os clientes e o intervalo de tempo é também chamado de tempo para falhar. Quando uma máquina falha ela chega aos sistemas de filas e lá fica até ser servida (reparada). Tempos de falhas para uma dada classe de máquinas têm sido caracterizados pelas seguintes distribuições: exponencial, Weibull e gamma (Banks et al., 2001).

Outro aspecto importante de modelos baseados em filas refere-se ao comportamento e a disciplina das filas. $\mathrm{O}$ comportamento diz respeito às ações do cliente enquanto espera pelo serviço na fila. Em algumas situações existe a possibilidades dos clientes que estão ingressando na fila realizarem as seguintes ações:

- Deixar a fila quando eles observarem que ela está muito grande;

- Deixar a fila quando esta estiver se movimentando muito vagarosamente;

- Trocar de fila quando o cliente notar que a fila em que estava está se movimentando muito vagarosamente

Já a disciplina das filas se refere à ordenação lógica dos clientes na fila e à maneira que os clientes serão escolhidos para serem servidos quando o servidor estiver livre. Comportamentos comuns de filas incluem:

- Primeiro a entrar, primeiro a sair (First in, first out - FIFO);

- Último a entrar, primeiro a sair (Last in, first out - LIFO);

- Serviço em ordem aleatória (Service in random order - SIRO); 
- Menor tempo de processamento primeiro (Shortest processing time first SPT);

- Serviço de acordo com prioridade (Service according to priority - PR).

Os tempos de serviço dos servidores também são fatores importantes a serem considerados durante os estudos de simulação de modelos de sistemas baseados em filas. Os tempos de serviços de chegadas sucessivas de clientes são denotadas por S1, S2, S3,... . Eles podem ser constantes ou de duração aleatória. Neste último caso, $\{\mathrm{S} 1, \mathrm{~S} 2, \ldots\}$ é normalmente caracterizado como uma sequiência independente e identicamente distribuída de variáveis aleatórias. As distribuições exponencial, Weibull e gamma já foram utilizadas com sucesso como modelos de tempo de serviço em diferentes situações (Banks et al., 2001).

\subsection{Simulação paralela/distribuída}

A simulação analítica é a visão clássica de simulação. O objetivo desse tipo de simulação é a análise de desempenho de sistemas complexos, possuindo pouca interferência do usuário durante a execução da simulação, sendo este apenas um observador externo. $\mathrm{O}$ tempo da simulação pode avançar mais rápido ou mais lentamente do que o tempo de execução, porém esse tempo de execução deve ser "o menor possível” (Fujimoto, 2000).

Quando o objetivo da simulação analítica é simular modelos mais complexos, a simulação seqüencial apresenta uma desvantagem: o tempo de simulação. Devido à aleatoriedade das variáveis de entrada, o programa de simulação deve ser executado diversas vezes de modo a garantir que esta aleatoriedade não interfira nos resultados da simulação. Neste caso, o principal objetivo é reduzir o tempo de execução da simulação e duas soluções vêm sendo estudadas: SRIP (Single Replication in Parallel) (Misra, 1986; Fujimoto, 1990) e MRIP (Multiple Replication in Parallel) (Heidelberger, 1988; Ewing et al., 1999). A seguir, serão discutidos aspectos relevantes da abordagem SRIP pois é a abordagem utilizada no núcleo . São discutidos ainda os protocolos de sincronismo conservativos e otimistas desta abordagem, cada um com suas particularidades.

A simulação SRIP possui um problema que pode ser observado analisando as estruturas básicas de uma simulação seqüencial (Bajaj et al., 1999):

1. As variáveis de estado que armazenam o estado do sistema;

2. Uma lista de eventos que armazena todos os eventos que foram escalonados, mas ainda não simulados; 
3. Um relógio global que controla o andamento da simulação.

Cada evento contém um timestamp que denota quando uma mudança no sistema irá ocorrer. A lista de eventos é classificada em ordem crescente do tempo de chegada. O programa de simulação consiste basicamente de um loop principal que repetidamente retira o evento com menor timestamp da lista de eventos e processa este evento. Processar um evento implica em executar algum código para efetivar a mudança de estado e, se necessário, escalonar novos eventos para o futuro. É muito importante notar nesta abordagem que o evento com menor timestamp $\left(\mathrm{E}_{\mathrm{min}}\right)$ deve ser o próximo evento a ser processado. Isto garante que os eventos sejam simulados em ordem cronológica no tempo de simulação (MacDougall, 1987). Se um evento $\left(E_{x}\right)$ que contém um timestamp maior que $E_{\min }$ for processado, este pode alterar as variáveis utilizadas por $\mathrm{E}_{\min }$ permitindo que o futuro influencie o passado. Erros desse tipo são chamados de erros de causa e efeito (Fujimoto, 1990).

A natureza seqüencial da lista de eventos e o relógio global limitam o potencial de paralelismo da simulação. A solução é, portanto, eliminar a lista de eventos em sua forma tradicional, e este é o objetivo da simulação SRIP (Reed et al., 1988).

Na simulação SRIP o sistema é visto como um conjunto de processos lógicos $\mathrm{PL}_{0}$, $\mathrm{PL}_{1}, \ldots, \mathrm{PL}_{\mathrm{n}}$, cada um representando um processo físico. Toda a interação entre os processos físicos é modelada por mensagens (eventos com timestamp) enviadas entre os correspondentes processos lógicos. Cada processo lógico contém uma parte do estado correspondente ao processo físico à que corresponde, bem como um relógio local que denota o quanto a simulação avançou.

Em uma simulação SRIP, garante-se que erros de causalidade não ocorrem se e somente se cada processo lógico executa eventos em ordem não decrescente de timestamp. Considere o seguinte exemplo: dois eventos, E1 no processo lógico PL1 e timestamp 10 e $\mathrm{E}_{2}$ no processo lógico $\mathrm{PL}_{2}$ e timestamp 20. Se E1 escalona um novo evento $\mathrm{E}_{3}$ para o PL2 com timestamp menor do que $20, \mathrm{E}_{3}$ pode afetar $\mathrm{E}_{2}$, sendo necessária a execução seqüencial dos três eventos. Se um PL não tem informações sobre qual evento pode ser escalonado por outro evento, conclui-se que o único evento que pode ser escalonado é o de menor timestamp, gerando uma simulação seqüencial (Fujimoto, 1990).

Para evitar que os erros de causa e efeito ocorram, diversos mecanismos têm sido propostos. Os mecanismos de sincronização podem ser divididos basicamente em duas categorias: conservativos e otimistas. Os protocolos conservativos impedem a possibilidade de qualquer erro de causalidade determinando quando é seguro processar um evento, ou seja, 
determinando quando todos os eventos que poderiam afetar os outros já foram processados. Já os protocolos otimistas utilizam a técnica de detecção e recuperação. Neste caso, os erros de causalidade são detectados e um mecanismo denominado rollback é utilizado na recuperação desse erro (Fujimoto, 1990).

Alguns autores citam três outras classes: os adaptativos, os mistos e os sem sincronização. Os adaptativos podem mudar dinamicamente seu comportamento no decorrer da simulação, de acordo com a evolução da simulação (Tay et al., 1997; Kawabata, 2005). No caso dos protocolos mistos podem existir submodelos executando protocolos otimistas ou conservativos (Bagrodia et al., 1998). Nos protocolos sem sincronização os erros de causalidade são ignorados (Thondugulam et al., 1999).

Os protocolos mais estudados, implementados e utilizados são os conservativos e os otimistas, e devido a estes fatos, são descritos nas seções 2.4.1 (conservativo) e 2.4.2 (otimista).

\subsubsection{Protocolos de sincronismo conservativos}

Historicamente, o primeiro mecanismo de sincronização para simulação distribuída seguia a abordagem conservativa e foi desenvolvido independentemente por Chandy e Misra (1979) e por Bryant (1977), sendo então denominado CMB (Chandy, Misra e Bryant). A principal característica deste protocolo é a determinação de quando é seguro executar um evento, ou seja, o evento só é executado quando há garantias de que nenhum outro evento com timestamp menor será executado. Enquanto isso não é garantido, o processo fica bloqueado o que pode gerar uma queda no desempenho e a situações de deadlock. Os mecanismos conservativos diferem entre si na maneira como o deadlock é tratado. Alguns previnem o deadlock e outros deixam que ele ocorra e depois utilizam algum mecanismo para recuperar o sistema. O protocolo $\mathrm{CMB}$ pode previnir o deadlock através da utilização de mensagens nulas ou da transmissão de mensagens nulas sob demanda. Uma outra abordagem consiste em não prevenir, mas detectar e recuperar os processos em deadlock.

Uma técnica importante utilizada nos protocolos conservativos é o lookahead. Lookahead pode ser definido como o intervalo de tempo em que um processo pode garantir o que acontecerá no futuro com absoluta certeza (Misra, 1986) ou a capacidade de prever o que acontecerá, ou o que não acontecerá, no tempo de simulação futuro (Fujimoto, 1990). Um lookahead de L representa que o processo pode garantir que nenhuma mensagem nova de 
evento será criada com timestamp menor do que $\mathrm{T}+\mathrm{L}$, onde $\mathrm{T}$ é o tempo de simulação do processo.

\subsubsection{Protocolos de sincronismo otimistas}

Os protocolos otimistas, ao contrário dos conservativos, não impedem os erros de causa e efeito, não precisando determinar quando é seguro processar um evento. Quando um erro é detectado um procedimento é chamado para recuperar o sistema e voltar a um estado seguro (rollback). A vantagem destes mecanismos é a possibilidade de explorar completamente o paralelismo em situações onde erros poderiam ocorrer, mas não ocorrem.

O mecanismo Time Warp é o mais conhecido protocolo otimista. Foi proposto por Jefferson em (Jefferson, 1985) e baseia-se no paradigma de Tempo Virtual.

Os protocolos otimistas oferecem grande potencial como mecanismos para simulação de propósito geral (Overeinder et al., 1991). A desvantagem é a necessidade de salvar periodicamente o estado dos PLs, utilizando mais memória do que os protocolos conservativos. Isso faz com que este mecanismo seja mais difícil de ser implementado (Fujimoto, 2000). As vantagens são que ele normalmente apresenta um speedup maior do que o apresentado pelos protocolos conservativos e também não é necessário que a topologia dos processos seja definida estaticamente. Diversas otimizações dos protocolos otimistas têm sido propostas com o objetivo de melhorar a utilização da memória e também limitar seu otimismo e reduzir o número de rollbacks (Steinman, 1993; Das, 1996; Tay \& Teo, 2001; Noronha \& Abu-Ghazaleh, 2002; Noronha \& Abu-Ghazaleh, 2002a; Moreira, 2005).

\subsection{Considerações finais}

Este capítulo apresentou alguns dos conceitos básicos sobre a modelagem e a simulação de sistemas, enfatizando os sistemas discretos, os quais serão os objetos de estudos principais desta pesquisa. Posteriormente passou-se a discutir aspectos e técnicas para simulação distribuída, uma vez que a simulação seqüencial possui desvantagens significativas com relação ao tempo de execução. Foi abordada a técnica SRIP, na qual várias replicações de um mesmo programa de simulação são executadas em diferentes processadores.

O Ambiente de Simulação Distribuída Automático (Bruschi, 2004) faz uso tanto da abordagem SRIP quanto da MRIP. Isso fornece ao usuário maior flexibilidade durante seu 
projeto de análise de desempenho. Optou-se por essa flexibilidade porque não existe "a melhor abordagem". A escolha deve ser feita com base nos parâmetros e características do modelo a ser simulado e do programa de simulação a ser gerado. Quando um modelo é muito grande, por exemplo, é possível que uma replicação não possa ser executada em um único processador em um tempo razoável. A flexibilidade, desta forma, constitui-se num aspecto importante a ser considerado na especificação de ambientes de simulação. O Scalable Simulation Framework (SSF) também possibilita ao usuário a utilização de simulação paralela. Esta característica reforça ainda mais as motivações de se inserir um padrão público de simulação no ASDA. No capítulo seguinte o ASDA e o SSF são discutidos mais profundamente. Outras características relevantes e de mais baixo nível de cada ferramenta serão observadas. 


\section{O ASDA e o SSF}

\subsection{Considerações iniciais}

Em 1993, Fujimoto e outros (Fujimoto, 1993a; Fujimoto, 1993b; Lin, 1993; Reynolds, 1993; Unger \& Cleary, 1993) expuseram o problema de que a simulação discreta distribuída não teve impacto significativo, apesar de muitos anos de pesquisa. Existia uma grande preocupação em relação à futura aplicabilidade da simulação paralela/distribuída para o estudo e entendimento de sistemas grandes e complexos. Eles sugeriram que, com o aumento da demanda por desempenho, técnicas de simulação paralela seriam adotadas em massa pela comunidade de pesquisa em simulação. Sugeriram ainda que os desafios e sucessos, no futuro, estariam em reduzir esforços e conhecimento necessários para a especificação de modelos a serem simulados, especialmente modelos grandes e complexos.

Simulações distribuídas de sistemas de larga escala consistem em milhares de entidades complexas, presentes e interagindo entre si em um grande ambiente virtual ou ferramenta que gerencie o modelo sendo simulado. Simulações detalhadas de modelos de larga escala requerem quantidades massivas de memória e espaço em disco para serem realizadas. A utilização de técnicas de simulação distribuída se faz, desta forma, fundamental para que a simulação de sistema de larga-escala ocorra de forma satisfatória. Porém, a falta de ferramentas que gerenciem estes modelos de maneira adequada ou que permitam a construção de modelos que realmente retratem sistemas reais, sem o uso excessivo de abstrações e simplificações, torna as simulações de larga-escala difíceis de serem analisadas.

De acordo com Liu (2003), as estratégias adotadas para a construção de um simulador de modelos de larga escala são direcionadas pelos requisitos computacionais necessários para a execução do simulador e da simulação e pela preocupação da ferramenta quanto à gerência de modelos de larga escala. O simulador deve possuir, portanto, as seguintes características:

1. Capacidade. Simular modelos grandes e complexos de maneira eficiente. Técnicas de simulação paralela já provaram ser capazes de expandir as limitações de tempo e espaço das simulações discretas seqüenciais; 
2. Escalabilidade. É fundamental que o simulador não perca desempenho excessivo de acordo com o crescimento dos modelos que são simulados;

3. Simplicidade. É importante fornecer interfaces simples e amigáveis para facilitar a expressão e a legibilidade do modelo e do programa de simulação;

4. Flexibilidade. O simulador deve fornecer ao usuário tanto visões de alto nível, isto é, modelos e dados de configuração, quanto visões de baixo nível, isto é, o programa de simulação em si;

5. Configurabilidade. O simulador deve permitir ao usuário modificar parâmetros sem ter que recorrer à recopilação do simulador.

6. Reusabilidade. Os modelos desenvolvidos para um cenário de simulação devem ser facilmente adaptáveis a outros cenários. O reuso de modelos é importante na construção de modelos complexos e permite a colaboração com outras linhas de pesquisa e comunidades.

A fim de diminuir a dificuldade de realização de simulações de modelos grandes e complexos, foi proposto e especificado um kernel para a construção de simulações que esbarram em problemas de escalabilidade. Trata-se de um padrão denominado Scalable Simulation Framework (SSF), que será detalhado na seção 3.3. Várias ferramentas que já foram propostas e desenvolvidas se baseiam nesse padrão, que não diz como as funções devem ser implementadas, apenas define o comportamento das funções e rotinas nele presentes. A modelagem de modelos de larga escala exige ainda uma linguagem de modelagem clara, leve, simples e expressiva. A Domain Modeling Language (DML) possui estes atributos e é ideal para esse tipo de modelagem.

Será apresentada neste capítulo a ferramenta desenvolvida no Grupo de Sistemas Distribuídos e Programação Concorrente, ICMC-USP, ASDA - Ambiente de Simulação Distribuída Automático. O ASDA tem como objetivo facilitar a elaboração de uma simulação no que se refere ao tempo de desenvolvimento do programa de simulação e nas tomadas de decisão necessárias para esse desenvolvimento. Posteriormente, o Scalable Simulation Framework será discutido em detalhes. Logo após, a DML também é explicada em detalhes. Ao final deste capítulo, todos os conceitos necessários para o entendimento do trabalho proposto nesta dissertação terão sido apresentados. 


\subsection{O Ambiente de Simulação Distribuída Automático}

O ASDA é um ambiente de simulação voltado à avaliação de desempenho de sistemas computacionais. Como os modelos que melhor representam esses sistemas são os dinâmicos e contínuos no tempo, estocásticos e de estados discretos, estes são os tipos de modelos considerados no ambiente desenvolvido.

O público alvo para o qual o ASDA foi desenvolvido são alunos, professores e pesquisadores interessados na avaliação de desempenho de sistemas computacionais, principalmente os baseados na teoria de redes de filas.

O objetivo do ASDA é oferecer ao usuário um ambiente automático para o desenvolvimento de simulação, seguindo as características descritas nos ambientes automáticos. Os usuários de um ambiente desse tipo podem apresentar diferentes tipos de conhecimento, como por exemplo (Bruschi, 2002):

1. Usuários que apresentam um grande conhecimento em simulação, mas pouco conhecimento em computação paralela;

2. Usuários que possuem conhecimento superficial tanto de simulação como de computação paralela;

3. Usuários com conhecimento em simulação e computação paralela, mas que disponham de pouco tempo para o desenvolvimento da simulação;

4. Usuários que desejam simular o mesmo sistema de maneira seqüencial e distribuída de forma a analisar o desempenho, etc.

O ASDA deve oferecer a flexibilidade necessária para auxiliar os diferentes perfis de usuários. Desta forma, alguns requisitos para o ASDA são (Bruschi, 2002):

1. Oferecer ao usuário um ambiente de fácil aprendizagem e utilização;

2. Possibilitar a geração completa de um problema de simulação para um usuário menos experiente;

3. Oferecer flexibilidade necessária para que um usuário mais experiente possa modificar os programas gerados;

4. Possibilitar a utilização de simulações seqüenciais já desenvolvidas; 
5. Oferecer diretrizes para que o usuário possa escolher entre as abordagens para simulação distribuída. Se o usuário preferir, o ambiente deve ser capaz de selecionar a abordagem mais adequada;

6. Facilitar a obtenção de dados confiáveis através da avaliação estatística dos resultados gerados pela simulação;

7. Minimizar o tempo de execução da simulação, oferecendo um escalonamento de processos eficiente.

O diagrama de estrutura modular proposto para o ASDA é apresentado na Figura 3.1. Para atingir os requisitos apresentados, o ASDA é composto por diversos módulos. Cada um destes módulos possui funções bem definidas, como pode ser observado a seguir:

- Módulo de Interface com o usuário: responsável por oferecer ao usuário uma interface que possibilite um acesso fácil às opções disponibilizadas pelo ambiente. Ao mesmo tempo oferece flexibilidade para usuários que prefiram tomar suas próprias decisões. É responsável ainda por oferecer ao usuário um editor gráfico onde será definido o modelo a ser simulado e é o maior responsável para a obtenção dos requisitos 1,2 e 3 ;

- Módulo Gerador: baseando-se na especificação gráfica e na decisão do módulo avaliador, gera o código do programa de simulação, conforme requerido pelos requisitos 1 e 3 ;

- Módulo Executor: responsável por controlar a execução dos programas de simulação, atendendo ao requisito 1 ;

- Módulo Avaliador: baseando-se nas variáveis do ambiente e no modelo a ser simulado, este módulo orienta o usuário na difícil tarefa de escolher a melhor abordagem para sua simulação. Neste módulo deve estar concentrado todo o conhecimento necessário para decidir ou para orientar o usuário sobre a melhor abordagem para a simulação, atendendo ao requisito 5;

- Módulo de Interface de Software: responsável por fornecer uma interface entre os programas de simulação já desenvolvidos e o módulo replicador, atende ao requisito 4;

- Módulo Replicador: gerencia as replicações da simulação e garante a obtenção de resultados confiáveis através da abordagem MRIP, conforme requerido pelo requisito 6; 
- Módulo Escalonamento: responsável pelo escalonamento dos processos gerados pelo módulo executor, atende ao requisito 7.

Dessa forma, qualquer que seja o usuário do ASDA, o módulo de interface com o usuário deverá ser utilizado. A partir desta interface, o usuário pode optar por: especificar um novo modelo de simulação; utilizar um programa de simulação já desenvolvido ou definir as variáveis de ambiente. Estas possibilidades oferecem a flexibilidade desejada pelos usuários mais experientes e oferecem todas as ferramentas requeridas pelos usuários menos experientes.

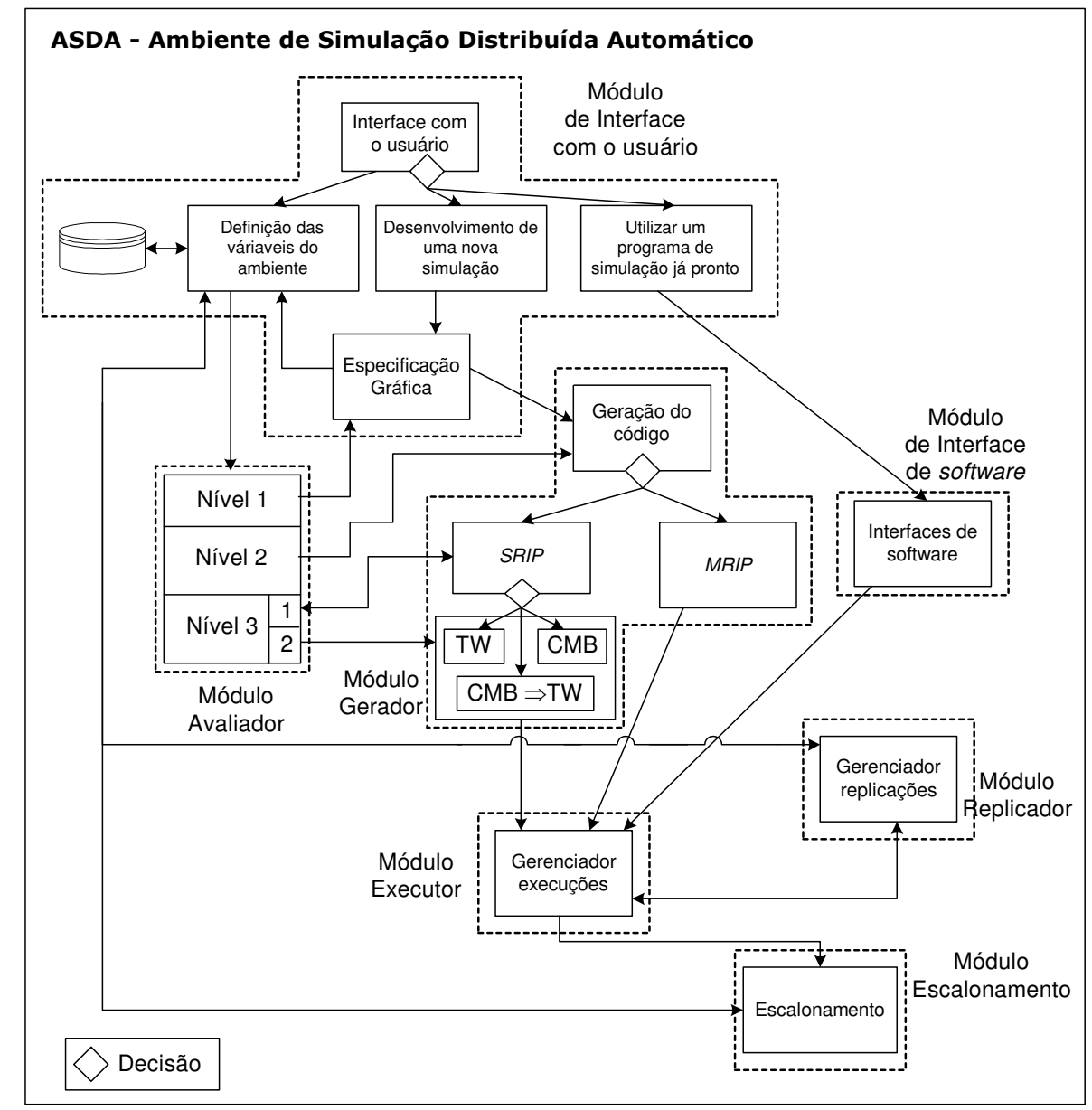

Figura 3.1. Diagrama Modular do ASDA (Bruschi, 2002).

Se a opção escolhida for a utilização de um programa de simulação já existente, o módulo de interface de software é ativado, inserindo no código já existente as funções necessárias para replicar o programa, utilizando a abordagem MRIP.

Caso a opção escolhida seja o desenvolvimento de um novo modelo então o usuário precisa especificar o modelo, tarefa esta realizada através do sub-módulo de especificação 
gráfica. A consistência do modelo é verificada com o auxílio do nível 1 do módulo avaliador. O módulo avaliador é o módulo "inteligente" do sistema e auxilia também em outras decisões.

Baseando-se na especificação gráfica do modelo a ser simulado e nas informações oferecidas pelos níveis 2 e 3 do módulo avaliador, o módulo gerador gera o código do programa de simulação. O nível 2 do módulo avaliador auxilia na decisão entre as abordagens seqüencial, SRIP, MRIP (Heidelberger, 1988) ou SRIP + MRIP. O nível 3 oferece os subsídios para a decisão entre os protocolos de sincronização SRIP. Três protocolos estão disponíveis para este caso: protocolo Time Warp (Jefferson, 1985), protocolo CMB (Chandy \& Misra, 1979; Chandy \& Misra, 1981) e protocolo CMB/Time Warp. O CMB/Time Warp é uma adaptação proposta neste trabalho para a opção desenvolvida por Morselli (Morselli, 2000) e analisada por Kawabata (Kawabata, 2005), onde os protocolos de sincronização podem ser trocados em tempo de execução.

Após o código ter sido gerado, o programa é compilado e encaminhado para o módulo executor, o qual gerencia as execuções. Caso sejam escolhidas as abordagens MRIP ou SRIP + MRIP, o módulo executor ativa o módulo replicador, o qual tem a função de gerenciar as replicações. O módulo executor é ainda encarregado de manter comunicação com o módulo escalonamento, o qual determina quais máquinas são mais adequadas para executar a simulação.

\subsection{O Scalable Simulation Framework}

O Scalable Simulation Framework (SSF) é um padrão público, relativamente novo, para simulações discretas de sistemas grandes e complexos, e foi desenvolvido no projeto Scalable Self-organizing Simulations (S3) (Ogielski, 1998; Cowie et al., 1999) por um conjunto de pesquisadores de redes, simulações paralelas e engenharia de software ligados a diversas instituições. O SSF se tornou um padrão para a construção de ambientes de simulação distribuída. Os modelos do SSF são compactos, flexíveis, portáteis e paralelisáveis de uma maneira transparente, assim como os modelos que podem ser gerados pelo ASDA.

O SSF é definido por uma Application Programming Interface (API) (Cowie, 1999) contendo cinco classes base:

- Entity (Entidade): A classe Entity permite a criação de instâncias que representam entidades lógicas na simulação. Ela serve como um contêiner para as variáveis de estado da simulação. Por exemplo, em um modelo de redes de 
computadores, cada host pode ser observado como uma entidade. Um objeto desta classe possui instâncias das classes Process, inChannel e outChannel. Um modelo normalmente possui um conjunto de entidades as quais se comunicam entre si através do envio e recepção de mensagens através dos canais de comunicação;

- Process (Processo): A classe Process é usada para especificar ações das entidades. O SSF adota uma visão orientada a processos. Cada processo no SSF é representado por instâncias da classe Process, que encapsula um método definido pelo usuário como sendo o corpo do processo. Um processo será suspenso ao esperar que uma mensagem chegue a um conjunto de canais de entrada (instâncias da classe inChannel), ou ao esperar que um determinado tempo de simulação passe, ou até mesmo ambos os casos;

- inChannel (Canal de entrada): Objetos desta classe representam o ponto final de um canal de comunicação entre as entidades. Os objetos são as portas de entrada de uma entidade, onde mensagens são entregues. Os objetos desta classe pertencem a um objeto da classe Entity (a qual se pode dizer que possui o canal de entrada). Processos das entidades esperam que mensagens sejam entregues nos canais de entrada;

- outChannel (Canal de saída): Objetos desta classe representam o ponto de partida do canal de comunicação entre entidades. De maneira similar aos objetos da classe inChannel, os canais de saída também pertencem a objetos da classe Entity. O SSF suporta multicasting: um canal de saída de uma entidade pode ser mapeado para vários canais de entrada e vice-versa. Uma mensagem escrita em um canal de saída será entregue a todos os canais de entrada aos quais ele está mapeado. Um tempo de atraso (delay) apropriado é aplicado à mensagem quando a mensagem é escrita no canal de saída, este processo consome um certo período de tempo de simulação antes que a mensagem reapareça nos canais de entrada aos quais o canal de saída está mapeado. Existem três tipos de atraso:

i. O atraso de canal, denotado por $\mathrm{C}$, é o atraso atribuído ao canal de saída e é aplicado a todas as mensagens que saem por este canal de saída.

ii. O atraso de mapeamento, denotado por $\mathrm{M}$, é especificado quando um canal de saída é mapeado para um canal de entrada. Este atraso é atribuído somente às mensagens que são entregues do canal de saída especificado para seu respectivo canal de entrada. 
iii. O atraso de escrita, denotado por W, é especificado sempre quando uma mensagem é escrita em um canal de saída. Toda mensagem escrita em um canal de saída pode receber atrasos diferentes.

Os três tipos de atraso devem ser valores não negativos. O total de atraso por mensagem pode ser calculado pela soma $\mathrm{C}+\mathrm{M}+\mathrm{W}$;

- Event (Evento): Objetos de classes derivadas da classe Event são usados como mensagens que transitam entre as entidades através dos canais de comunicação, ou seja, os "eventos" são os pacotes de informação que serão trocados entre as entidades.

O comportamento externo dos modelos escritos com a API SSF pode ser visto como coleções de entidades e mapeamentos de canais de saída para canais de entrada, entre entidades. Trata-se de um grafo direcionado: os nós do grafo são as entidades e as arestas são os mapeamentos. Ou seja, a API SSF é bem genérica para sistemas que podem ser modelados como coleções de objetos as quais se comunicam por troca de mensagens. Isto é uma vantagem para o desenvolvimento de modelos de larga escala, onde todo o modelo pode ser construído conectando-se as entidades como os blocos de construção.

Com o SSF, as entidades também podem formar relacionamentos alinhados com outras entidades. Entidades que estão co-alinhadas provavelmente terão um envolvimento mais próximo entre si. Elas podem acessar diretamente as variáveis de estado das entidades que estão co-alinhadas com elas, com a garantia que as entidades estão sincronizadas com seus respectivos tempos de simulação. Ou seja, estas entidades avançam seus relógios de simulação juntas umas com as outras durante a simulação. O SSF fornece suporte à simulação paralela. Entidades que não estão alinhadas com outras, provavelmente, serão atribuídas a outros processadores, para processamento concorrente. Se duas entidades não estão coalinhadas, é incorreto que uma entidade acesse as variáveis de estado da outra, uma vez que é possível que o relógio de simulação de cada uma das duas entidades esteja com valores diferentes.

Entidades co-alinhadas são agrupadas em grupos de alinhamento, os quais são chamados de timelines. A API SSF deve implementar cada timeline como um processo lógico separado do outro. Cada processo lógico possui uma lista de eventos futuros e pode ser atribuído a um outro processador. Se observarmos o modelo como uma coleção de timelines, o modelo continua sendo um grafo direcionado: os nós do grafo são os timelines e as arestas são os mapeamentos entre as entidades que pertencem a diferentes timelines. 
O SSF dá suporte à simulação orientada a processos. Em uma simulação orientada a processos, as mudanças no estado do modelo podem ser expressas via um número de processos interagindo entre si, isto é, o sistema de eventos discretos é visto como um conjunto de entidades que se submetem a processos. Em simulações orientadas a eventos, as entidades são modeladas por manipuladores de eventos. A Tabela 3.1 deixa mais clara a diferença entre as entidades presentes em simulações orientadas a processos e simulações orientadas a eventos. Pode-se notar que na simulação orientada a processos, as entidades ficam mais caracterizadas, com mais identidade.

Tabela 3.1. Pseudo-código que ilustra a diferença entre as abordagens de simulação

\begin{tabular}{|l|l|}
\hline \multicolumn{1}{|c|}{ Simulação orientada a eventos } & \multicolumn{1}{c|}{ Simulação orientada a processos } \\
\hline $\begin{array}{l}\text { ChegadaEvt(Avião_1) }\{\ldots\} \\
\begin{array}{l}\text { PousoEvt(Avião_1) }\{\ldots\} \\
\text { PartidaEvt(Avião_2) }\{\ldots\}\end{array}\end{array}$ & $\begin{array}{l}\text { Avião_1 }\{\text { Chegar(); Pousar(); Partir() }\} \\
\text { Avião_2 }\{\text { Chegar(); Pousar(); Partir() }\} \\
\begin{array}{c}\text { Evião_3 }\{\text { Chegar(); Pousar(); Partir() }\} \\
\text { Avidades modeladas por manipuladores de } \\
\text { eventos (Event handlers) }\end{array}\end{array}$ \\
\hline
\end{tabular}

No SSF, os processos pertencem a entidades e não podem migrar para outras entidades. Tem-se ainda o fato de que uma entidade possuir um processo é imutável, o que diminui a sobrecarga causada pela migração de processos entre entidades. Isto é contrário ao que se prega em simulações puramente orientadas a processos, onde estes podem migrar livremente entre as entidades. Isto foi especificado no padrão de modo proposital, uma vez que o fato de ser puramente orientada a processo, faz com que se perca o caráter modular dos modelos e dificulta a criação de modelos complexos e de larga escala (Liu, 2003).

O mapeamento dos canais de saída nos canais de entrada é um processo muito importante. O mapeamento não somente define o padrão de comunicação entre as entidades como também determina toda a estratégia de exploração de paralelismo. Como mencionado anteriormente, entre cada par de canais de saída e de entrada, existem três tipos de atraso: atraso de canal (C), atraso de mapeamento (M) e o atraso de escrita (W). O tempo a ser consumido pela mensagem a ser escrita no canal de saída e entregue no canal de entrada é a soma dos três atrasos. Não é permitido que ambos os atrasos de canal e de mapeamento sejam iguais a zero quando o canal conecta dois timelines distintos.

A modelagem de sistemas pode ser realizada de forma programática, isto é, construir um modelo de classes utilizando diretamente a API SSF. Entretanto um modelo construído a partir de uma linguagem de modelagem propriamente dita é mais legível que o modelo feito 
como um programa. É dentro deste conceito que é introduzida a Domain Modeling Language, ou DML.

\subsection{Domain Modeling Language (DML)}

A Domain Modeling Language tem uma sintaxe muito simples. Basicamente, trata-se de uma lista de atributos, onde cada atributo é um par "chave-valor". A chave se trata de um identificador e o valor pode ser um número (inteiro ou de ponto flutuante) ou uma string. A seguir, é mostrado um exemplo:

$\begin{array}{ll}\text { planeta } & \text { "Terra" } \\ \text { peso } & 6.5 e 21 \\ \text { populacao } & 6242324585\end{array}$

A DML permite atributos aninhados. Isto é, o valor de um atributo também pode ser uma lista de atributos, delimitados por colchetes. Sabendo disso, o exemplo anterior pode ser expandido do seguinte modo:

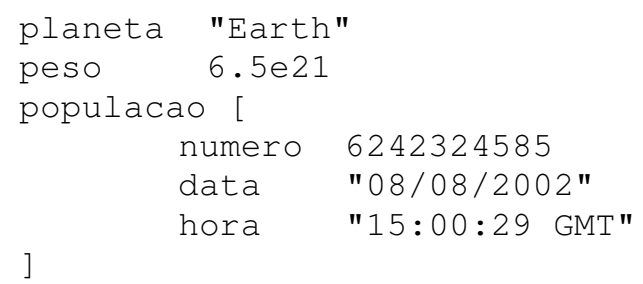

Se o valor do atributo for uma string que não possui espaços em branco ou caracteres especiais como “(“" ou outros, não é necessário utilizar as aspas delimitando a string. Entretanto, é recomendado que sempre se utilize as aspas para evitar qualquer inconsistência.

Conceitualmente, a DML se trata de uma árvore. A raiz e todos os outros nós da árvore, inclusive os nós terminais, representam as listas de atributos. Desta forma, qualquer atributo pode ser referenciado especificando-se um caminho de busca, assim como arquivos e diretórios em um sistema de arquivos, isto é, um atributo é como um diretório. Mas ao invés de utilizar "/" ou "l" para separar os arquivos e pastas no caminho de busca, utiliza-se "." na DML. Por exemplo, pode-se referenciar o número populacional no exemplo anterior com “populacao.numero". O primeiro "." serve para informar que o caminho de busca tem início na raiz. Obviamente, então, podem-se utilizar caminhos relativos e a DML "sabe" que a busca tem inicio na lista corrente de atributos.

Existem três tipos especiais de chaves na DML: find,_extends e _schema. A chave _schema é usada para aplicar uma verificação de esquema em um arquivo DML, da mesma 
- Capacidade: O DaSSF consegue simular modelos extremamente grandes de uma forma eficiente. Normalmente, estes modelos possuem milhares ou milhões de entidades, como servidores, roteadores, hosts, etc.;

- Simplicidade: A API provida pelo DaSSF simplifica o desenvolvimento de modelos fornecendo tanto a visão orientadas a processos quanto a orientada a eventos. É possível ainda que o usuário expresse seu modelo com alto grau de abstração, e mesmo assim, alcançar resultados e desempenho satisfatórios;

- Escalabilidade: A implementação dos timelines do DaSSF contribui significativamente para manter o desempenho da simulação mesmo quando mais entidades e eventos são adicionados ao sistema.

O DaSSF 3.0 pode ser executado em ambientes de memória distribuída. Ele possui esquemas de sincronização separados para memória compartilhada e distribuída. Em uma visão global do funcionamento do kernel, o modelo é particionado em um determinado número de subsistemas. Cada um reside em um nó de processamento e sincroniza com os outros subsistemas via passagem de mensagem. Em uma visão local, em cada nó, o subsistema pode ser posteriormente particionado em múltiplos processadores dentro deste mesmo nó. A sincronização entre estes processadores em um mesmo nó é feita através de memória compartilhada. A Figura 3.2 ilustra a organização dos processos no DaSSF. Ela mostra um exemplo onde o sistema consiste de quatro nós de processamento conectados por uma rede de computadores. Em cada nó, existem dois processadores que são sincronizados via memória compartilhada.

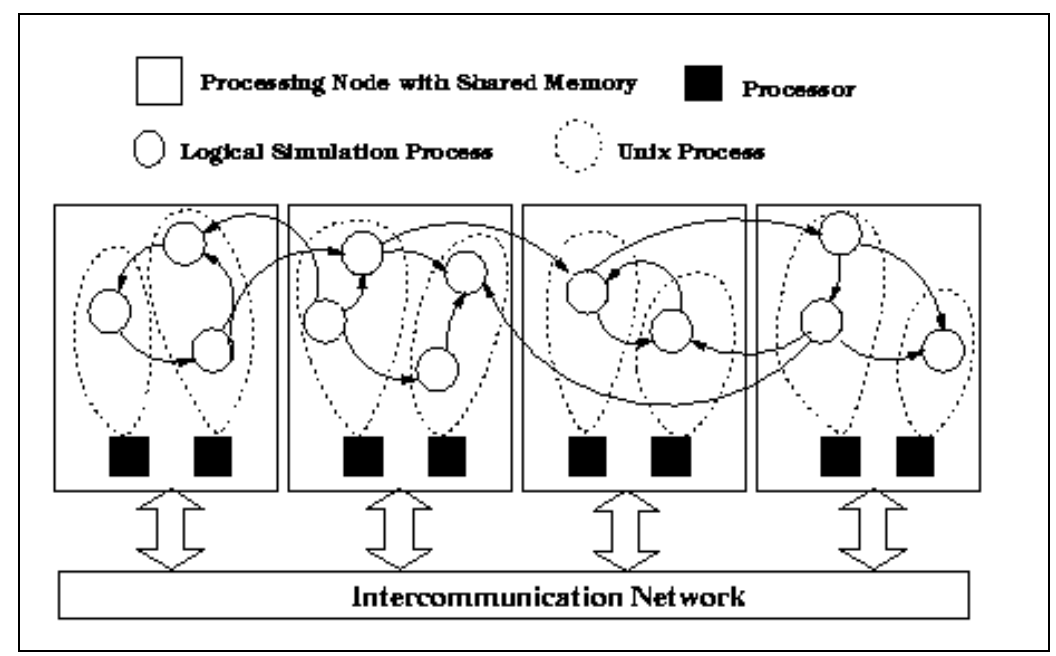

Figura 3.2. Organização dos processos no DaSSF (Liu \& Nicol, 2001). 
O particionamento do modelo é realizado automaticamente. O DaSSF 3.0 também inclui um novo kernel de sincronização que combina protocolos de sincronização conservativos síncronos e assíncronos. Essa composição alcança um desempenho superior uma vez que permite que o kernel adapte o mecanismo de sincronização do modelo que está sendo simulado. O kernel pode encontrar automaticamente a combinação ótima de canais síncronos e assíncronos dos processos lógicos.

A atual versão do DaSSF fornece basicamente duas maneiras de construir um modelo. $\mathrm{O}$ usuário pode utilizar scripts DML para particionar e construir modelos de uma forma distribuída. Um script escrito em DML basicamente descreve o modelo utilizando uma lista hierárquica de atributos. São necessários três arquivos DML os quais têm as seguintes responsabilidades:

- Descrever a topologia do modelo;

- Especificar a plataforma de hardware na qual a simulação será executada, isto é, prover o número de máquinas com memória distribuída que serão envolvidas na simulação e o tipo e número de processadores usados em cada uma dessas máquinas;

- Prover informação de tempo de execução, isto é, fornecer os tempos de início e fim da simulação, bem como os nomes dos arquivos DML do modelo e das máquinas;

Os três arquivos DML são primeiramente passados ao interpretador DML, o qual é responsável por particionar o modelo. A partir da topologia do modelo e das informações sobre a arquitetura do sistema onde a simulação será executada, o interpretador constrói um grafo de nós (timelines) e arestas (ponderadas pelo atraso de mapeamento mínimo entre as entidades dos timelines). Este grafo é, então, particionado em $\mathrm{N}$ submodelos, um para cada nó do sistema de memória distribuída. O submodelo pode ser posteriormente particionado para múltiplos processadores em cada nó de memória compartilhada. O resultado da partição é escrito em um outro arquivo DML, que é estruturalmente equivalente ao original adicionado de informação sobre partições e parâmetros de execução da simulação.

Quando a simulação inicia, o arquivo DML produzido pelo particionador é lido por todo processador do sistema. Neste ponto, um outro interpretador DML é usado para cada nó no sistema de memória distribuído. O segundo interpretador reconhece timelines, entidades e diretivas de mapeamento "mapto ( )". Logo após, constrói o submodelo que pertence ao nó e 
os canais de saída são mapeados para os canais de entrada. O modelo é então construído e a simulação fica pronta para se iniciar.

A partir da versão 3.1 do DaSSF e dos simuladores que foram derivados desta versão (iSSF (Nicol et al., 2003), MaSSF (Lui et al., 2003), RINSE (Liljenstam et al., 2005) e outros), a construção de modelos pode ser realizada diretamente a partir das funções do SSF. O usuário pode fornecer uma função main ( ) e construir o modelo programaticamente ao invés de utilizar os scripts DML, juntamente com classes que implementem um domínio específico de aplicação, por exemplo, classes de redes de filas. É a partir desta funcionalidade em que foi baseada a geração do programa de simulação de forma automática, a partir de um modelo DML.

\subsection{Considerações finais}

Pode-se concluir que mesmo com algumas poucas restrições, a API SSF e a linguagem de modelagem DML são ricas em termos de expressividade. A especificação é cuidadosamente definida com um balanço entre a expressividade necessária a um modelo e requisitos de desempenho. O framework é realmente genérico em termos de projeto modular. Camadas de componentes adicionais que são específicas para certos domínios, como sistemas baseados em filas, podem ser desenvolvidas sobre a API.

O capítulo seguinte detalha o desenvolvimento de uma classe que possui um conjunto de atributos e métodos necessários para a construção de modelos baseados em filas. $\mathrm{O}$ capítulo mostra ainda alguns testes realizados com o intuito de validar tal classe de modo que ela possa ser utilizada para modelas sistemas compostos de inúmeros objetos desta classe. 


\section{Redes de Filas na API SSF}

\subsection{Considerações iniciais}

A API SSF foi especificada tendo por base os princípios já citados por Liu (2003): capacidade, escalabilidade, simplicidade, flexibilidade, configurabilidade e reusabilidade. Desta forma, é relativamente simples que profissionais que trabalham com simulação e avaliação de desempenho construam modelos utilizando as cinco classes já discutidas da API SSF. Para ilustrar isso, foram desenvolvidas classes baseadas na API SSF que modelam redes de filas. Posteriormente, estas classes serão adicionadas no simulador proposto nesta dissertação.

Este capítulo tem por objetivo detalhar o desenvolvimento e o funcionamento de classes de redes de filas bem como validá-las, comparando os resultados da execução de um programa de simulação que as utiliza com os resultados obtidos pelo mesmo modelo simulado em ambientes já validados.

\subsection{Redes de fila usando o SSF}

Uma rede de filas é composta por um ou mais centros de serviços ligados entre si e mensagens que trafegam entre estes centros. A Figura 4.1 mostra uma visão conceitual de como um centro de serviço pode ser mapeado em objetos das cinco classes SSF. Um centro de serviço poderia ser um objeto de uma classe derivada da classe Entity. Esta classe contém variáveis de estado que descrevem seu comportamento e outras para a coleta de dados estatísticos, todas elas, derivadas de uma das cinco classes base da API do Scalable Simulation Framework.

Um cliente é representado por um evento, isto é, um objeto de uma classe derivada da classe Event, da API SSF. A entidade tem um canal de entrada para receber clientes (mensagens) de outros centros de serviço e um ou mais canais de saída para enviar clientes (mensagens). O centro ainda possui dois processos: um que trata a chegada de eventos e os 
insere na fila do centro e outro que manipula e processa os eventos enfileirados. Cada processo é criado simplesmente criando-se uma instância da classe Process usando um argumento que é um ponteiro para a função que representa o corpo do processo. O processo de chegada se inicia esperando no canal de entrada a chegada de mensagens. O processo fica suspenso até que uma mensagem apareça no canal de entrada especificado. A mensagem que chega é então inserida na fila interna presente no centro de serviço. Se a fila se encontra vazia no momento em que a mensagem chega, então o processo de chegada deve informar o processo servidor para começar a servir as mensagens da fila. Isto é feito através de um semáforo que também é uma das variáveis de estado do centro de serviço.

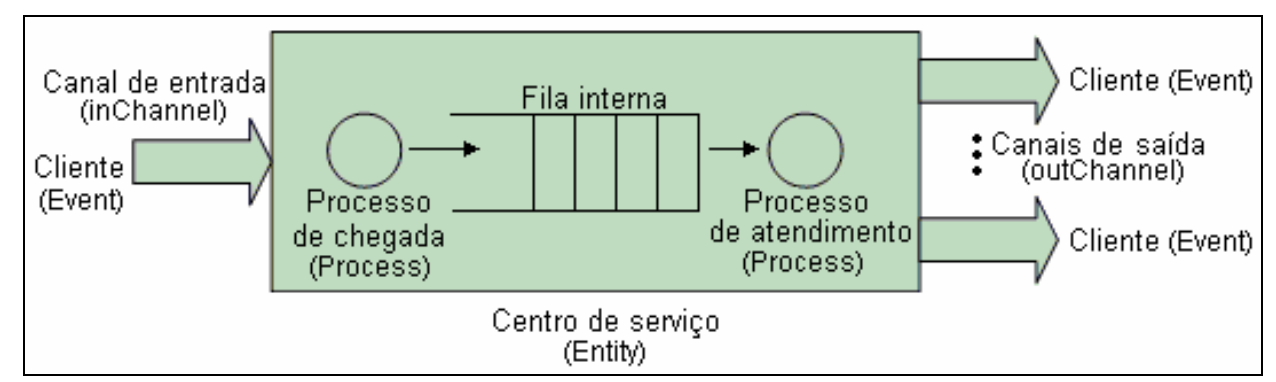

Figura 4.1. Visão conceitual de um centro de serviço

O processo de chegada deve enviar um sinal para "acordar" o processo servidor. Quando o controle chega ao fim da função, ele retorna ao seu início e inicia novamente. O processo servidor inicia aguardando um sinal do processo de chegada. Quando mensagens são inseridas na fila interna, o processo servidor começa a servir as mensagens uma por uma, a partir do início da fila. O processo consome um tempo de simulação aleatório gerado pela variável "rng" (random number generator) e se suspende através da chamada à função "waitFor()", da API SSF. Isto representa o processamento da mensagem. Passado o tempo, o processo servidor volta à sua execução imediatamente após a chamada da função “waitFor ( )", e escreve a mensagem no respectivo canal de saída.

Utilizando os métodos definidos pela API SSF, os canais de saída de um centro de serviço podem ser mapeados para os canais de entrada de outro centro, assim como é realizado na listagem de código mostrada na Figura 4.2. Todos os mapeamentos foram especificados como tendo o atraso M igual a 1 (último parâmetro do método "mapTo ( )"). Desta forma, uma unidade de tempo de simulação irá ser consumida quando uma mensagem for escrita em um canal de saída e quando ela surgir em um canal de entrada. O centro de serviço $i d_{0}$ é um pouco diferente dos outros e pode enviar mensagens tanto para o centro de serviço $i d_{1}$ quanto para $\mathrm{o} i d_{2}$, com probabilidade de $50 \%$ para cada canal de saída. Vale 
lembrar que o centro de serviço, neste caso, foi modelado com dois canais de saída. Porém, o centro pode possuir quantos canais o usuário desejar.
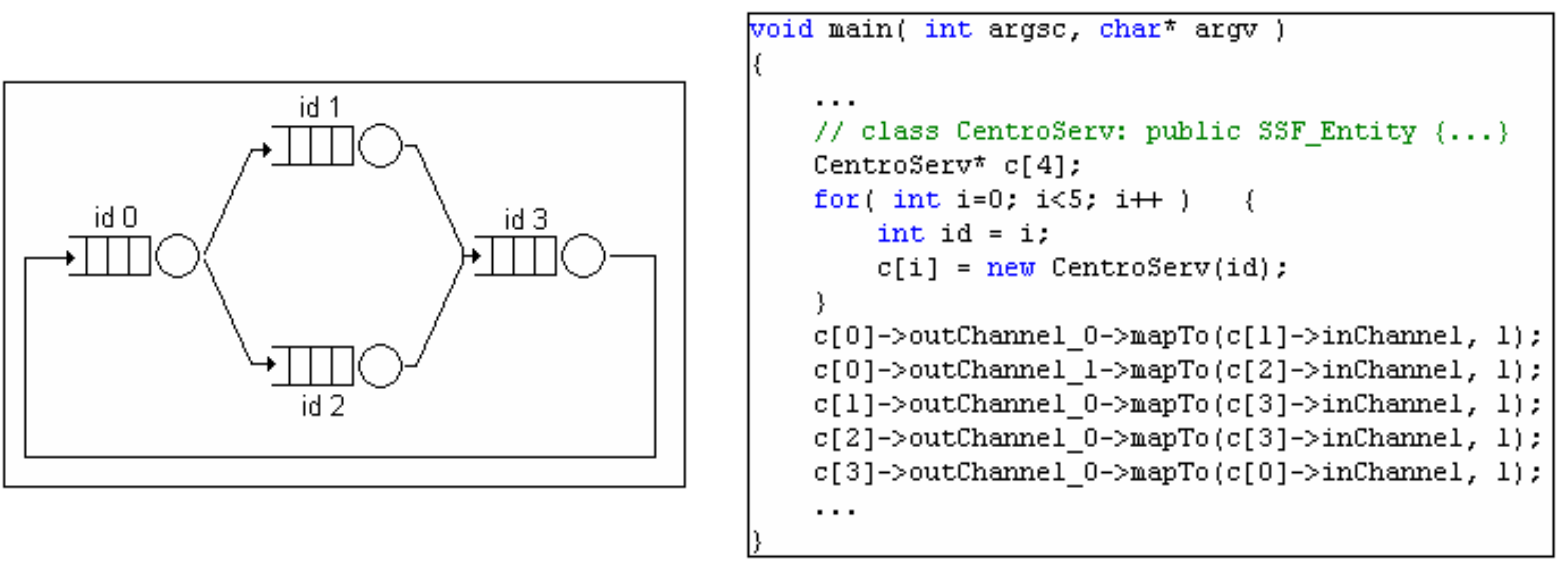

Figura 4.2. Modelo de redes de filas e mapeamento dos canais de saída para canais de entrada

\subsection{A classe FIFO_QueueNode}

A classe criada foi denominada FIFO_QueueNode e um objeto dessa classe denota um centro de serviço. A Figura 4.3 mostra o código de parte do construtor e ambos os processos de chegada e servidor. Para parametrizar o centro de serviço, deve ser fornecido ao objeto os seguintes atributos:

- identificador: um identificador para o centro de serviço. Geralmente se trata de um número;

- tempo médio de serviço: tempo médio gasto pelo centro de serviço. O tempo médio é definido seguindo-se uma distribuição de probabilidade. $\mathrm{O}$ valor deve ser maior ou igual à zero;

- número inicial de clientes: número inicial de clientes presentes na fila interna do centro de serviço. Deve ser maior ou igual à zero;

- número de canais de saída: número de canais de comunicação de saída, isto é, canais por onde sairão os clientes que já foram servidos pelo processo de atendimento do centro de serviço; 
- vetor de pesos para canais de saída: Um vetor de números de pontos flutuantes que denotam os pesos atribuídos para cada canal de saída. O vetor deve possuir tantas posições quanto forem o número de canais de saída.

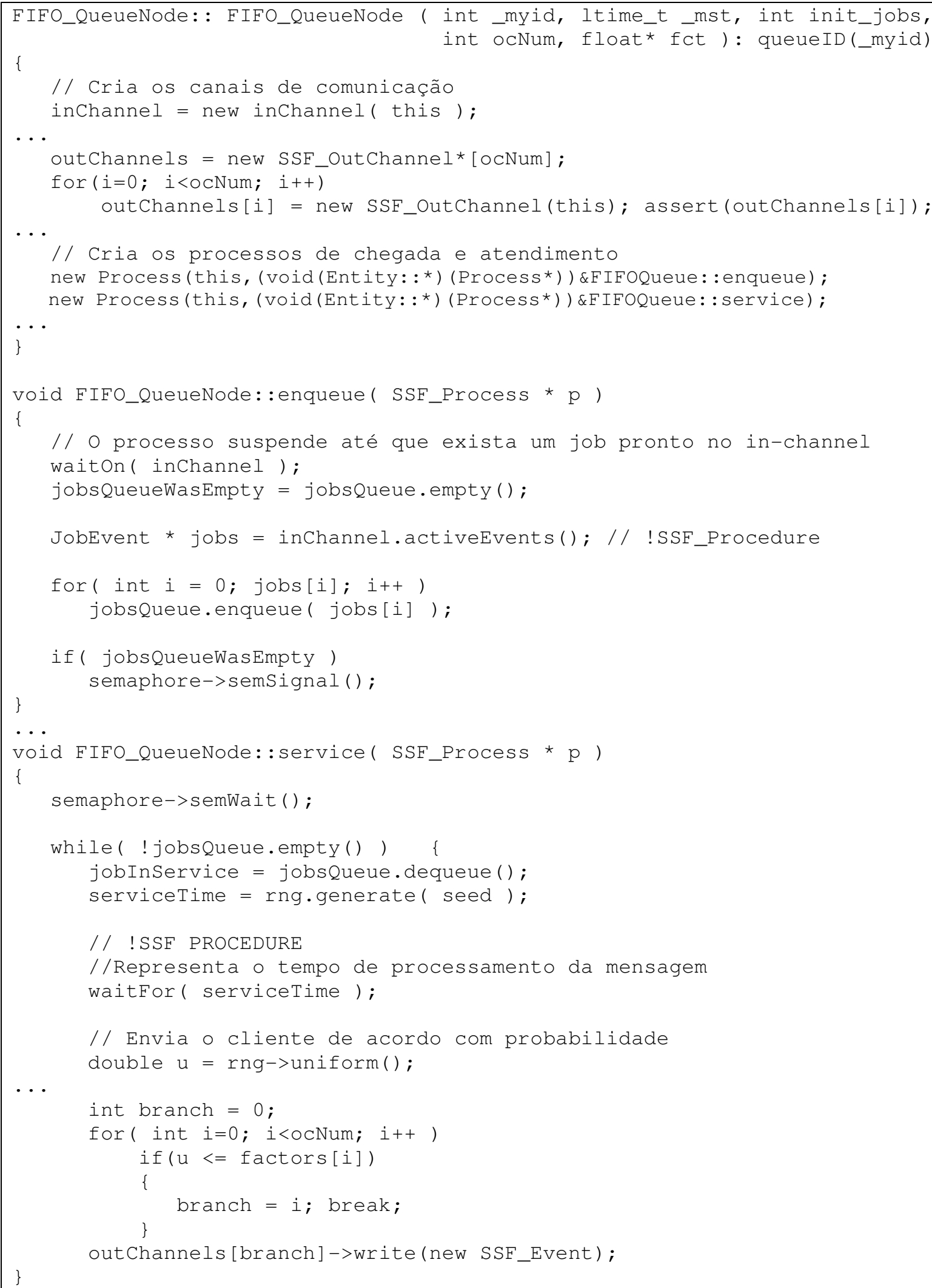

Figura 4.3. Uso da API SSF para modelar a rede de filas. 
A classe possui ainda outras funções membro que tratam da criação de clientes iniciais na centro de serviço, instruções para "logging", de modo a registrar todos os passos e comportamentos das entidades durante a simulação, entre outras funcionalidades. As funções listadas na Figura 4.3 foram simplificadas para que os trechos código ficassem mais legíveis e de fácil entendimento. A Tabela 4.1 fornece o nome dos métodos e suas funções. Para informações mais detalhadas, recomenda-se a leitura e análise do código das classes de domínio nos apêndice A e B.

Tabela 4.1. Métodos e Funções da FIFO_QueueNode.

\begin{tabular}{|c|c|}
\hline Método & Função \\
\hline $\begin{array}{c}\text { FIFO_queueNode(int myid,_ltime_t mst, } \\
\text { int init_jobs); }\end{array}$ & $\begin{array}{c}\text { Construtor para servidores com apenas um canal } \\
\text { de saída }\end{array}$ \\
\hline $\begin{array}{c}\text { FIFO_QueueNode(int myid,ltime_t mst,int } \\
\text { init_jobs,int nouts, float*factors); }\end{array}$ & $\begin{array}{c}\text { Construtor para servidores com mais de um canal } \\
\text { de saída }\end{array}$ \\
\hline virtual $\sim$ FIFO_QueueNode(); & $\begin{array}{c}\text { Destrutor da classe, desalocando a memória } \\
\text { ocupada por clientes remanescentes no buffer } \\
\text { interno e outras estruturas }\end{array}$ \\
\hline virtual void wrapup(); & $\begin{array}{c}\text { Coleta dados das entidades em tempo de } \\
\text { execução }\end{array}$ \\
\hline Void enqueue(SSF_Process*); & $\begin{array}{c}\text { Recebe um cliente do canal de entrada e } \\
\text { armazena-o no buffer interno }\end{array}$ \\
\hline Void service(SSF_Process*); & Atende um cliente \\
\hline void insert_init_jobs(int njobs); & $\begin{array}{c}\text { Insere clientes no buffer interno antes da } \\
\text { simulação ter sido iniciada }\end{array}$ \\
\hline
\end{tabular}

No arquivo de cabeçalho da classe FIFO_QueueNode está presente ainda uma classe simples para representar as mensagens que trafegam pelo centro de serviço, chamada Client. Assim como já foi mencionado, a classe é herdada de SSF_Event e seus objetos são enviados e recebidos através dos canais de comunicação do centro de serviço. Existe ainda uma terceira classe que funciona como geradora de clientes, chamada ClientSource, que gera clientes para a rede de filas. Esta classe deve ser utilizada apenas em redes de filas abertas e é colocada no centro de serviço inicial da rede. Entretanto, para redes de filas fechadas, o usuário poderá inserir clientes na fila interna dos centros de serviço antes mesmo da simulação ter início.

Um bom gerador de números aleatórios é um importante aspecto de qualquer simulador estocástico. O DaSSF fornece a classe Random, responsável por esta importante tarefa. A classe fornece aproximadamente uma dúzia de distribuições de probabilidades. A semente é passada ao DaSSF através da opção de linha de comando "-seed <nro>" e várias instâncias 
da classe Random, totalmente independentes entre si, podem ser utilizadas. As funções membro da classe Random são:

a) Distribuições contínuas

- double uniform();

- double uniform(double a, double b);

- double exponential(double x);

- double erlang(long $\mathrm{n}$, double $\mathrm{x})$;

- double pareto(double $\mathrm{k}$, double a);

- double normal(double $\mathrm{m}$, double s);

- double lognormal(double a, double b);

- double chisquare(long $\mathrm{n})$;

- double student(long $\mathrm{n})$;

b) Distribuições dicretas:

- long bernoulli(double p);

- long equilikely(long a, long b);

- long binomial(long $\mathrm{n}$, double p);

- $\quad$ long geometric(double p);

- $\quad$ long pascal(long $\mathrm{n}$, double $\mathrm{p}$ );

- long poisson(double m);

Existe também dois métodos que podem ajudar a obter a permutação de $n$ números (de 0 até n-1). O usuário pode tanto fornecer um vetor pré-alocado quando o DaSSF pode criar um.

- $\quad$ void permute(long *vet, long n);

- $\quad$ long *permute(long n);

Todos estes métodos podem ser utilizados pelas classes de domínio específico. No apêndice, pode-se observar que para o parâmetro "mst" da classe FIFO_QueueNode, o qual denota o tempo médio de serviço, é usada a distribuição exponencial. Entretanto, qualquer outro tipo de distribuição poderia ser utilizada. 


\subsection{Validação}

Para a validação da classe de domínio FIFO_QueueNode, foi construído um pequeno programa de simulação a fim de simular o modelo $\mathrm{M} / \mathrm{M} / 1$. O programa criado é mostrado na listagem de código do Apêndice C. O esquema conceitual do sistema M/M/1 é mostrado na Figura 4.4. Pode ser observado que, para este exemplo, foram criadas duas entidades: Um centro de serviço e uma fonte geradora de clientes. Será visto, posteriormente, que essa última será gerada automaticamente caso o modelo simulado se trate de uma rede aberta.

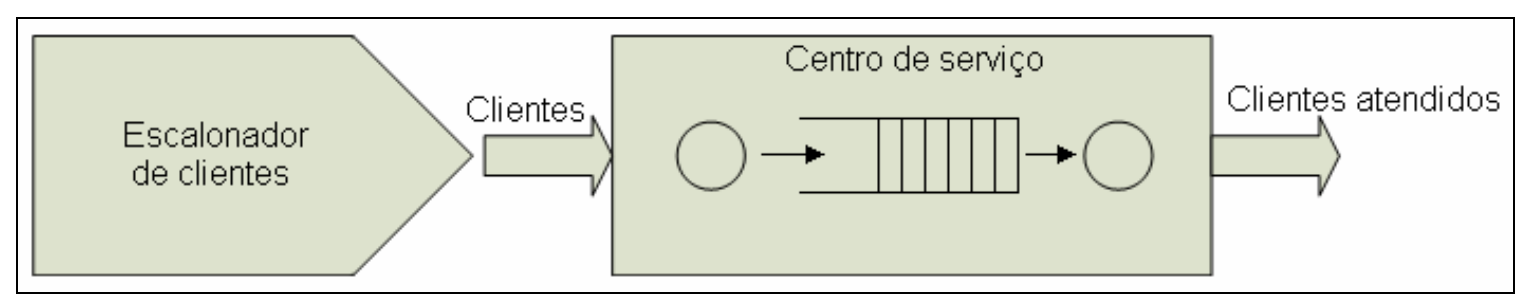

Figura 4.4. Modelo $M / M / 1$.

A fonte gera clientes a uma taxa exponencial. A taxa de atendimento aos clientes, pelo processo do centro de serviço, também é exponencial. Este modelo foi resolvido analiticamente em (Silva, 2000) e os resultados fornecidos neste trabalho são utilizados para validar o sistema. O valor da taxa de chegada é 0.0833 e da taxa de serviço é 0.05 .

O valor que será analisado neste modelo é a utilização do centro de serviço. O resultado analítico, utilizando o método de análise do valor médio (AVM) para modelos abertos, fornecido em (Silva, 2000) é 0.6, ou seja, o centro de serviço tem $60 \%$ de utilização.

A Tabela 4.2 exibe os valores obtidos da utilização do centro de serviço, em 16 execuções do programa de simulação, usando diferentes sementes. Como podem ser observados, os valores são bem próximos ao valor obtido na resolução analítica do modelo em (Silva, 2000).

Com estes testes realizados, provou-se que a classe de domínio de redes de filas FIFO_QueueNode pode ser utilizada na construção de redes de filas mais complexas, com vários centros de serviços e mais clientes envolvidos. O usuário dessa classe poderá ter certeza que os resultados obtidos serão confiáveis, pois quando comparados a resultados obtidos de forma analítica, estes se mostraram muito próximos. 


\subsection{Considerações finais}

Este capítulo mostrou o desenvolvimento e a validação das classes de domínio específico a partir da API SSF. Tais classes serão necessárias para o desenvolvimento de programas que simulem modelos extremamente grandes. Com essas classes, o usuário não precisará desenvolver novas entidades sempre que deseja simular sistemas baseados em fila. Poderá também abstrair grande parte do conhecimento necessário para lidar com a API SF e suas particularidades, favorecendo usuários leigos, mas permitindo que usuários experientes modifiquem os seus comportamentos.

O próximo capítulo explorará e detalhará o desenvolvimento de um simulador de modelos de larga escala baseado no padrão SSF. Toda a teoria envolvida no desenvolvimento já foi apresentada bem como a validação de classes de domínio específico que serão usadas como templates para a geração de código do simulador.

Tabela 4.2. Resultados dos testes efetuados com a classe FIFO_QueueNode.

\begin{tabular}{|c|c|}
\hline Execução & Taxa de utilização \\
\hline 01 & 0.59865 \\
\hline 02 & 0.59963 \\
\hline 03 & 0.599321 \\
\hline 04 & 0.599806 \\
\hline 05 & 0.600557 \\
\hline 06 & 0.59963 \\
\hline 07 & 0.600469 \\
\hline 08 & 0.599855 \\
\hline 09 & 0.599742 \\
\hline 10 & 0.600468 \\
\hline 11 & 0.599724 \\
\hline 12 & 0.599702 \\
\hline 13 & 0.600008 \\
\hline 14 & 0.600605 \\
\hline 15 & 0.599427 \\
\hline Média & 0.599785 \\
\hline Dsv. Padrão & 0.000502 \\
\hline IC ( $\boldsymbol{\alpha}=\mathbf{0 , 0 5})$ & 0.000254 \\
\hline
\end{tabular}




\section{Um simulador baseado no SSF}

\subsection{Considerações iniciais}

Uma das etapas mais importantes do desenvolvimento de qualquer projeto é o planejamento. Apenas a teoria científica não é suficiente para que um projeto seja um sucesso. A etapa de planejamento é responsável por direcionar e orientar o andamento do projeto e ajudar para que os indivíduos que nele trabalham não se percam nas próprias idéias e cheguem a resultados incorretos ou imprecisos, ou até pior, não cheguem a resultado algum.

Dessa forma, o desenvolvimento do simulador iniciou-se primeiramente com a revisão bibliográfica, a qual foi relatada sinteticamente nos capítulos 2, 3 e 4 . Posteriormente, passouse a esta importante etapa: o desenvolvimento de um plano de desenvolvimento e sua posterior execução.

Além do plano de desenvolvimento, este capítulo detalha toda a arquitetura do simulador. Detalha também os programas de simulação gerados a partir dos modelos definidos pelo usuário e como estes podem ser alterados, visando aperfeiçoá-los. Por fim, são exibidas as conclusões que podem ser tomadas após a execução dos programas de simulação.

\subsection{0 plano de desenvolvimento}

O desenvolvimento do simulador iniciou-se com a modelagem de alguns módulos básicos, os quais são normalmente encontrados em ambientes de simulação. Trata-se de interfaces intuitivas e modos de entrada e saída de dados flexíveis, entre outros. O simulador possui três módulos essenciais: a interface com o usuário; um processador de modelos, que inclui um compilador o qual transforma o modelo escrito em uma linguagem de modelagem de alto nível em um programa de simulação em linguagem C++ e que utiliza a API SSF; e um módulo executor, que invoca o DaSSF a fim de executar os programas de simulação e armazena os resultados em relatórios. Além disso, foi especificada uma camada de componentes de domínio específico para sistemas baseados em redes de filas. Esta camada foi 
planejada de modo a ser desenvolvida sobre a API SSF e será bastante útil para minimizar a complexidade do programa de simulação gerado, uma vez que este terá um caráter mais modular, com classes de entidades já definidas e encapsuladas, necessitando-se apenas a declaração de instâncias destas classes. De modo a viabilizar a utilização do simulador como uma ferramenta consistente na simulação de sistemas de larga escala e de inseri-lo num contexto de ambiente de simulação, foi definido também nesta fase de planejamento que o protótipo construído seria integrado ao ASDA.

A Figura 5.1 exibe um diagrama modular do simulador e a Figura 5.2 mostra um fluxograma da execução da simulação no simulador.

A Figura 5.3 ilustra uma associação dos módulos propostos para o simulador e os módulos definidos no ASDA.

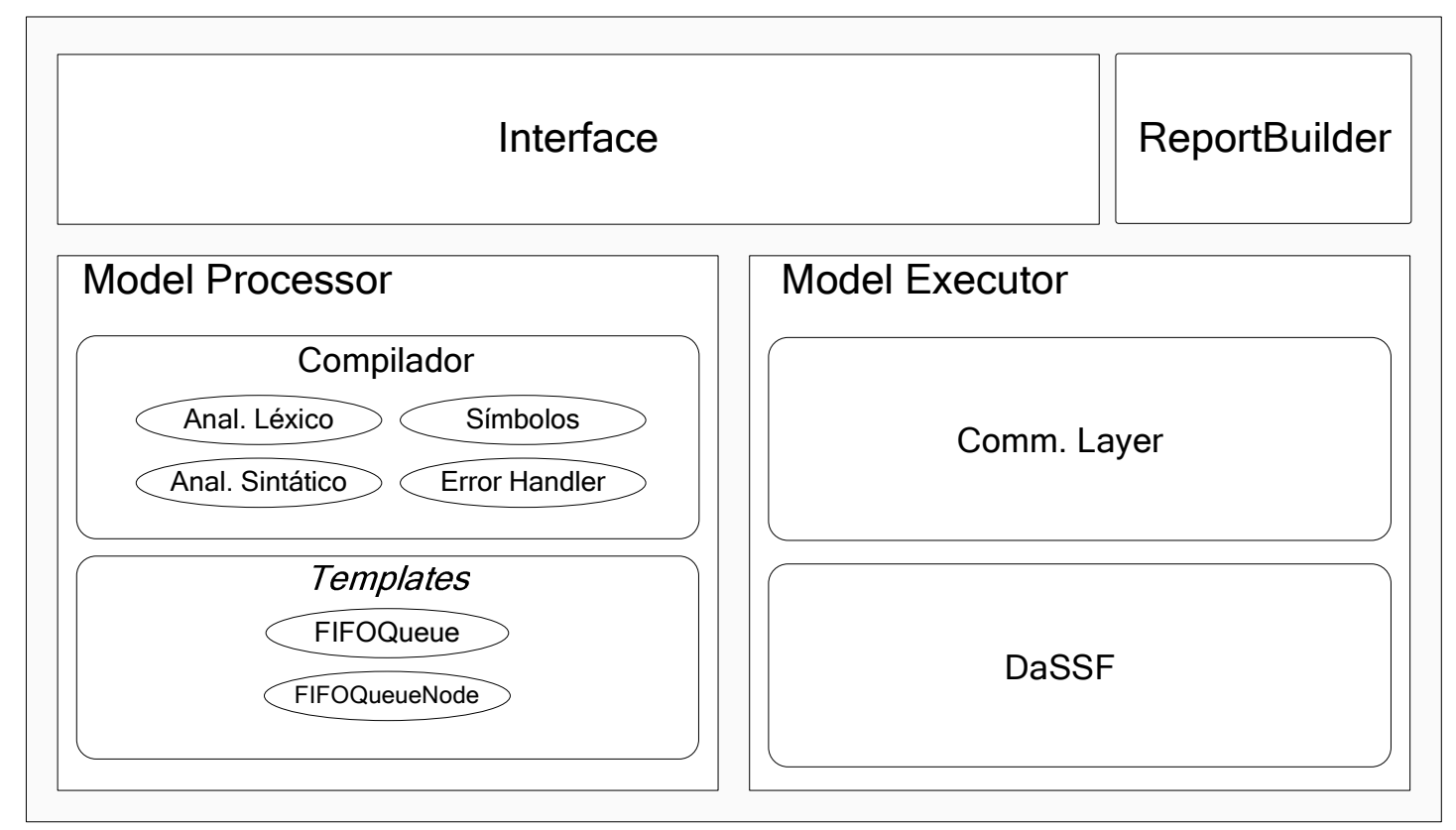

Figura 5.1. Diagrama modular do simulador.

Após a modelagem dos módulos do simulador, foi decidido que cada módulo iria operar de maneira relativamente independente um do outro. Cada módulo seria basicamente uma classe ou um pequeno conjunto de classes que interagiriam entre si por meio de mensagens. Essa fórmula modular e não monolítica ajuda a manter o código claro e facilita o desenvolvimento, uma vez que os módulos não precisam ser desenvolvidos necessariamente com uma ordem definida. O que devia ser definido realmente é o tipo de mensagens que os módulos iriam trocar entre si. 


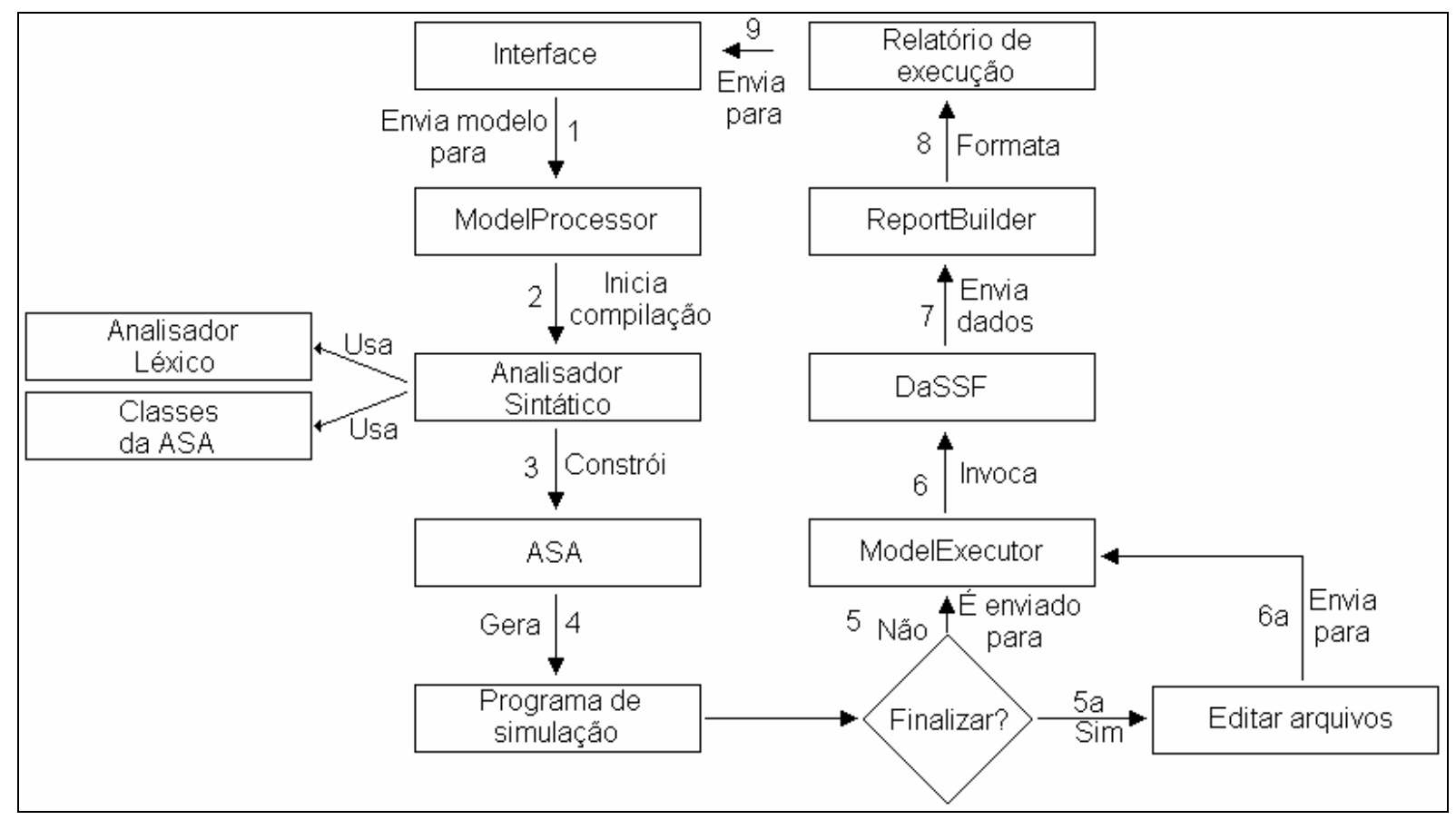

Figura 5.2. Fluxograma exibindo as atividades desempenhadas pelos componentes do simulador.

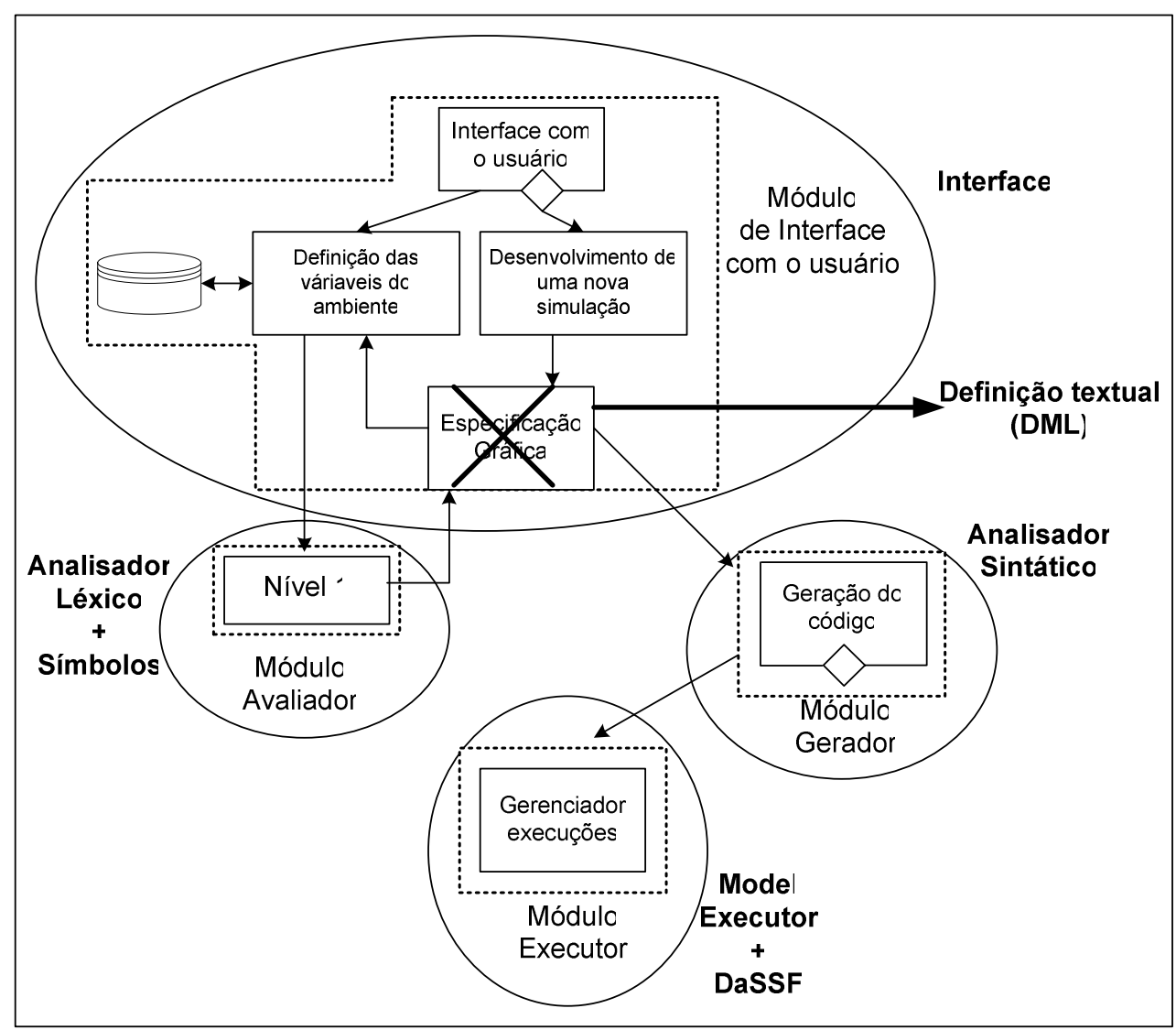

Figura 5.3. Associação entre os módulos do simulador e do ASDA. 
O módulo ModelProcessor é responsável pelo processo de criação do programa de simulação a partir do modelo. Ele é composto por dois submódulos: o compilador e os templates, com as classes de domínio específico. O compilador, formado pelo analisador léxico, pelo analisador sintático, uma tabela de símbolos, classes que comporão a árvore de sintaxe abstrata e uma classe responsável por manipular e tratar erros léxicos e sintáticos. $\mathrm{O}$ analisador léxico da linguagem de modelagem DML recebe um stream contendo o modelo a ser simulado. Ele verifica se os elementos léxicos utilizados no modelo estão de acordo com a tabela de símbolos do simulador. O analisador léxico é usado para serializar este stream de bytes, retornando ao analisador sintático, cada token lido do modelo escrito. O analisador sintático, além de verificar se a sintaxe do modelo está correta, tem o papel de construir a árvore de sintaxe abstrata (ASA) do modelo. Cada elemento da ASA é um objeto que denota uma entidade do modelo e cada um destes objetos é responsável por gerar o código do programa de simulação.

O ModelProcessor é responsável também por gerar Makefiles, arquivos de cabeçalho e classes de suporte ao programa principal. O módulo ainda cria pastas próprias de armazenamento de cada um dos programas de simulação gerados a partir dos modelos definidos pelo usuário. Ele organiza os arquivos e os prepara para envio para o módulo executor do sistema.

O módulo executor ou ModelExecutor, tem uma arquitetura um pouco mais complexa que o restante do sistema e é responsável por invocar o compilador e o kernel DaSSF, repassando o programa de simulação como seu argumento. Este módulo é dividido em duas partes, cliente e servidor, e cada uma possui uma camada de comunicação, responsável por trocar mensagens entre si. O cliente tem como objetivo repassar os arquivos do programa de simulação ao kernel DaSSF, receber os dados estatísticos da simulação e repassa-los ao construtor de relatórios ReportBuilder. O ModelExecutor será descrito em detalhes na seção 5.5. Com base nos dados gerados pela execução do programa de simulação, o ReportBuilder constrói um relatório com formato amigável e o exibe ao usuário.

Todo o simulador, com exceção de parte do módulo executor, é escrito em linguagem Java, uma vez que o ASDA é escrito nesta linguagem e isso permitirá uma rápida integração de ambos os softwares. Outro motivo de se ter escolhido a linguagem Java foi pela facilidade em escrever interfaces com o usuário e pelo fato de ser totalmente orientada a objetos, o que facilita a escrita, manutenção e entendimento do código. $\mathrm{O}$ compilador gera código em $\mathrm{C}++$ pois o kernel de simulação DaSSF é também escrito nesta linguagem. 
A fim de organizar o código do simulador, as classes são divididas nos seguintes pacotes:

1. simulador. *: Contém as classes da interface com o usuário e a interface de software que se comunica com os outros módulos do simulador. Contêm ainda a classe principal do analisador sintático, o ModelProcessor e a parte cliente do ModelExecutor. O ReportBuilder também está incluso neste pacote;

2. lexer . *: Contém as classes do analisador léxico e da tabela de símbolos;

3. utils. *: Contém classes utilitárias e de suporte ao sistema, tais como classes de armazenamento de informações de arquivos, classes de gerenciamento de I/O em arquivos, classes de exceções personalizadas para tipos específicos de erros internos, entre outras;

4. asa.*: Contém as classes do analisador sintático e da árvore de sintaxe abstrata, as quais possuem implementadas também os métodos de geração de código;

5. domains. *: Contêm as classes de domínio específico. As classes definidas pelo usuário, como extensão ao simulador, devem ser colocadas neste pacote e devem herdar de asa.ModelElementDec.

O simulador foi denominado SSFSimulator. Mais à frente, durante o detalhamento do módulo executor, será mostrado que o simulador possui também um lado servidor, o qual foi chamado de SSFSimulatorServer. O motivo para o desenvolvimento de um processo servidor será explicado posteriormente.

O simulador possui uma interface com o usuário a qual será posteriormente integrada ao ASDA. A interface permite que o usuário entre com modelos escritos em DML e receba como saída os arquivos do programa de simulação bem como os dados coletados pelo módulo executor após a execução do programa gerado. Existe ainda um local para a edição de modelos. Na seção seguinte a interface é detalhada.

\subsection{0 módulo GUI: a interface com o usuário}

A interface com o usuário deve ser simples e clara. Por se tratar de uma extensão de um ambiente de simulação automático, esta deveria considerar que os usuários não seriam apenas os experientes, mas também aqueles menos familiarizados com simulação de modelos. Como 
já foi dito, o ambiente deve favorecer tanto os mais experientes quanto os mais leigos e oferecer as ferramentas para que estes tirem o máximo de proveito do ambiente e se tornem usuários mais experientes. Podemos observar na Figura 5.4 a tela principal do simulador, com a área de edição do modelo ao lado direito e o menu de opções acima, com operações básicas de abertura, salvamento, fechamento, edições de preferências e uma ajuda.

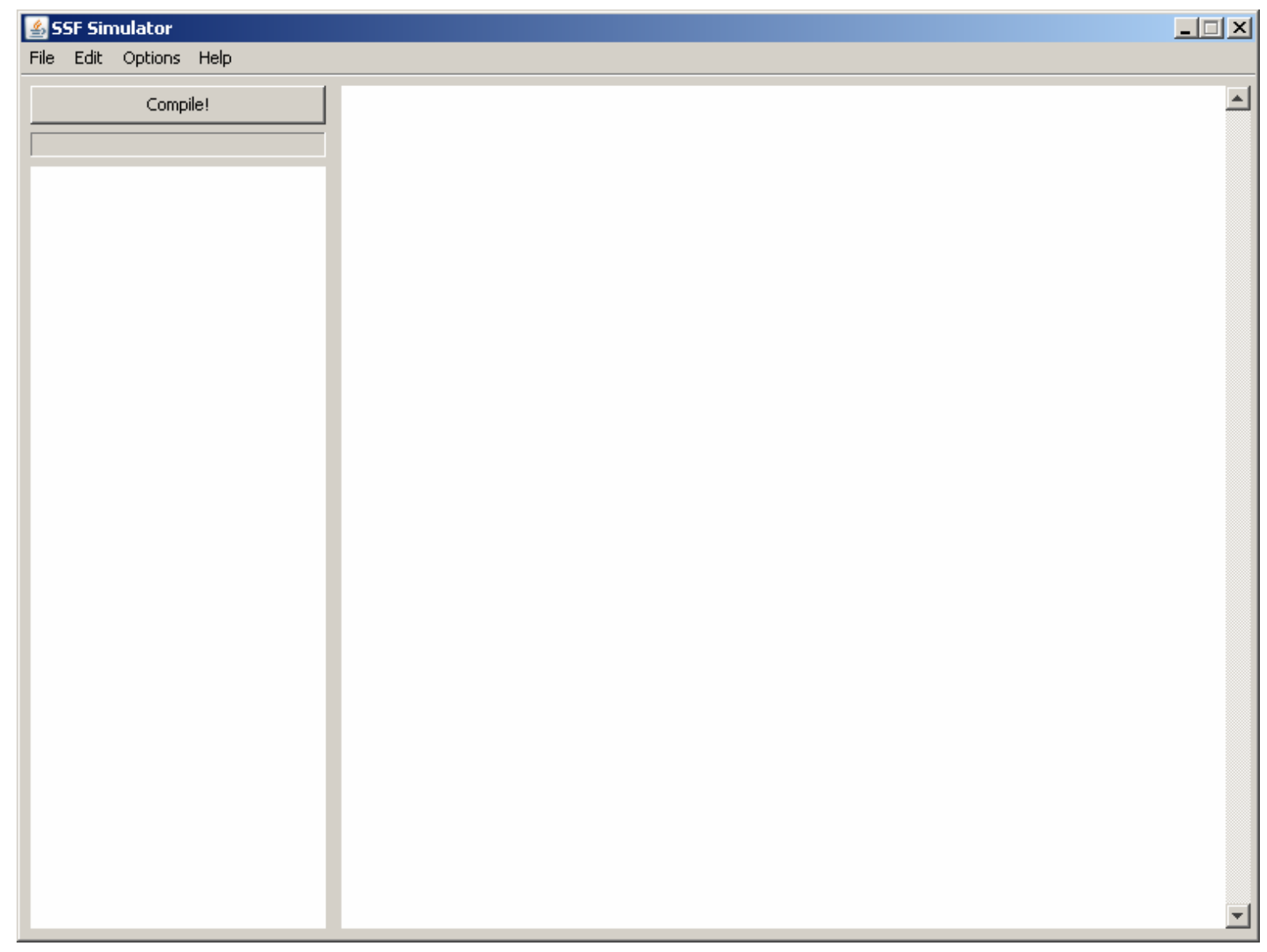

Figura 5.4. Tela principal do simulador.

Um botão simples permite ao usuário iniciar o processo de compilação. Abaixo dele, existe uma área de logging, que registra o andamento do processo de compilação e execução do modelo. O usuário pode ainda entrar com modelos já prontos no sistema e executá-los normalmente. Os modelos são salvos com a extensão “.dml” e o menu que permite salvar um modelo pode ser acessado a partir do menu principal de opções.

O botão "Compile!" inicia a compilação do modelo e permite que o programa compilado seja posteriormente executado. Assim que a compilação é concluída, o usuário tem a opção de modificar o programa de simulação. Este passo é muito delicado e deve ser tomado apenas por usuários experientes e familiarizados com a API SSF. O usuário pode, então, prosseguir com a simulação e iniciar a execução do programa gerado. 
Quando a simulação é finalizada, uma mensagem contendo o relatório de execução é exibida. O usuário poderá salvar o relatório no disco ou simplesmente descartá-lo. Caso ocorra algum erro na simulação, o relatório não será exibido e o tipo de erro detectado é informado ao usuário.

Podemos observar que a interface, apesar de simples, é bem expressiva e robusta. Sempre existe um retorno para o usuário, deixando-o informado sobre a situação do sistema em determinado momento.

\subsection{0 módulo processador de modelos: ModelProcessor}

O ModelProcessor é o módulo que processa o modelo em DML definido pelo usuário e gera o programa de simulação. Ele é composto por dois componentes principais: o analisador léxico e o analisador sintático. $\mathrm{O}$ analisador sintático utiliza o analisador léxico para verificar se os elementos léxicos do modelo escrito são válidos. $\mathrm{O}$ analisador sintático também é responsável pela construção da árvore de sintaxe abstrata (ASA) e pela posterior geração do código dos programas de simulação.

Nesta seção, além do detalhamento dos componentes são mostrados vários diagramas de classes. Optou-se por mostrar cada componente em diagramas separados, para favorecer a visualização. Os componentes são detalhados a seguir.

\subsubsection{O analisador léxico}

O analisador léxico é o componente do compilador que faz a interpretação de cada unidade léxica do modelo. Como já foi mencionado, o modelo definido pelo usuário é escrito em DML. O kernel de simulação utilizado no simulador, o DaSSF, inclui um analisador léxico DML. Porém, este não se mostrou muito flexível e não permitia uma rápida modificação que permitisse uma posterior integração com o analisador sintático do compilador. Dessa forma, optou-se pelo desenvolvimento de um novo analisador léxico, mais simples, e que permitisse a integração com o analisador sintático desenvolvido para o simulador.

O analisador léxico foi escrito totalmente em Java. Ele é basicamente formado por duas classes: Symbol e Lexer, conforme descrito pelo diagrama de classes da Figura 5.5. Nenhum objeto da classe Symbol é instanciado. Tal classe serve apenas para "nomear" todas 
as palavras chaves da linguagem de modelagem bem como os caracteres especiais utilizados durante a construção dos modelos. A classe Symbol é usada diretamente por outras classes do simulador acessando-se suas variáveis constantes estáticas. Durante a execução do simulador, apenas um objeto da classe Lexer é instanciado. Este objeto armazena uma cadeia de caracteres que contém todo o modelo definido pelo usuário. O processo de "tokenização" fica rápido e eficiente. A quantidade de memória utilizada pelo modelo não é relevante, uma vez que logo após a criação da árvore de sintaxe abstrata, anteriormente à geração de código, toda a memória ocupada pelo modelo é liberada. Temos ainda que a definição de um modelo grande, de larga escala, não ocuparia mais que alguns megabytes de memória. A Figura 5.5 mostra ainda a classe CompilerError, que além de disparar exceções em caso de erros na analise sintática, também sinaliza erros durante o processo de análise léxica.

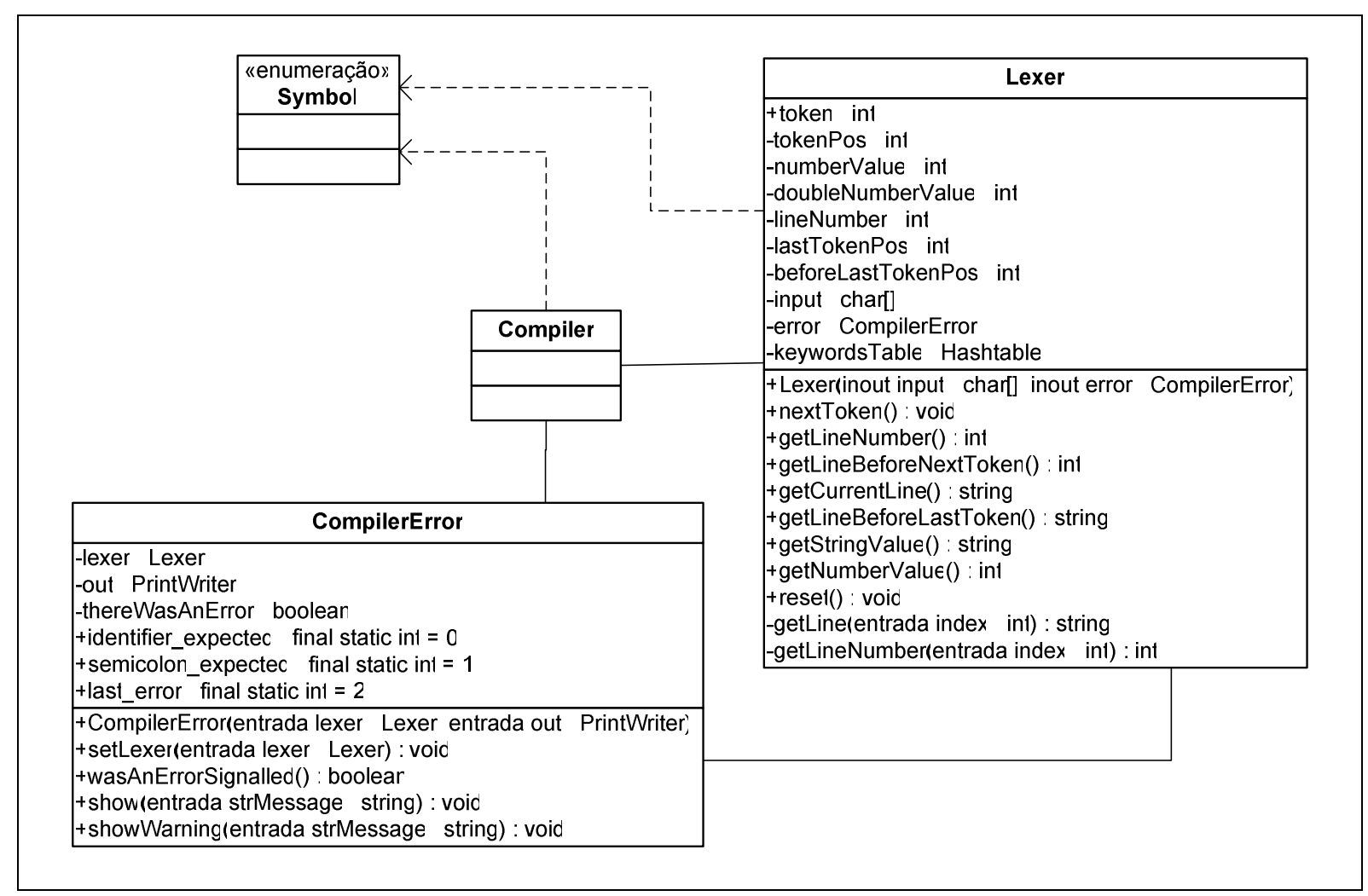

Figura 5.5. Diagrama de classes do analisador léxico do sistema.

Durante a interpretação do modelo, caso um caractere desconhecido seja detectado pelo analisador léxico, este termina a execução da interpretação. O analisador guarda ainda uma tabela hash contendo todas as palavras chave da linguagem de modelagem, mapeadas com as constantes da classe Symbol. A detecção de se um token é ou não uma palavra chave se dá pela busca de uma constante nesta tabela hash a partir do token coletado do modelo. 
O modelo pode conter comentários ao estilo da linguagem de programação $\mathrm{C}$, isto é, inicia-se um comentário por “/*” e finaliza-se com “*/". Esta funcionalidade foi implementada a fim de que o usuário possa definir seu modelo e inserir quantas linhas de explicações quiser, a fim de permitir a manutenibilidade e o entendimento do modelo por parte de outros usuários que venham a utilizar o modelo de alguma forma.

A estrutura de programação do analisador permite uma fácil expansão deste componente caso mais palavras chaves ou caracteres especiais se façam necessários para a definição de modelos mais complexos.

Um objeto Lexer troca mensagens também com objetos da classe CompilerError. Este objeto é o manipulador padrão de erros do simulador. Quando um erro é detectado, o objeto CompilerError dispara uma exceção, que termina a execução do programa e libera um stream que contém uma mensagem apropriada de erro.

\subsubsection{A DML}

A DML, como já foi mencionada, se trata de uma linguagem semelhante à linguagem de marcação XML. É formada basicamente por um conjunto de pares atributos-valor, onde os valores podem ser conjuntos de atributos.

A DML implementada no simulador é mais simples que a DML original e suportada pelo parser contido no kernel de simulação DaSSF. A DML do modelo DaSSF possui diversas particularidades que a tornam uma poderosa linguagem de modelagem. Tais particularidades, apesar de importantes, não foram levadas em consideração no protótipo do simulador, por fugirem do escopo de construir um simulador de modelos de larga escala básico. Tais características servem para tornar mais fácil a definição de modelos por usuários mais experientes. Vale ressaltar que o nome da linguagem não foi alterado porque a inclusão de tais particularidades na linguagem definida nesta dissertação está prevista como trabalho futuro.

A DML desenvolvida foge do conceito de uma linguagem auto-configurável. Ao contrário da DML do DaSSF, a linguagem de modelagem do simulador não suporta a definição de schemas. Os schemas funcionam como documentos de definição de tipo ou “document-type-definitions" (DTD). Dessa forma, podem ser definidas diversas gramáticas da linguagem sem a necessidade de modificação do código do kernel. Porém, como o escopo é o de simular modelos mais genéricos, que serviriam para simular uma ampla gama de 
aplicações, a gramática e a sintaxe foram definidas de maneira estática, isto é, o analisador sintático não segue um DTD, e sim espera que o modelo siga uma gramática já previamente definida. Para mudar esta gramática, seria necessário o desenvolvimento de um novo analisador sintático. Esta abordagem torna o motor do simulador muito simples de ser entendido, ao contrário do kernel DaSSF. A manutenção do código também é favorecida. Isso também faz com que o usuário do simulador não se preocupe com a criação dos DTDs e se dedique apenas na criação e na execução de seu modelo. A Figura 5.6 detalha como é a gramática aceita pelo simulador.

Apesar de simples, a gramática é bem expressiva e abrangente para modelos que trocam mensagens entre si, assim como a API SSF. A partir da linguagem DML aqui definida, espera-se que possam ser definidos inúmeros tipos de domínios de aplicação, assim como o domínio aqui definido, que especifica modelos de sistemas baseados em redes de filas.

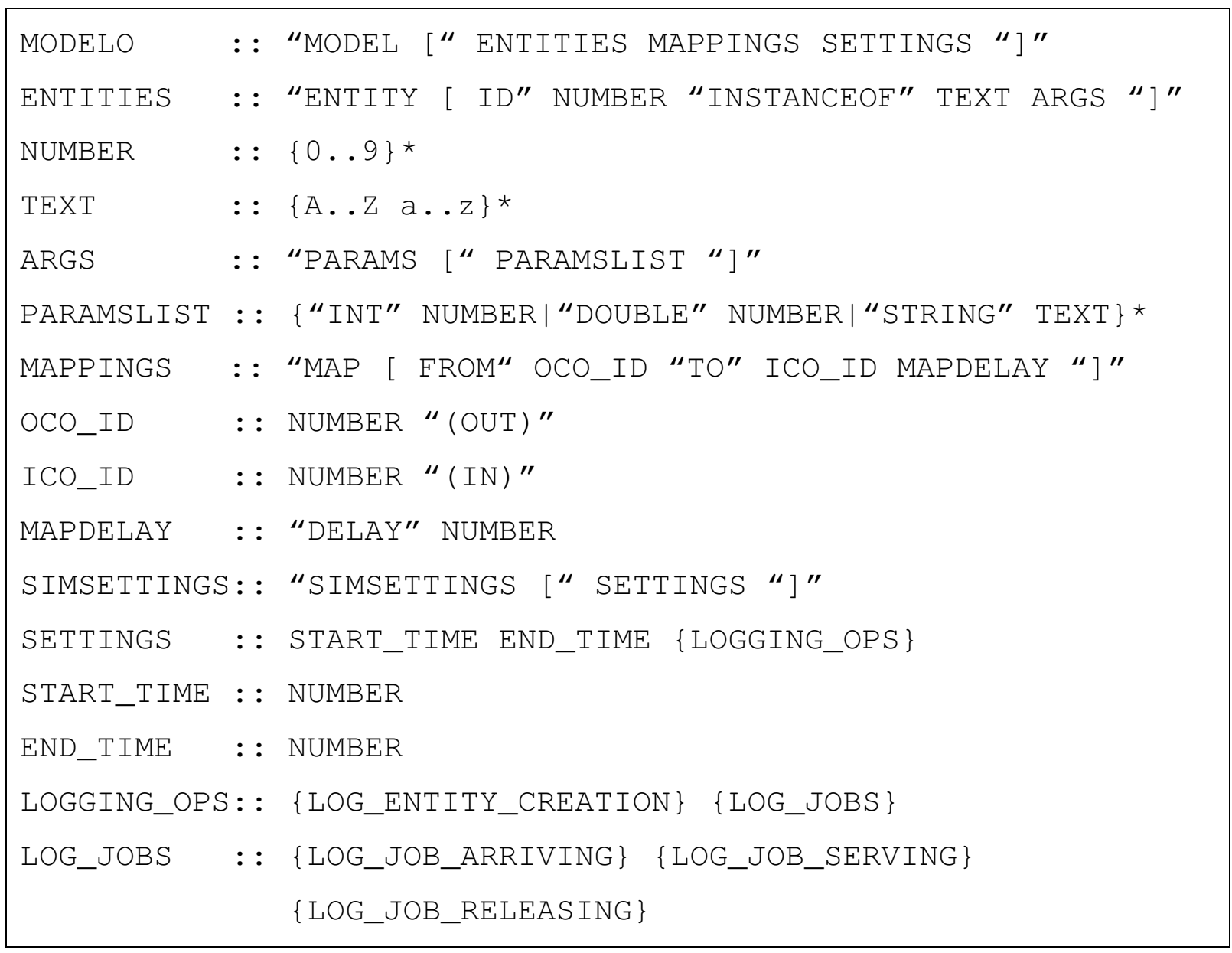

Figura 5.6. Especificação da gramática aceita pelo compilador.

Na DML, um modelo é um conjunto de objetos que armazenam informações sobre entidades, mapeamentos e configurações. Cada entidade possui um identificador e é uma 
instância de uma classe de domínio. Durante a declaração de uma entidade, deve ser especificada uma lista com os parâmetros a serem passados na definição desta entidade no programa de simulação. O usuário deve consultar a documentação de cada classe de domínio para especificar a lista de parâmetros da maneira correta. Após a declaração de entidades, o usuário deve especificar os mapeamentos entre elas. $\mathrm{O}$ mapeamento entre entidades é feito entre canais de saída e canais de entrada. Para cada mapeamento deve ser especificado um tempo de atraso, que denota o tempo consumido para o mapeamento de um canal de saída de uma entidade para um canal de entrada. O último bloco de informação presente no arquivo DML em que é especificado o modelo, é a lista de parâmetros da simulação. As informações contidas são os tempos de início e fim da simulação e os dados a serem armazenados em relatórios, durante a execução do programa. Os dados que podem ser armazenados são as criações das entidades, as mensagens que chegam a um canal de entrada, as que são processadas e as que são enviadas por um canal de saída. O apêndice pode ser consultado a fim de observar tais operações, as quais se encontram devidamente comentadas.

\subsubsection{Classes de domínio específico}

O SSFSimulator é um simulador flexível. Além de ser considerado em um ambiente automático de simulação, ele oferece algumas funcionalidades extremamente úteis para o profissional que trabalha com simulação: o fato dele ser extensível. Ser extensível significa que ele pode ser usado para simular uma ampla gama de classes de domínio, como sistemas baseados em filas como mainframes e sistemas em batch, sistemas multiplexers, protocolos de roteamento de uma rede (BGP, OSPF) entre outros. Neste trabalho de mestrado foi definido um pacote de classes para a simulação de sistemas baseados em redes de filas. Para simular outros tipos de entidades o usuário deve definir suas próprias classes. Para a modelagem de uma classe específica de entidades, o usuário do simulador deve desenvolver duas classes e dois templates de arquivos. As classes de domínio são acessíveis pelo analisador sintático do SSFSimulator, e por isto devem ser detalhadas antes desse módulo. Todas elas devem ser colocadas no pacote "domains" do simulador. Para exemplificar como devem ser definidas as classes e os templates, o pacote para a simulação de redes de filas é detalhado a seguir.

Como foi discutido, duas classes devem ser definidas e existe uma regra para a sua nomenclatura: A primeira classe deve ser chamada com o nome da classe de domínio e a segunda deve ter o mesmo nome seguido da palavra "Node". Desta forma, temos os seguintes arquivos onde estão as classes para o domínio de redes de filas: 
- FIFO_Queue.java;

- FIFO_QueueNode.java.

Ambas as classes devem herdar de ModelElementDec, uma classe abstrata para todas as classes de domínio específico. A classe ModelelementDec possui ainda uma função abstrata genC(), que deve ser definida por todas as classes que herdam de ModelElementDec e que é usada para a geração de código em C++ adequado para aquela classe. A primeira classe é chamada de classe de definição de rede e a segunda é chamada de classe de definição de nós. A primeira possui apenas um construtor sem parâmetros e com o corpo vazio e a função de geração de código normalmente é a definição de um vetor de objetos da classe de definição de nós. A Figura 5.7 ilustra o corpo da função genC () da classe FIFO_Queue.

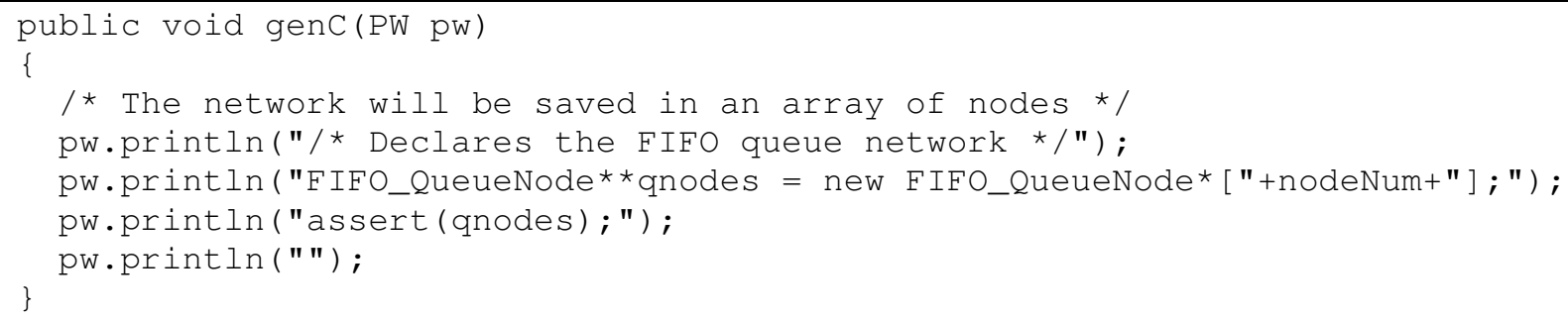

Figura 5.7. Código da função genC() da classe FIFO_Queue.

O objeto da classe PW é um stream onde são impressos os trechos de código C++ e que posteriormente serão impressos em um dos arquivos do programa de simulação. A função "println()" imprime uma linha no stream e salta uma linha. A variável "nodenum" é declarada como protegida na classe ModelElementDec e deve ser usada para especificar o número de nós que podem ser armazenados na rede. $\mathrm{O}$ usuário deve observar que no programa de simulação não são criados objetos da classe de definição de rede. Apenas objetos da classe de definição de nós são criados.

Para a classe de definição de nós o usuário deve se preocupar com os atributos passados ao construtor de classe da entidade. Estes atributos são usados na função genC ( ) para gerar o código de construção de objeto para cada uma das posições do vetor de nós da rede. Uma classe de definição de nós normalmente possui uma variável estática para a contagem de declarações de nós na rede. Esta variável pode ser usada para a identificação da posição do 
vetor em que deve ser declarada o objeto que está chamando genC () naquele instante. $\mathrm{O}$ código da função genC ( ) da classe FIFO_QueueNode é exibido a seguir, na Figura 5.8.

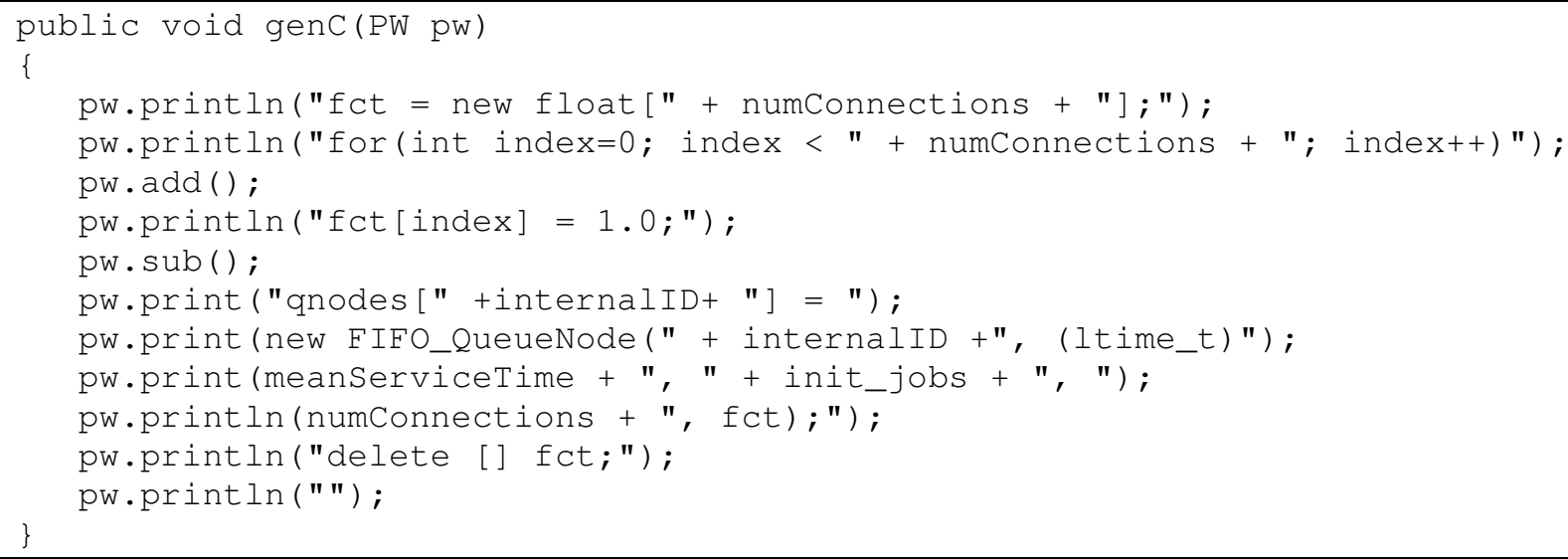

Figura 5.8. Corpo da função genC() da classe FIFO_QueueNode.

Os templates a serem definidos pelo usuário implementam as classes de domínio que serão usadas na construção do programa de simulação. O usuário que define uma classe de domínio deve conhecer a API SSF e suas particularidades. Não é o escopo deste trabalho de mestrado detalhar o funcionamento de toda a API SSF, porém, algumas características e seu uso são discutidos ao longo desta monografia. Além disso, as informações a respeito da API podem ser obtidas em (Cowie, 1999). Os templates são os esqueletos da implementação das entidades das classes de domínio específico. Os dois arquivos necessários para a construção de um template são: um arquivo para o cabeçalho da classe e outro para a definição de suas funções. Também existe uma regra para a nomenclatura dos arquivos, que se segue:

- <classe de definição de nós>.tmplh: arquivos de cabeçalho;

- <classe de definição de nós>.tmpl : arquivos de implementação.

Normalmente os templates possuem, além da implementação das entidades, uma função estática global, acessível pelo programa principal a fim de coletar e exibir dados estatísticos coletados da simulação.

Para uma classe de domínio de rede de filas, os arquivos com extensões "h" e "cpp" disponibilizados nos Apêndices A e B representariam, respectivamente, os arquivos . tmpl e .tmplh

Estes são os únicos passos necessários para a inserção de uma nova classe de domínio específico. O desenvolvedor não precisa se preocupar com qualquer modificação no analisador sintático ou nas outras classes da ASA. Isso acontece devido à presença de um 
objeto da classe DomainClassestoader, a qual procura classes disponíveis no pacote "SSFSimulator.domains" e os instancia quando necessário, de acordo com o modelo definido pelo usuário. Posteriormente, o método genC () adequado é invocado, utilizando técnicas de polimorfismo. Para maiores detalhes, o código do simulador deve ser consultado.

É o analisador sintático que criará uma árvore de sintaxe abstrata, seguindo conceitos e práticas de construção de compiladores. $O$ fato da presença da classe Domainclassestoader, um pacote para o armazenamento de classes de domínio específico, e a arquitetura modular do compilador, permitiram um mecanismo simples e eficiente de extensibilidade ao SSFSimulator. A seguir, o analisador sintático do simulador é explicado em detalhes.

\subsubsection{O analisador sintático}

O analisador sintático é o principal módulo do compilador presente no simulador. Ele é composto por dois componentes principais: um verificador de sintaxe e a árvore de sintaxe abstrata (ASA). O primeiro é definido pela implementação dos métodos da classe Compiler e o segundo é definido por um pacote de classes, cujos objetos representam os nós da árvore. A seguir, o verificador de sintaxe é detalhado. Logo após, uma outra subseção detalha a criação e do funcionamento da árvore de sintaxe abstrata.

A classe Compiler funciona como "porta de entrada" para o coração do simulador. É a partir de seus métodos e handlers (entidades que enviam e recebem mensagens de outras classes), os quais são invocados pelos objetos da classe ModelProcessor, que o processo de compilação tem início. A Figura 5.9 mostra que os objetos da classe Compiler possuem um objeto da classe Lexer, o qual é responsável por efetuar a análise léxica de cada token do modelo. Caso a análise léxica seja efetuada com sucesso, a sintaxe utilizada pelo modelo é avaliada. Outros objetos são criados, como o da classe CompilerError, o qual detecta qualquer tipo de erro léxico ou sintático feito pelo usuário durante o desenvolvimento do modelo. Um objeto Compiler guarda ainda duas tabelas hash, responsáveis por armazenar os identificadores de entidades do modelo e as classes de entidade que podem ser usadas pelo desenvolvedor durante a criação de seu modelo. 


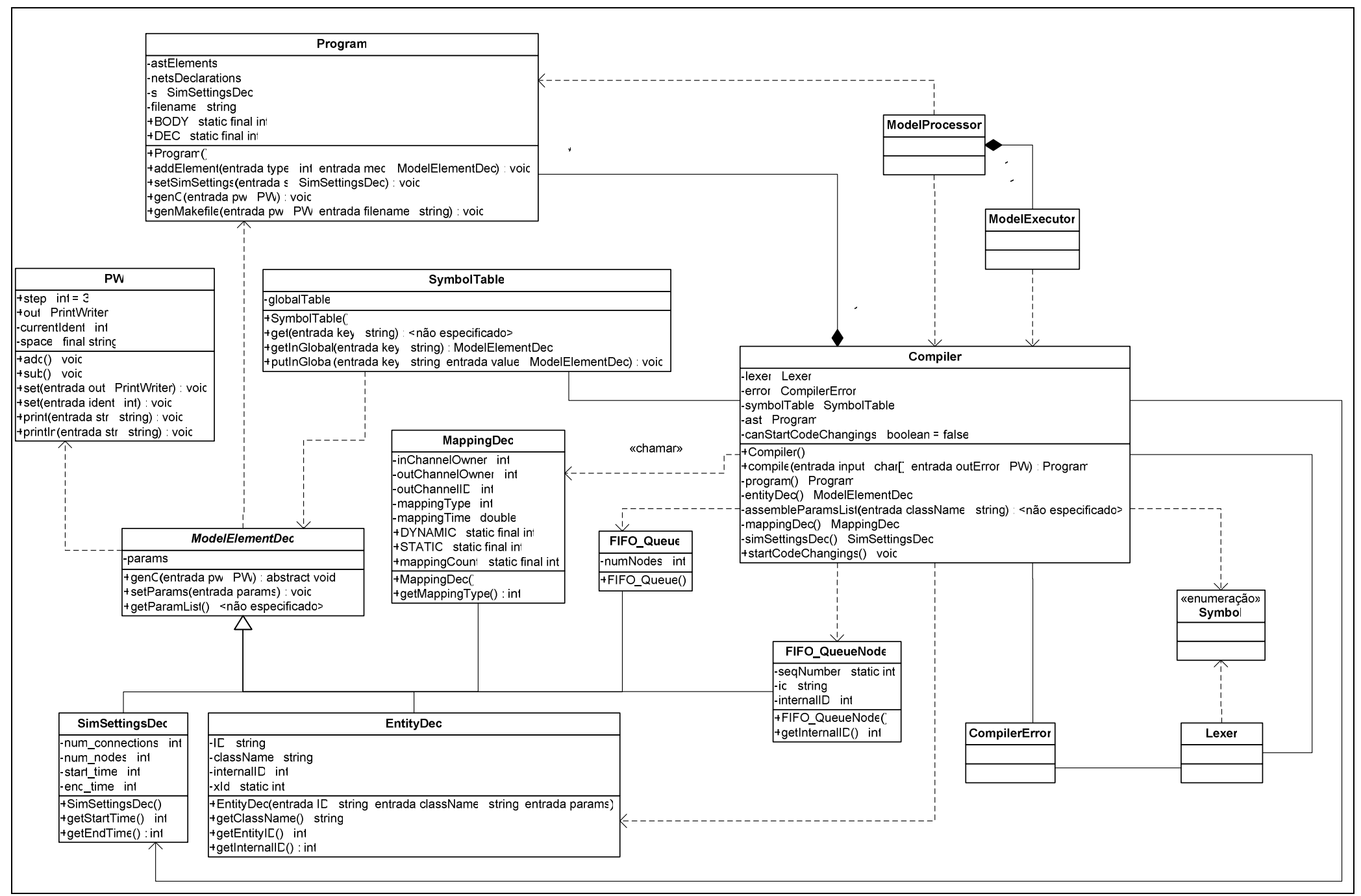

Figura 5.9. Diagrama de classes do analisador sintático do SSFSimulator. 
Os métodos da classe Compiler analisam minuciosamente o modelo e caso este não siga a sintaxe definida pela gramática da DML, mensagens de erro são enviadas para as classes de camadas mais altas do simulador a fim de que o usuário seja alertado sobre onde erros foram encontrados. O processo de análise sintática do modelo inicia-se com a criação de um objeto da classe Compiler e a chamada ao método compile() cujo objetivo é construir em memória a ASA do modelo.

A raiz da árvore é sempre um objeto da classe Program e ela pode ser recuperada através da chamada ao método getAbstractSyntaxTree(), da classe Compiler. Entretanto, não existe como o usuário percorrer manualmente a ASA. Caso a raiz exista após a chamada ao método compile(), significa que o processo de criação da árvore foi realizado com sucesso. Caso contrário significa que um ou mais nós tiveram problemas durante sua criação e que o processo de compilação teve de ser cancelado.

Ao final da criação da ASA nenhum código do programa de simulação ainda foi gerado. Esta ação é de inteira responsabilidade da ASA, cujo funcionamento é detalhado a seguir.

\subsubsection{A árvore de sintaxe abstrata (ASA)}

Os objetos das classes do pacote "ast" são usados para criar nós da ASA. Estes objetos foram implementados de forma hierárquica. A Figura 5.10 mostra como funciona a hierarquia de classes, que permitiu que o código do programa de simulação fosse gerado de forma clara, simples e eficiente.

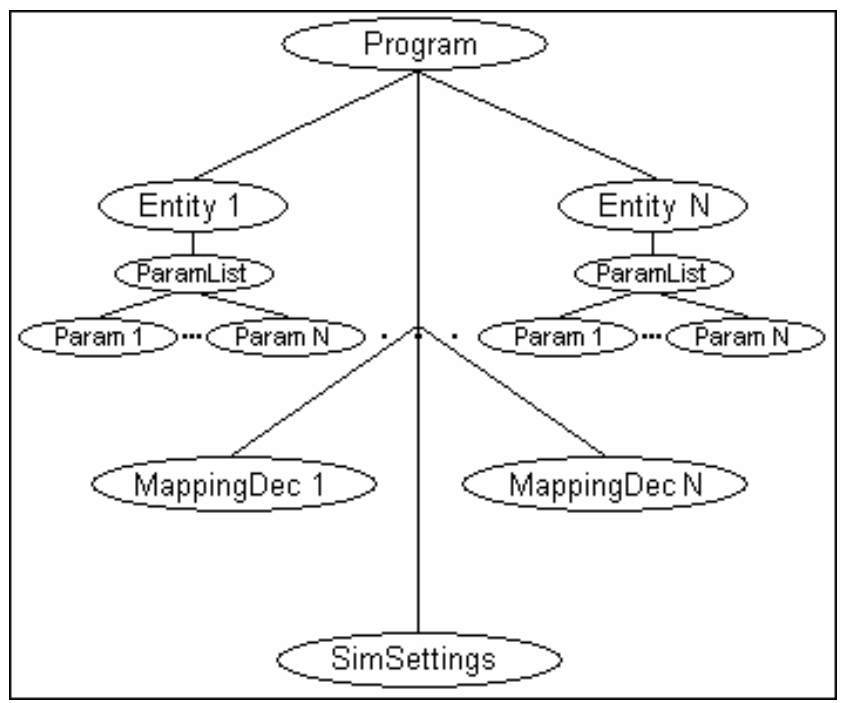

Figura 5.10. Visão conceitual da árvore de sintaxe abstrata. 
O objeto da classe Program chama seu método genC(). Este objeto possui uma árvore de nós de vários tipos, todos herdados de ModelElementDec. Chamando o método genC ( ) para cada um destes nós, na ordem em que foram inseridos na árvore, faz com que os métodos adequados para cada nó seja chamado. Isso faz com que o código vá sendo gerado corretamente, de forma linear.

\subsubsection{A geração de código}

Foi a partir da possibilidade de fornecimento de uma função main() que se pôde adequar o uso do simulador DaSSF no Ambiente de Simulação Distribuída Automático. Até então, o usuário do kernel DaSSF ficava limitado a definir modelos em scripts DML e a executá-los diretamente no simulador. O código intermediário instrumentado que o DaSSF gera se mostra em muitos trechos ilegível, uma vez que muitas informações de baixo nível são geradas no programa de simulação. A partir da versão 3.1, o usuário pode definir o programa de simulação manualmente, de maneira programática, o que é uma atividade muito dispendiosa em termos de tempo consumido na definição do programa. Ao inserir um kernel como o DaSSF em um ambiente de simulação automático como o ASDA, adiciona-se maior flexibilidade para o usuário que necessita simular modelos de larga escala em um simulador de alta performance. Isso acontece porque se pode a partir de um modelo DML gerar um programa de simulação que utilize a API SSF. O código gerado seria o mesmo que o usuário teria de definir manualmente ou aquele código intermediário que o DaSSF gera, porém, antes da instrumentação ser inserida. O ambiente de simulação automático proveria flexibilidade suficiente tanto para usuários avançados quanto para usuários iniciantes, uma vez que permite a modificação do programa de simulação gerado, antes da simulação ter início.

A função main( ) será chamada por cada máquina do sistema de memória distribuída. Entretanto, em cada um dos nós de memória distribuída, apenas uma instância da função main() é chamada (pelo processador 0), mesmo que haja mais de um processador dividindo o mesmo espaço de memória. O esqueleto da função main ( ) é exibido na Figura 5.11 .

A implementação de threads é uma das partes mais complicadas para qualquer simulador orientado a processos. Por esta razão, alguns simuladores evitam este problema empregando um pacote pré-existente de bibliotecas para threads. Esta abordagem, entretanto, não é a solução ideal para simuladores de alto desempenho por duas razões: 


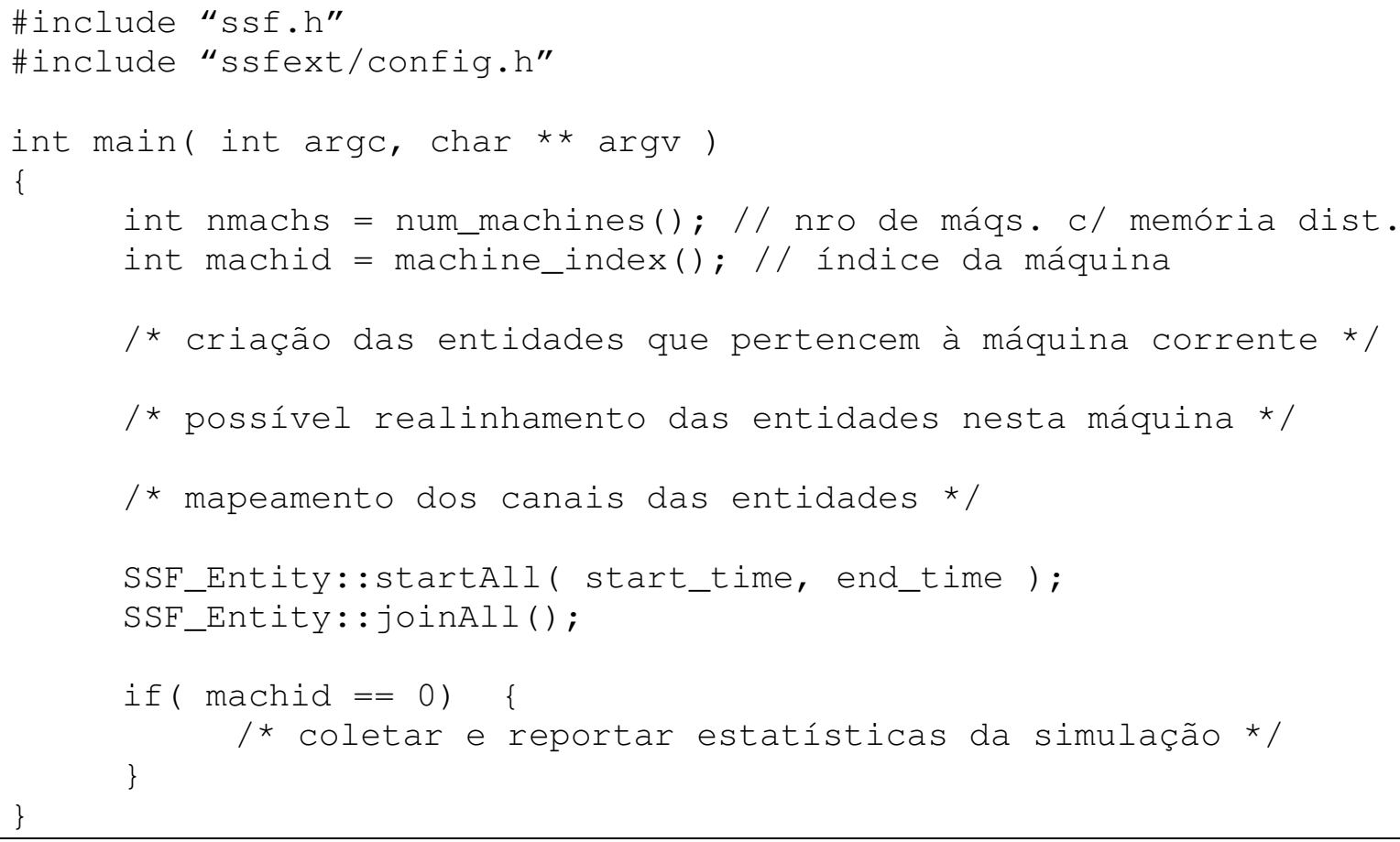

Figura 5.11. Esqueleto da função main(), do programa de simulação.

1. Em pacotes de threads genéricos, uma entidade normalmente pré-aloca uma quantidade fixa de memória para cada pilha das threads. O tamanho da pilha deve ser levado em conta no pior caso, resultando em utilização ineficiente de memória caso existam muitas threads. No DaSSF existem tantas threads quanto forem os processos que pertencem às entidades. Se um modelo é grande (um modelo pode consistir em milhões de entidades), o número de threads será alto, na mesma escala e a quantidade de memória se torna um número absurdamente grande.

2. O tempo de chaveamento de contexto de threads de pacotes genéricos é normalmente alto. O escalonador temporal do simulador deve residir no topo da thread do escalonador provido pelo pacote. Toda esta sobrecarga residiria em um caminho de execução freqüentemente visitado. Pode-se sugerir uma outra abordagem em que cada thread utiliza uma pilha de execução normal, mas o chaveador de contexto copia a pilha para a memória heap. Esta abordagem obtém controle de forma mais rápida sobre o escalonamento de threads, mas sofre com o custo de cópia potencialmente alto se a pilha for grande. Ainda, portar um algoritmo como este iria requerer conhecimento íntimo da arquitetura da máquina e do ambiente de execução onde do simulador. 
O DaSSF implementa o comportamento das threads instrumentando o código do programa de simulação. Particularmente, o DaSSF realiza tradução de código de forma a embarcar os mecanismos de threads no código $\mathrm{C}++$ regular. Esta abordagem foi também utilizada por outros simuladores. Por exemplo, o TeD/GTW insere o código do programa no framework de orientado a processos TeD (Perumala et al, 1998). O Nops utiliza um tradutor de código-fonte em linguagem $\mathrm{C}$, construído a partir da modificação do Cilk (Blumofe et al., 1995), para dar suporte à sua abordagem orientada a processos. Uma abordagem similar pode também ser encontrada no simulador Parsec (Bagrodia et al., 1998).

Uma vantagem dessa abordagem é que o consumo de espaço de memória é adaptado para apenas o que é explicitamente usado. O chaveamento de contexto também pode ser planejado cuidadosamente a partir do conhecimento dos requisitos da simulação. As threads são criadas e gerenciadas na heap ao invés de na pilha de execução do programa. A desvantagem é que, para fazer isso, deve-se escrever um tradutor de código. Uma vez que o $\mathrm{C}++$ é complexo e normalmente intimamente ligado ao sistema operacional e à arquitetura da máquina, pode-se levar muito tempo para desenvolver um parser $\mathrm{C}++$ totalmente funcional que suporte todas as plataformas. No DaSSF um tradutor desta magnitude não está presente, mas sim um tradutor simples, escrito em Perl, o qual não verifica sintaxe alguma do programa. Para realizar a tradução, o DaSSF espera que o programa de simulação escrito pelo usuário contenha as informações necessárias de onde realizar alguma instrumentação.

A transformação do código fonte somente é necessária para aqueles métodos que poderão estar na pilha quando uma thread suspender. Estes métodos são chamados de procedures (procedimentos). Uma procedure é transformada no seu ponto de entrada, nas referências às suas variáveis de estado local, nas chamadas às sub-rotinas e nos locais de retorno de procedimento. Uma estrutura de dados chamada $p$-frame é usada para representar uma procedure, que contêm informações de como o procedimento é chamado, variáveis de estado e um ponteiro para o valor de retorno. Quando uma thread suspende, uma pilha de $p$ frames representa o estado da thread no momento da suspensão, e o escalonador a usará posteriormente para dar continuidade à execução da thread.

No DaSSF, existem três locais nos quais o usuário necessita informar sobre onde inserir o mecanismo de threads. Essa informação é dada na forma de comentários especiais, representados por “//! SSE":

1. O usuário deve utilizar "//! SSF PROCEDURE" para identificar um procedimento tanto onde é declarado quanto onde é definido. O tradutor distinguirá este método de 
outros métodos regulares e irá instrumentar o código da procedure;

2. O usuário deve declarar variáveis locais em um procedimento com “//!SSF STATE”. O tradutor criará um campo correspondente no p-frame associado ao procedimento e transformará as referências às variáveis locais para referências àquelas no $p$-frame.

3. Sempre que outra procedure é chamada de uma procedure, o usuário precisa identificá-la com "//! SSF CALL”. O tradutor inserirá mecanismos de threading envolvendo a chamada da procedure, criando um p-frame correspondente e manipulando a suspensão da thread.

Em um ambiente de simulação automático, a inserção deste tipo de informação no código do programa de simulação não é viável. O usuário deste tipo de ambiente pode ser tanto experiente quanto um leigo em simulação. Ser experiente em simulação não garante também conhecer tão profundamente a API SSF e kernel DaSSF. É por isso que toda a instrumentação do código já está inserida nos templates de classes de domínio.

A instrumentação do código arquivos-fonte modelo, ou templates (ver seção 5.4.3). Os templates ficam localizados em um diretório especial da pasta do SSFSimulator, na seguinte configuração, mostrada na Figura 5.12. O usuário que definir um template para um novo domínio de aplicação deve utilizar as diretivas de instrumentação do SSF adequadamente. Tal operação é recomendada apenas para usuários que possuem conhecimentos mais avançados do framework.

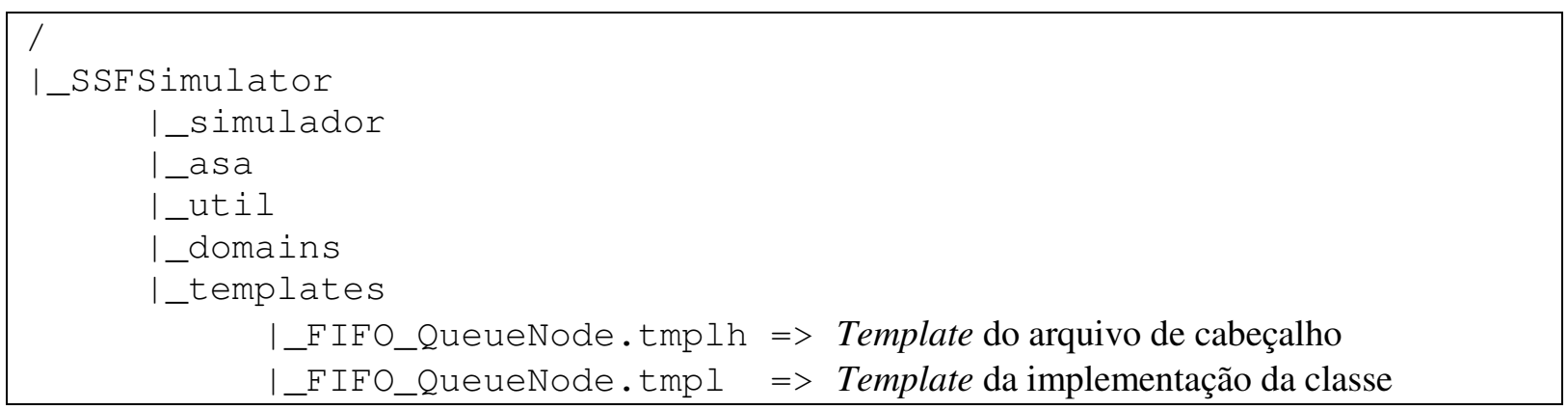

Figura 5.12. Estrutura de diretórios (pacotes) do SSFSimulator. 


\subsection{O módulo executor: ModelExecutor}

A fim de que o programa de simulação seja executado de forma mais eficiente, é recomendado que ele seja transferido para uma outra máquina que contenha o kernel de simulação DaSSF totalmente compilado, permitindo que os programas gerados façam chamadas à API SSF e que seja dedicada apenas a esta atividade. O SSFSimulator tem total suporte à execução do programa de simulação em máquinas diferentes das de onde o modelo é construído e compilado. É a partir do princípio da descentralização que é introduzido neste momento o módulo executor do simulador SSF. O módulo executor foi dividido em duas partes: um cliente, o qual é integrado à interface do simulador, e um servidor o qual é executado se forma separada do cliente, em um outro processo, e que pode ou não ser executado na mesma máquina do cliente. Nas seções seguintes, cada uma das partes do módulo executor é detalhada.

\subsubsection{Lado cliente}

No lado cliente, o módulo executor é constituído de duas classes: ModelExecutor e CommandHandler.

A classe ModelExecutor implementa o protocolo de comunicação com o lado servidor do módulo. Cada passo do protocolo é sinalizado ao usuário uma vez que a parte cliente do ModelExecutor é totalmente integrada com o módulo interface do sistema. De uma forma bem definida e que deve ser seguida de maneira seqüencial e completa, o módulo realiza as seguintes tarefas:

1. Inicia uma conversação com o servidor a partir de uma operação de "aperto de mãos" ou handshake, no qual o cliente envia seu pedido de conexão ao servidor e este o responde caso a conexão possa ser realizada;

2. Acessa as pastas geradas pelo ModelProcessor, coleta e envia informações sobre a quantidade e nomes dos arquivos do programa de simulação ao servidor;

3. Envia cada um dos arquivos do programa de simulação e aguarda por uma confirmação de recebimento;

4. Aguarda o término da simulação e recebe os dados estatísticos da execução do modelo;

5. Solicita ao servidor o fechamento da conexão e envia ao usuário um sinal de que a simulação chegou ao fim e os dados estatísticos já estão disponíveis. 
A classe ModelExecutor não implementa funções de baixo nível, como por exemplo, a montagem de pacotes a serem enviados ao servidor e o acesso aos canais de comunicação com o servidor. Tais funções são implementadas na classe CommandHandler. Tal classe funciona como uma máquina de estados. Como pode ser observado no diagrama de classes mostrado na Figura 5.13, o CommandHandler possui basicamente apenas duas funções públicas, get() e post(), responsáveis por permitir ao cliente requisitar informações e responder algo ao servidor. O CommandHandler permite as seguintes requisições ao servidor, os quais são passados como argumento à função get ( ) :

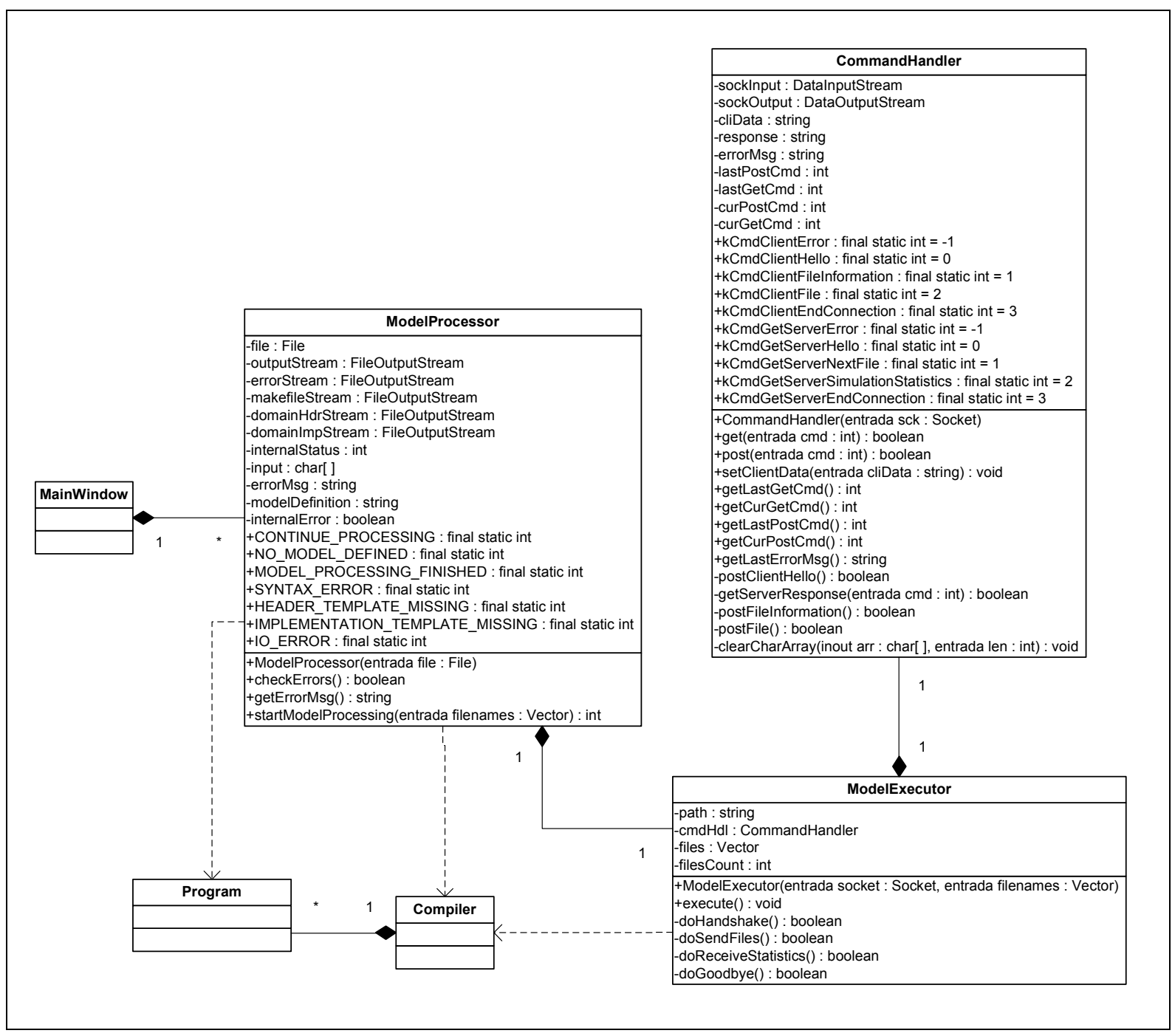

Figura 5.13. Diagrama de classes do lado cliente do módulo executor.

- GetServerError: Pergunta ao servidor se houve algum erro de comunicação ou de recebimento nos arquivos; 
- GetServerHello: Requisita ao servidor a cadeia de caracteres de reconhecimento de conexão com o cliente. Esta requisição é utilizada logo após o envio da cadeia de caracteres de identificação do módulo cliente;

- GetServerNextFile: Pergunta para o servidor se este está pronto para o recebimento de um arquivo;

- GetServerSimulationStatistics: Requisita ao servidor o envio dos dados estatísticos da simulação após o término desta;

- Get ServerEndConnection: Solicita o servidor o término da conexão.

O cliente também recebe requisições do servidor como pôde ser observado na Figura 5.13. Como resposta a estas requisições, o ModelExecutor realiza o envio de informação através do uso da função post ( ), passando como argumento uma das seguintes opções:

- CmaClientError: Envia ao servidor o erro ocorrido durante a comunicação ou no envio de informação;

- CmdClientHello: Envia ao servidor a cadeia de caracteres de identificação do cliente do simulador, durante o handshake;

- CmdClientFileInformation: Envia ao servidor os dados do programa de simulação coletados após a execução do ModelProcessor;

- CmdClientFile: Envia um arquivo do programa de simulação ao servidor;

- CmaClientEndConnection: Envia a cadeia de caracteres de fechamento da conexão do lado cliente para o servidor.

O ModelExecutor foi desenvolvido desta maneira visando ter um funcionamento distribuído, robusto e tolerante a falhas. Mesmo ocorrendo falhas no envio ou recebimento de informação, os passos podem ser realizados novamente, evitando a perda de tempo por parte do usuário. O protocolo de comunicação foi projetado para ser simples e eficiente e mostrou um ótimo desempenho durante os testes realizados. O tempo de envio do programa de simulação não é considerado como sendo tempo consumido pela execução do programa de simulação. Na realidade, a simulação só é iniciada após o recebimento e a compilação do programa já no lado servidor do simulador e não cabe à parte cliente do módulo executor realizar a coleta de tempos e dados estatísticos diretamente durante a execução do programa de simulação, e cabe sim ao lado servidor do módulo, o qual será detalhado na seção seguinte. 


\subsubsection{Lado Servidor}

O lado servidor foi escrito em C++. Esta linguagem foi escolhida por ser a mesma do kernel DaSSF e qualquer integração que venha a ser necessária no futuro, será facilitada por esta escolha. Por se tratar de um módulo complexo, optou-se por desenvolvê-lo como um outro processo, totalmente independente da execução do cliente. $\mathrm{O}$ novo processo foi chamado de "SSFSimulatorServer".

O SSFSimulatorServer foi implementado de forma modular, orientado a objetos, assim como o cliente SSFSimulator. Uma classe Socket implementa funções de comunicação de baixo nível utilizando como base funções da API de sockets do Linux. A classe ServerSocket herda de Socket para implementar uma camada de maior abstração para sockets que são usados apenas para servidores, isto é, aqueles que aguardam uma conexão ao ficar "escutando" uma porta. O SSFSimulatorServer aceita por padrão no máximo cinco conexões com clientes. Porém, este número pode ser modificado pelo usuário, mas não é recomendável uma vez que pode haver quedas nos desempenhos das simulações se o número destas for muito alto. Assim como no lado cliente, o servidor possui uma classe CommandHandler que não só implementa as funções de baixo nível para a comunicação com o cliente como também interpreta as requisições que chegam por seus canais de comunicação. $O$ CommandHandler é usado pela classe ModelExecutor para a implementação do protocolo de comunicação com o cliente. A classe principal do SSFSimulatorServer contém a função principal, encarregada de inicializar instâncias da classe ServerSocket e processos filhos os quais serão responsáveis pelo recebimento dos arquivos do cliente e pela invocação do kernel de simulação DaSSF. O processo pai apenas volta a gerenciar as conexões existentes e aguardar por novas após a criação de um processo filho. O diagrama de classes da Figura 5.14 exibe as classes do SSFSimulatorServer.

Podemos observar que o SSFSimulatorServer possui uma arquitetura distribuída e multitarefa. Ele é capaz de iniciar a simulação de não apenas um modelo, e sim de tantos quanto forem necessários, de acordo com um arquivo de configuração fornecido pelo usuário.

Assim como o lado cliente do ModelExecutor, o SSFSimulatorServer possui um CommandHandler capaz de interpretar diversas requisições do cliente e de enviar respostas a estas requisições. A seguir, vemos a lista de requisições aceitas e respostas enviadas ao cliente: 


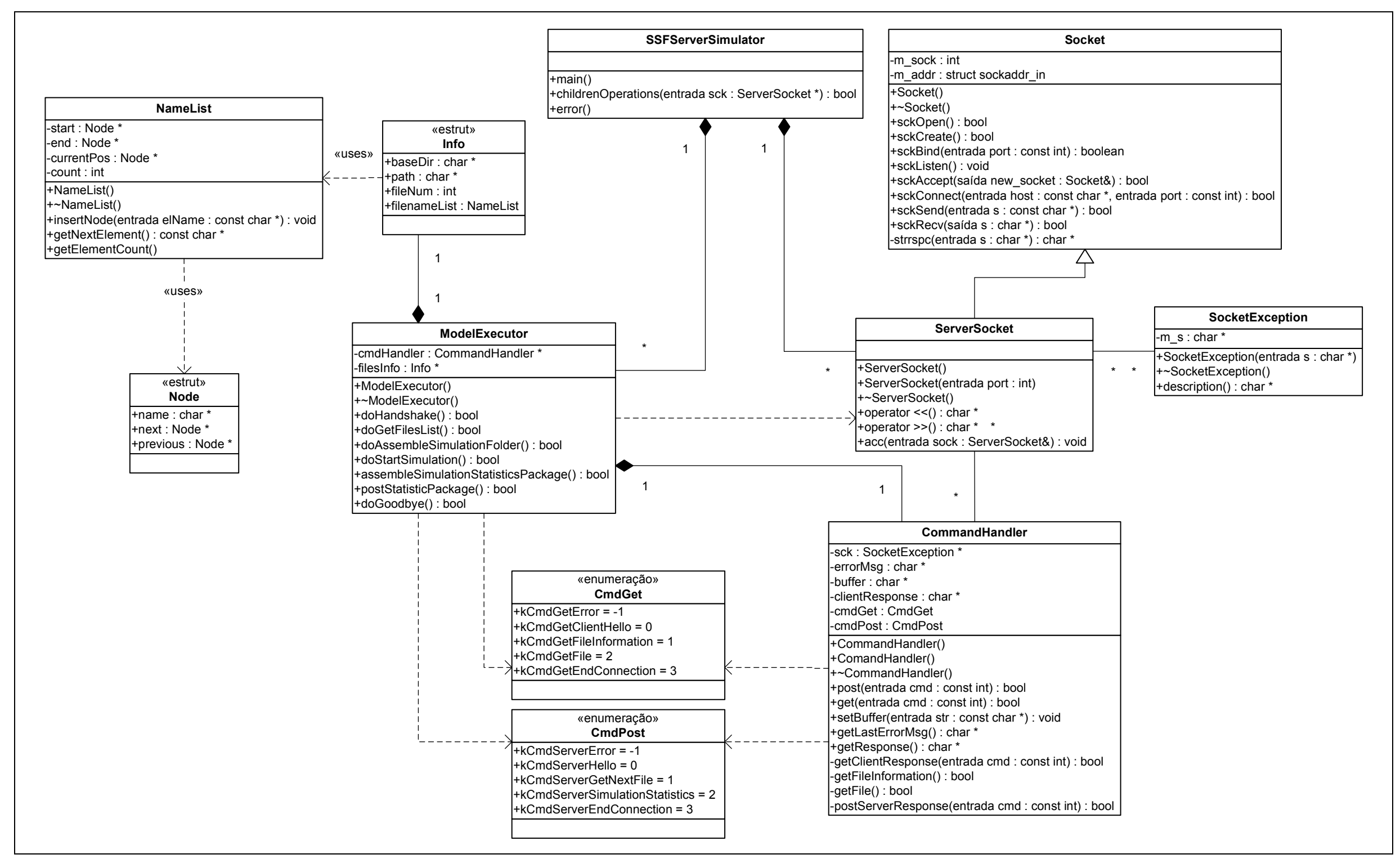

Figura 5.14. Diagrama de classes do SSFSimulatorServer. 
a) Requisições:

- CmdGeterror: Pergunta ao cliente se houve algum erro durante a transmissão de dados;

- CmdGetClienthello: Requisita a cliente a cadeia de caracteres de reconhecimento de conexão. Esta requisição é utilizada logo após o recebimento da cadeia de caracteres de identificação do módulo cliente;

- CmdGetfileInformation: Requisita ao cliente os dados quantitativos dos arquivos do programa de simulação, tais como nome e tamanho de cada arquivo e o número total de arquivos;

- CmdGetFile: Após o recebimento das informações do programa de simulação, requisita um dos arquivos ao cliente. Esta requisição é realizada até o número de arquivos gerados pelo cliente ser esgotado;

- CmdGetEndConnection: Requisita ao cliente o final da conexão por parte do servidor.

b) Respostas:

- CmdServerError: Envia ao cliente o erro ocorrido no lado servidor durante a transmissão de dados;

- CmaServerHello: Envia ao cliente a cadeia de caracteres de identificação do servidor durante o handshake;

- CmaServerGetNextFile: Solicita um arquivo ao cliente;

- CmdServersimulationStatistics: Envia ao cliente as estatísticas da simulação;

- CmdServerEndConnection: Envia a cadeia de caracteres de fechamento da conexão do lado servidor para o cliente.

O SSFSimulatorServer deve ser instalado juntamente com o kernel DaSSF 3.1. Durante o recebimento dos arquivos gerados pelo cliente, o SSFSimulatorServer criar uma pasta para armazenar o programa de simulação e os dados estatísticos da simulação. O nome da pasta é concatenado ao PID do processo filho e ao timestamp do horário em que a comunicação com o cliente foi estabelecida, a fim de diminuir a possibilidade de que programas de simulação com os mesmos nomes de arquivos sejam armazenados nas mesmas pastas. A estrutura de diretórios é mostrada na Figura 5.15. 
O local de instalação do DaSSF é opcional, mas todos os outros diretórios devem ser construídos desta maneira.

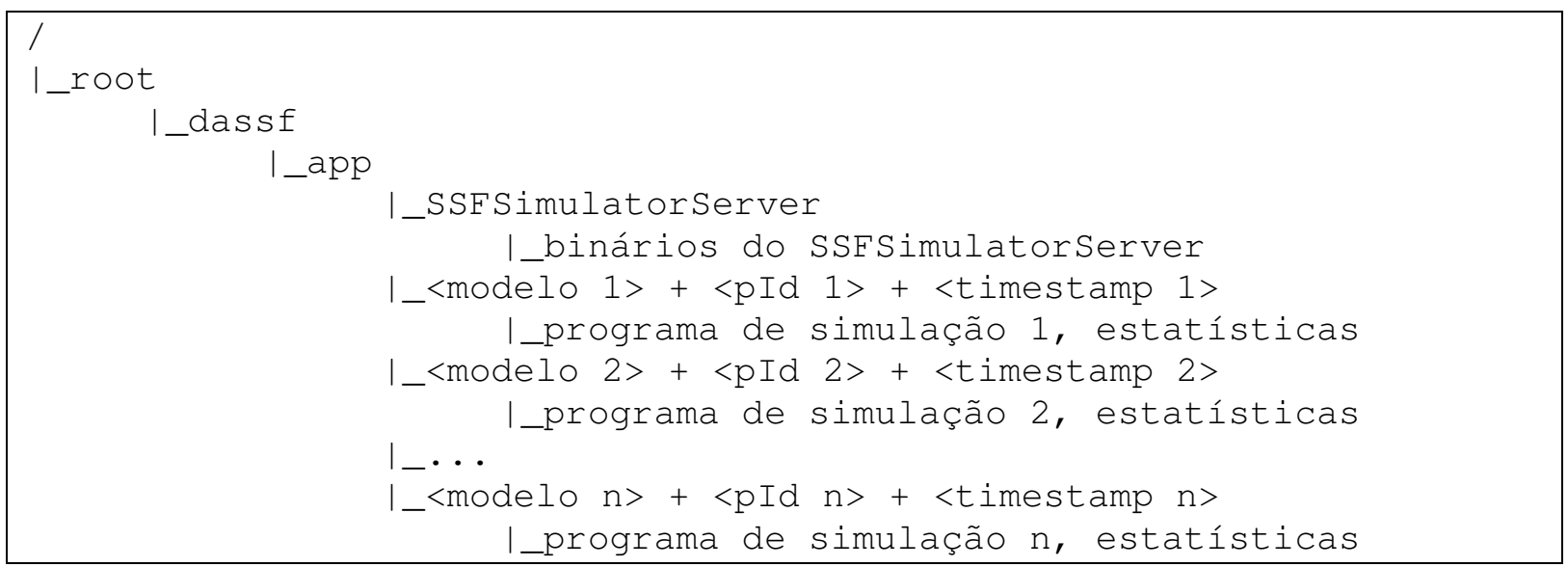

Figura 5.15. Estrutura de diretórios do SSFSimulatorServer dentro da pasta do DaSSF.

\subsection{0 módulo construtor de relatórios: ReportBuilder}

O ReportBuilder é um módulo simples, composto de uma única classe, responsável por fornecer métodos que organizem em ordem cronológica os dados enviados pelo ModelExecutor e os formatem em um relatório de execução, de formato amigável.

O módulo se comunica com a interface com o usuário de modo a permitir que ele possa salvar o relatório em um local que desejar. A Figura 5.16 exibe parte de um relatório de execução, com os timestamps já organizados e outros dados em formato mais amigável.

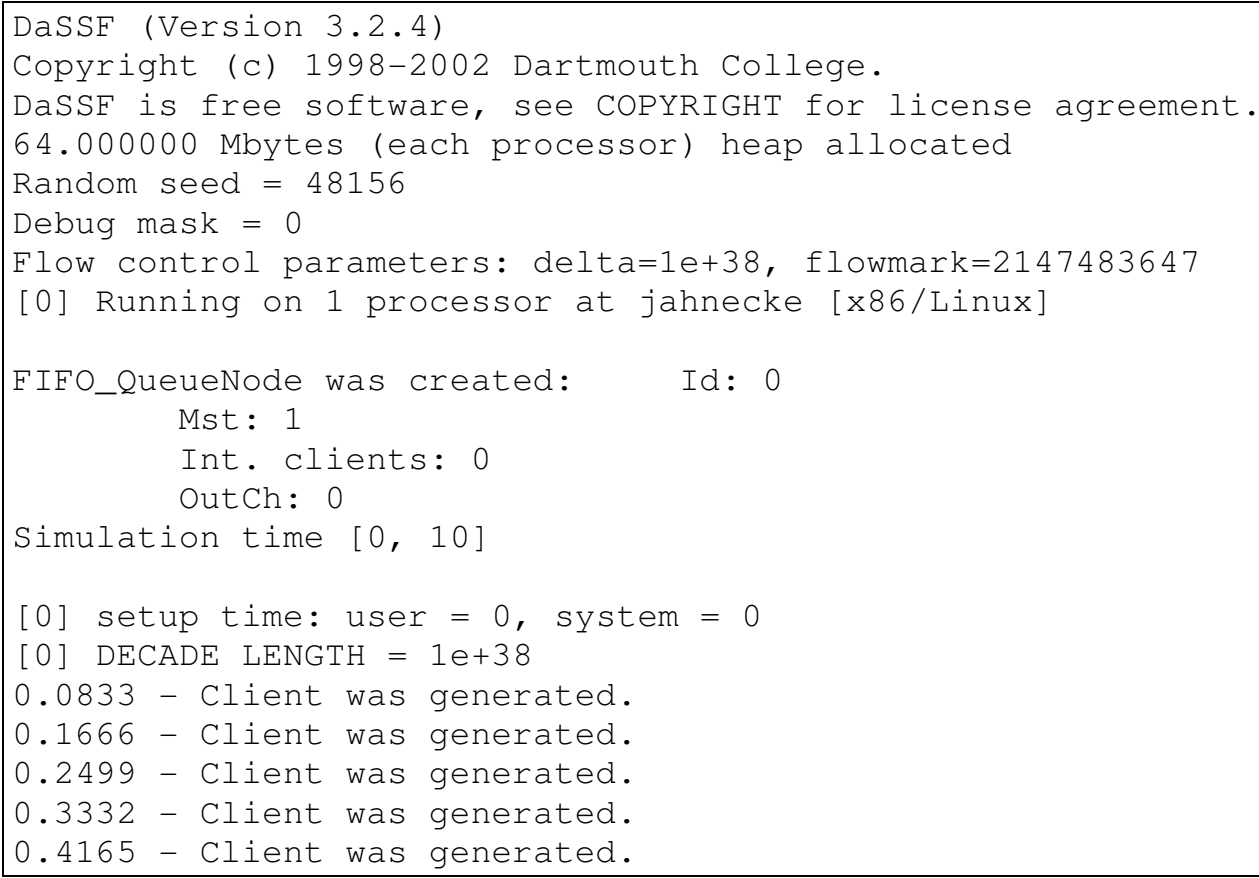




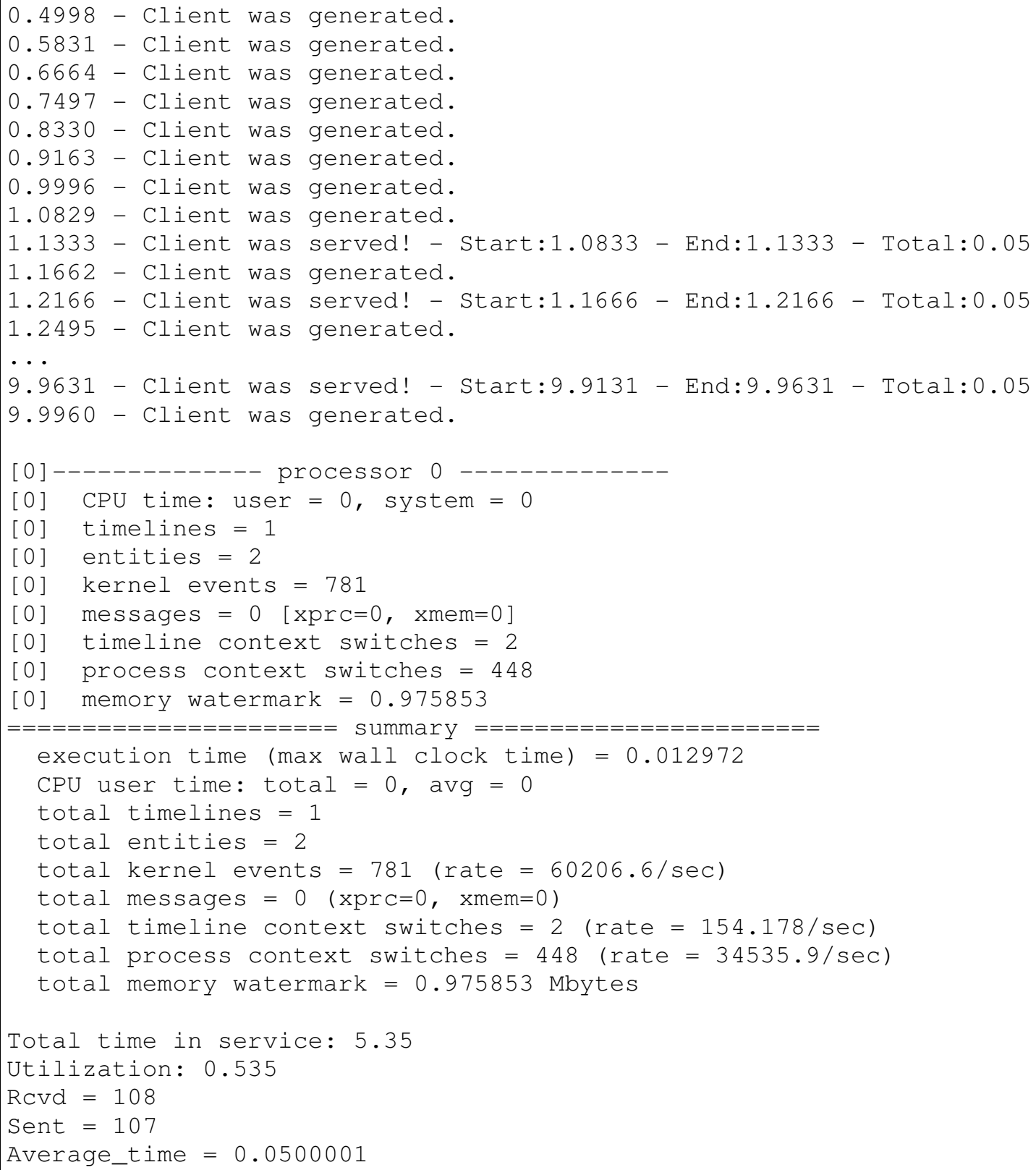

Figura 5.16. Relatório de execução formatado pelo ReportBuilder.

\subsection{Considerações finais}

O SSFSimulator possui, de modo geral, uma arquitetura complexa. O aplicativo é considerado como um sistema cliente-servidor, multithreaded e multitarefa. O SSFSimulator pode ser executado em qualquer tipo de arquitetura que possua a máquina virtual Java. Porém, o módulo executor requer uma máquina Unix ou Linux, onde esteja compilado a versão 3.1 do DaSSF. Apesar de complexa, a arquitetura faz com que o sistema seja robusto, de fácil entendimento e manutenção. 
O próximo capítulo é destinado à execução de um teste completo do SSFSimulator. Será mostrado o desenvolvimento de uma simulação, desde a definição de um modelo até a exibição dos resultados. 


\section{Testes com o SSFSimulator}

\subsection{Considerações iniciais}

O capítulo 4 apresentou um teste realizado com uma classe de domínio específico de redes de filas. O teste foi realizado a fim de que os mecanismos internos dos objetos instanciados fossem validados e de que a classe pudesse ser utilizada nos programas de simulação gerados pelo SSFSimulator.

Este capítulo tem o objetivo de relatar, através de dois exemplos, o desenvolvimento de simulação utilizando o SSFSimulator. O primeiro exemplo parte da modelagem de sistemas baseados em filas até a exibição dos resultados emitidos pelo programa de simulação em um relatório de execução. O segundo exemplo ilustra um modelo de maior porte e a facilidade de modelagem utilizando a DML.

\subsection{Modelo 1}

Um dos sistemas descritos neste capítulo é uma rede de filas fechada, que contém seis servidores interligados entre si da maneira mostrada na Figura 6.1. Os clientes que circulam pela rede são representados como mensagens trocadas entre os centros de serviço. A Figura 6.2, mostrada posteriormente, representa o modelo em DML deste modelo de rede de filas. Podemos observar claramente no código os dois blocos principais e mandatórios para a modelagem de um sistema que serve como entrada para o SSFSimulator: o bloco MODEL (início linha 1) e o bloco S IMSETTINGS (início linha 21).

O código em DML mostrado na Figura 6.2 mostra, inicialmente, que está declarado cada servidor, os quais são modelados como entidades da classe FIFO_QueueNode. É importante relembrar que o modelo pode ser comentado ao estilo da linguagem $\mathrm{C}$, usando “/ " para iniciar um bloco de comentários e “*/” para fechá-lo. A lista de mapeamentos declara como os canais de saída das entidades são mapeados para os canais de entrada. Neste ponto, o usuário pode declarar também tantos canais de saída quanto desejar. É importante notar na 
declaração dos servidores que apenas um se diferencia dos outros, por possuir dois canais de saída (linha 3). Tal particularidade é declarada no bloco de parâmetros, na declaração da entidade. Os parâmetros, discutidos na seção 4.3, devem ser declarados seguindo a seguinte ordem:

1. Tempo médio de serviço (máximo);

2. Número inicial de clientes;

3. Número de canais de saida;

4. Vetor de pesos para canais de saída (Opcional, caso não exista, a probabilidade será a mesma para todos os canais de saída).

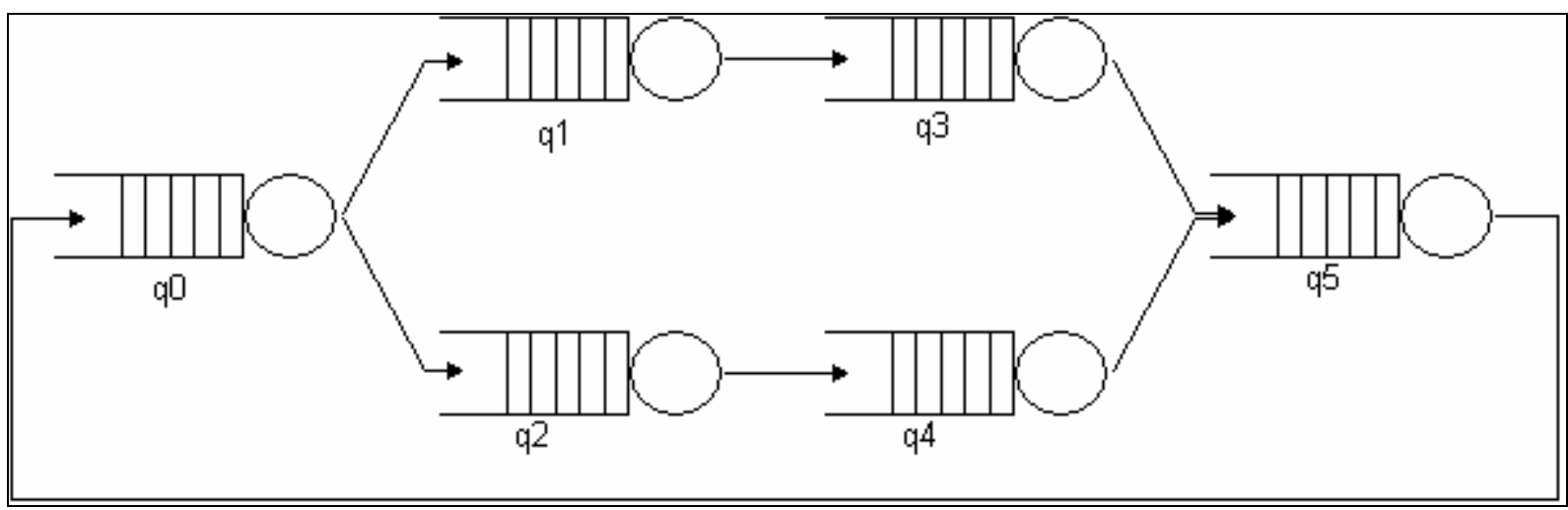

Figura 6.1. Modelo visual de redes de filas que o modelo em DML representa.

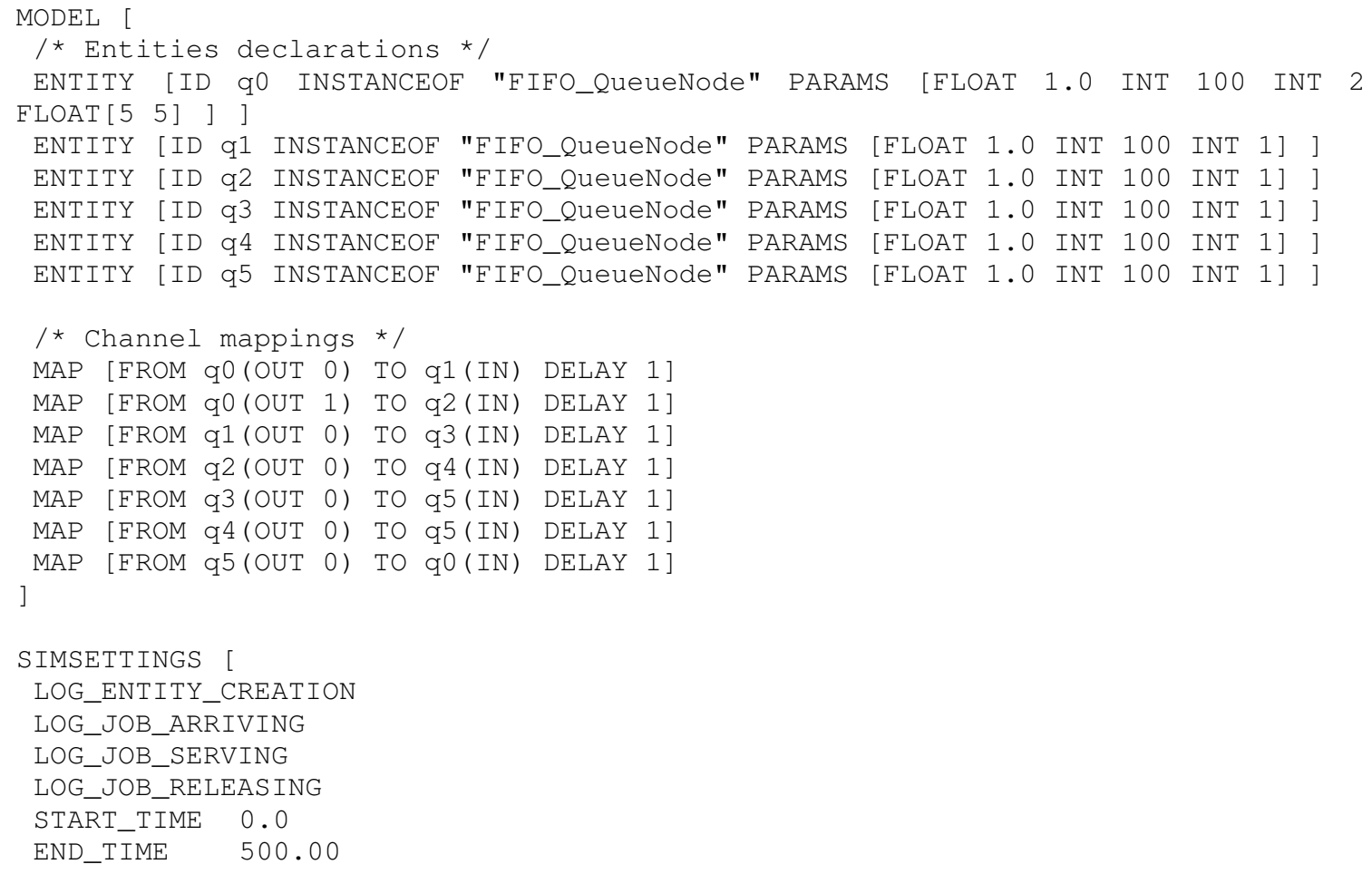

Figura 6.2. Modelo em DML usado como exemplo. 
Após a declaração do modelo, segue a declaração das configurações da simulação. Aqui estão declarados o tempo de início e o tempo final de simulação. Caso o campo START_TIME não exista, o simulador considerará o tempo de início da simulação como sendo zero. Neste bloco, podemos observar que todas as opções de logging foram utilizadas. O relatório gerado pelo SSFSimulator será, portanto, bastante detalhado. Por fim, podemos observar que o tempo de simulação será de 500 unidades.

A primeira fase da simulação é a compilação do modelo DML em um programa de simulação. Para isso, o modelo foi inserido na área de modelagem da interface com o usuário e o botão "Compile!" foi acionado, gerando, assim, o programa de simulação e o exibindo na tela. A Figura 6.3 mostra a janela de exibição dos arquivos gerados pelo simulador. Pode-se notar a existência de botões que permitem ao usuário salvar os arquivos após modificações, antes de estes terem sido enviados ao módulo executor.

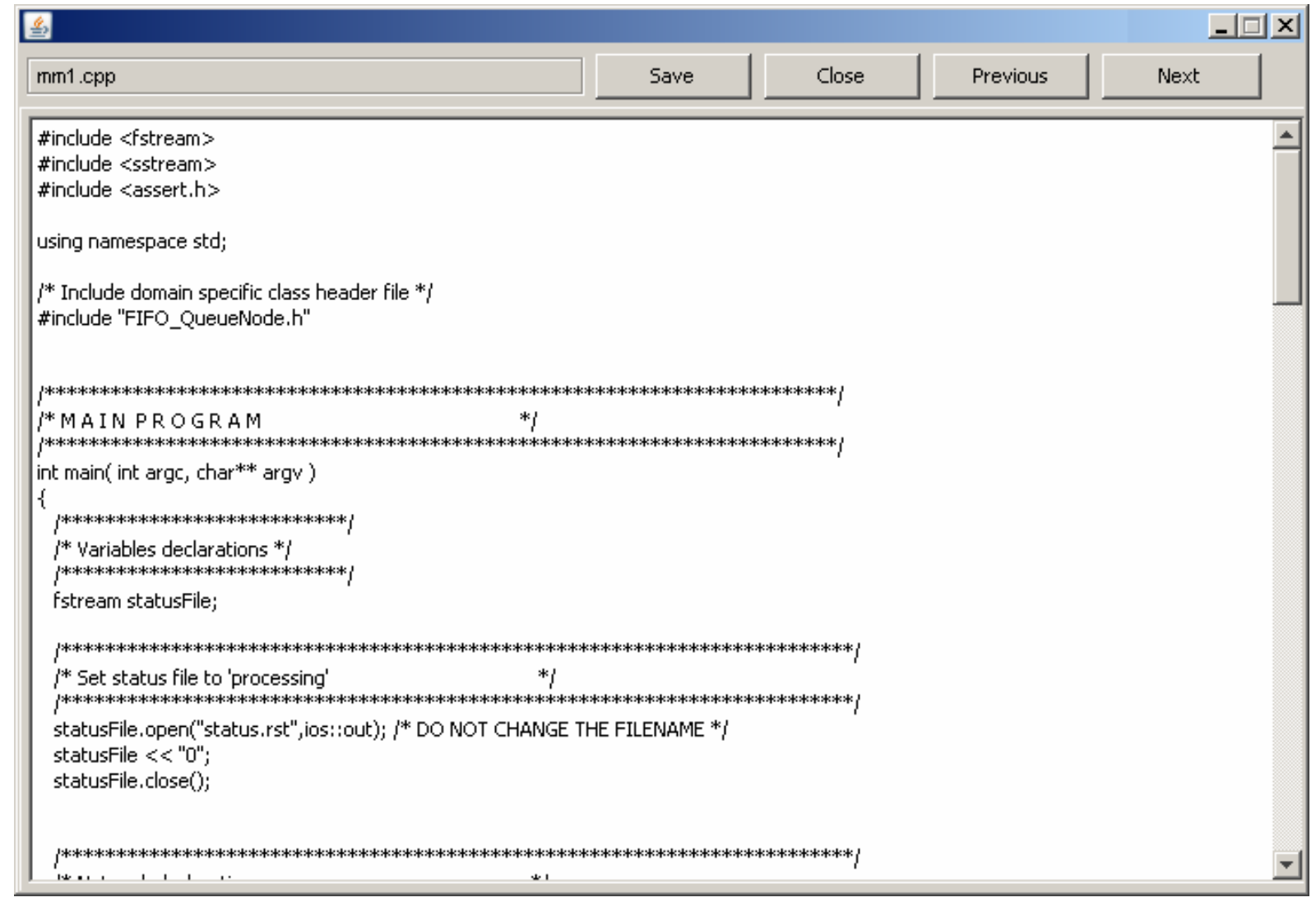

Figura 6.3. Tela de exibição dos arquivos gerados do programa de simulação.

A seção seguinte detalha o programa de simulação e os arquivos gerados. 


\subsubsection{Geração do programa de simulação}

O programa de simulação é a versão em linguagem C++ utilizando a API SSF do modelo definido pelo usuário e ele deve ser executado no ambiente onde está configurado o kernel de simulação DaSSF. Porém, o usuário pode, antes de iniciar a execução do simulador, alterar qualquer arquivo do programa de simulação. Esta é uma das principais funcionalidades do simulador aqui proposto: flexibilizar ao máximo o processo de simulação de um modelo. O programa de simulação gerado é totalmente compatível com a API SSF, utiliza todas as funcionalidades, facilidades e particularidades do kernel DaSSF e ainda fornece flexibilidade ao usuário, para que este modifique da maneira que desejar o programa de simulação. Assim sendo, a tarefa mais complicada e mais desgastante em termos de tempo consumido que é a construção do programa de simulação, já está realizada. O programa de simulação é composto por quatro arquivos, sendo eles:

- Makefile: O arquivo de Makefile contém as instruções necessárias para a compilação do programa de simulação. É importante ressaltar que apesar de permitir também a modificação deste arquivo, não é recomendável que o usuário faça qualquer modificação a menos que saiba exatamente o que está fazendo. Caso haja algum erro neste arquivo, a simulação não será efetuada com sucesso e será necessária a recompilação do modelo. Esta recompilação fará com que todos os arquivos do programa de simulação sejam reconstruídos e qualquer modificação realizadas anteriormente serão perdidas. Por segurança, o usuário tem a opção de guardar seu programa de simulação em uma pasta particular.

- <classe de domínio >.h: Este é o arquivo de definição de uma classe domínio. Nele contêm as definições de todas as classes, atributos e funções necessárias para implementar pacotes de entidades de domínio específico. Normalmente, o arquivo traz a definição de uma classe derivada de SSF_Entity da qual pode-se instanciar objetos que denotam uma entidade física ou teórica para o estudo utilizando a simulação como ferramenta, e um classe derivada de SSF_Event, da qual pode-se instanciar outros objetos que funcionam como mensagens trocadas entre entidades.

- <classe de domínio>.cpp: Contêm a implementação das funções cujos protótipos estão localizados no arquivo de cabeçalho. Não possui somente funções membro e de apenas uma classe. Contém todas as funções necessárias para a simulação e não definidas pela API SSF e pelo kernel DaSSF; 
- <nome do arquivo do modelo no cliente>.cpp: Este é o arquivo onde está presente o programa principal, isto é, este arquivo contém a função main(). Nesta função o vetor de entidades é declarado e cada posição armazena um objeto da classe de domínio especificada. Este trabalho de Mestrado especificou e implementou classes de domínio específico para sistemas baseados em redes de filas. Após a declaração da rede, são especificados os mapeamentos entre canais de entrada e de saída. Após todos os mapeamentos serem declarados com o uso da função da API SSF "mapto ( ) ", a simulação tem início, a partir da chamada da função SSF_Entity : : startAll () . Quando a simulação acaba, a função SSF_Entity: : joinAll() é invocada para sincronizar todos os processos e threads iniciados pelo kernel. Após o fim da simulação, as estatísticas são coletadas e armazenadas em um arquivo.

O tamanho do programa de simulação dependerá do tamanho do modelo especificado pelo usuário. Vale lembrar que todos os programas gerados devem ser necessariamente compiláveis. Entretanto, o simulador não garante a compilação caso um dos arquivos do programa tenha sido alterado antes de seu envio ao servidor.

Tendo sido gerado o programa de simulação, o usuário pode dar início à sua execução. Entretanto, a execução do programa em si, ainda não pode ser efetuada. O programa na linguagem $\mathrm{C}++$ deve ser compilado em linguagem de máquina e o DaSSF deve ser invocado a fim de que a execução possa ter sucesso. Essas ações são tomadas pelo ModelExecutor e são descritas na próxima seção.

\subsubsection{Execução do programa de simulação}

Assim que o usuário dá início ao processo de execução do programa de simulação, o SSFSimulator invoca seu módulo executor, o ModelExecutor. Como já foi discutido na seção 5.5 desta dissertação, o ModelExecutor é divido em uma parte cliente, integrada com a interface com o usuário; e uma parte servidor, que é executada em uma máquina que possui o DaSSF instalado. O lado cliente inicia a comunicação com o lado servidor e ele envia programa de simulação a fim de que este possa ser compilado em linguagem de máquina. Após o recebimento do programa de simulação, o SSFServerSimulator inicia uma thread que compila o programa em linguagem de máquina. Caso a compilação não seja concluída com sucesso, o servidor encerra a simulação do modelo e sinaliza ao cliente uma mensagem de erro de compilação adequada. Caso contrário, a execução do programa de simulação tem 
início. Infelizmente, por enquanto, não é possível a interação do usuário com o programa de simulação durante a sua execução. Porém, está previsto como trabalho futuro, a inserção do SSFSimulator como um simulador "imersivo", no qual o usuário poderá interagir com a simulação.

A execução da simulação não é iniciada com a execução do programa. A simulação só tem início após a chamada à função SSF_Entity: :startAll(). Como já foi mencionado, esta função recebe os tempos de início e fim da simulação como argumento e logo após a sua chamada, deve ser chamada a função SSF_Entity: :joinAll(), que aguardará o término de todos os processos para prosseguir.

Após a simulação, um arquivo, contendo informações da execução e dados estatísticos coletados, é enviado ao cliente. Este por sua vez, passa estes dados como argumento para o módulo gerador de relatórios, ou ReportBuilder. Quando o relatório for concluído, ele é mostrado ao usuário do SSFSimulator.

\subsubsection{Análise de dados}

Após o envio dos dados da execução do programa de simulação por parte do lado servidor do ModelExecutor, para o lado cliente, este os entrega para o ReportBuilder. Este módulo formata os dados, organiza cronologicamente os eventos e gera um relatório em formato amigável, o qual é posteriormente exibido na tela.

Por se tratar do relatório completo de execução e pela quantidade de informação armazenada no relatório, foi inviabilizada a presença do relatório completo na dissertação. Entretanto, podemos observar na Figura 6.4 o relatório básico de execução quando não são utilizadas opções de logging.

O usuário tem a opção de salvar os dados do relatório em um arquivo a parte. Por definição, independente do local onde o arquivo é salvo, uma cópia é armazenada na pasta de execução do modelo, a qual contém os arquivos do programa de simulação e uma cópia do modelo definido em DML.

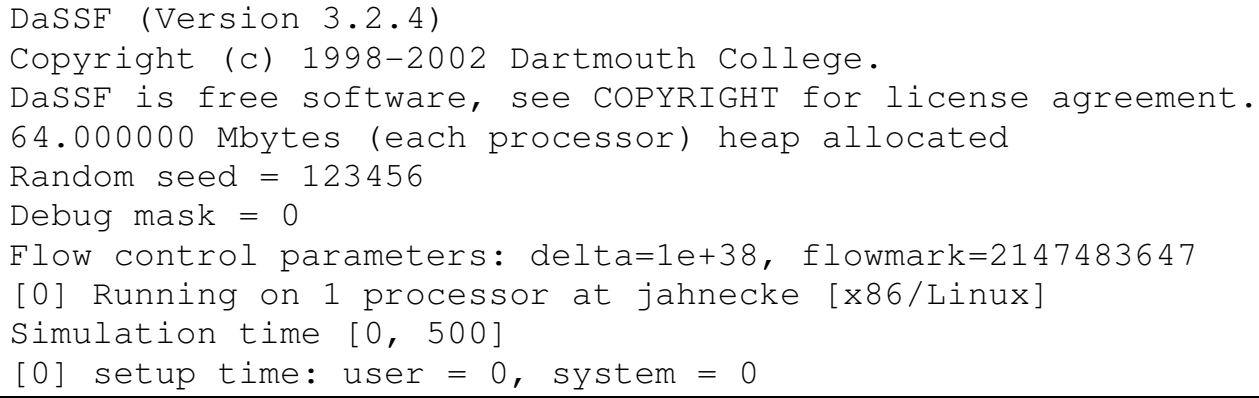




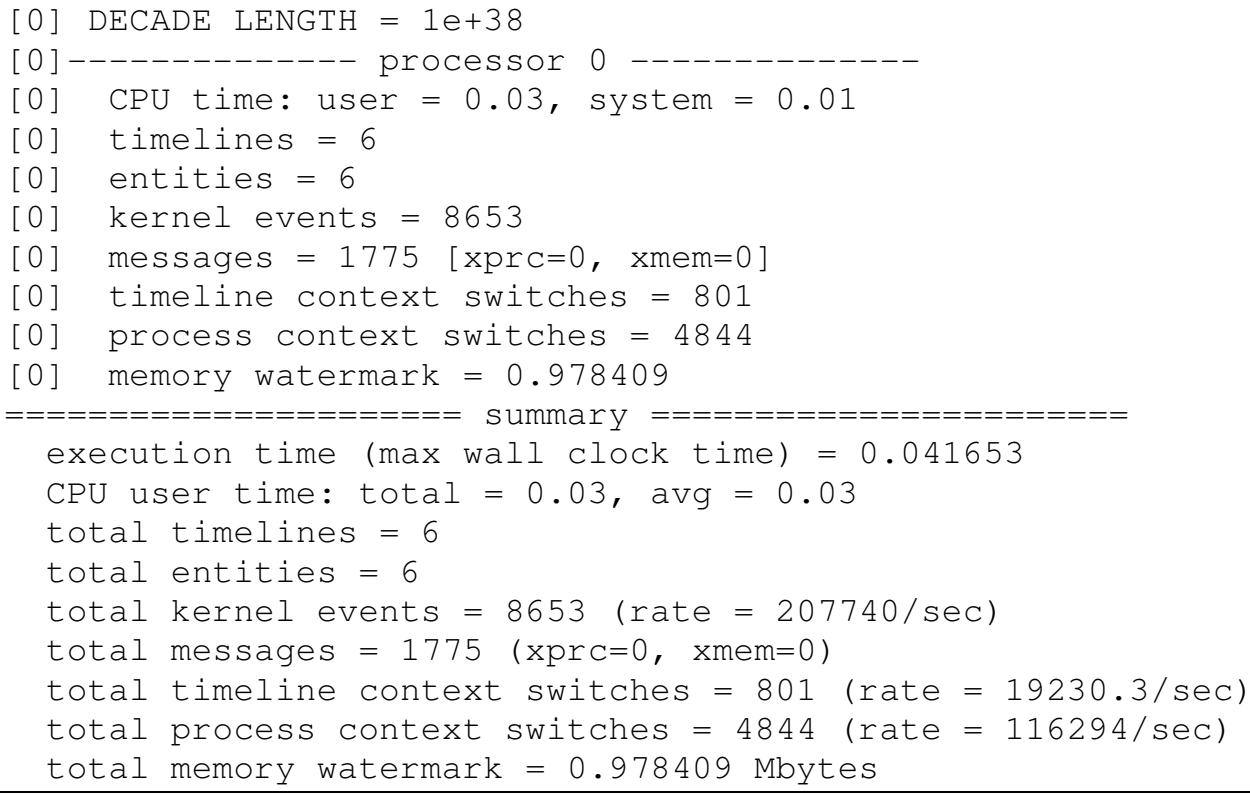

Figura 6.4. Relatório básico de execução do programa de simulação, sem qualquer tipo de opção de logging.

\subsection{Modelo 2}

Para exemplicar a facilidade da definição de uma simulação de modelos de larga escala, a figura 6.5 exibe um modelo com cerca de 50 entidades. Testes com o DaSSF, mostraram que ele suporta a simulação de modelos com milhões de entidades sem comprometimento significativo de seu desempenho.

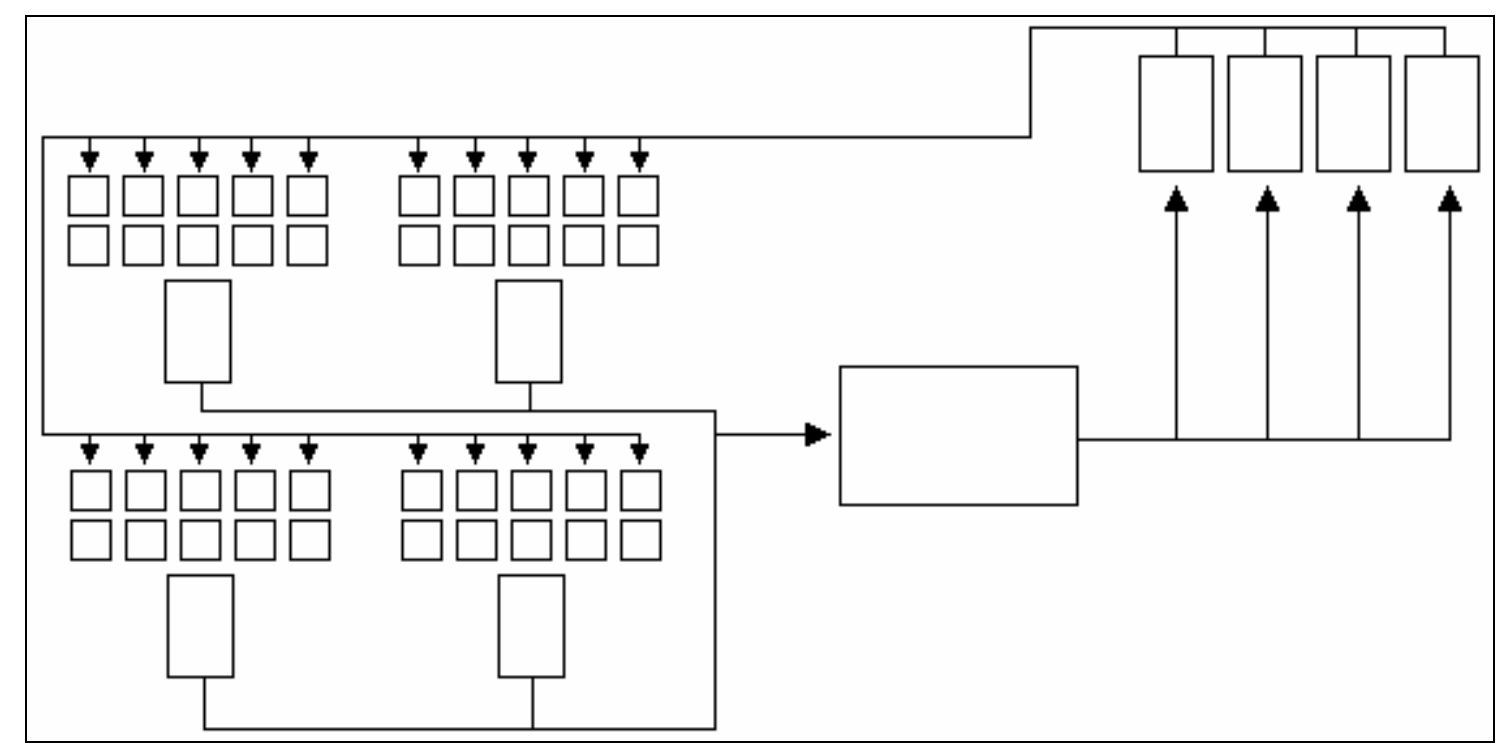

Figura 6.5. Modelo de redes de computadores. 
O modelo discutido aqui se trata de redes de computadores que fazem requisições a um servidor central. Cada rede possui um servidor local, que repassa as requisições da rede para o servidor central. Este, por sua vez, repassa as requisições para outros servidores específicos, que respondem diretamente à máquina que realizou a solicitação. A Figura 6.5 mostra como as redes estão disponibilizadas.

O objetivo deste exemplo não foi o de efetuar mais uma simulação, mas ilustrar a facilidade e a viabilidade de construção de modelos grandes e com inúmeras entidades. $\mathrm{O}$ código DML exibido no Apêndice D demonstra o modelo da Figura 6.5. Pode-se observar que, apesar de extenso, é relativamente simples escrever um modelo grande em DML.

\subsection{Considerações finais}

Este capítulo mostrou o funcionamento básico do SSFSimulator a partir de um modelo de rede de filas. Foram discutidos em alto nível o papel de cada módulo já detalhados nesta dissertação. Com o exemplo proposto, pôde-se observar que o SSFSimulator segue todos os princípios de um ambiente de simulação automático, dentre os quais se destacam a facilidade e a flexibilidade. A sua fácil utilização e a sua flexibilidade favorecem tanto usuários menos quanto mais experientes e permite que o modelo a ser simulado possa ter seu comportamento modificado à medida que o usuário observa que ainda não atingiu seus objetivos.

Todos os arquivos gerados pelo SSFSimulator neste exemplo estão disponíveis no apêndice A. O relatório de execução também foi fornecido. Podemos concluir, por fim, que o SSFSimulator pode ser facilmente integrado a um ambiente de simulação automático e que é viável a sua utilização neste contexto. 


\section{Conclusões}

\subsection{Considerações iniciais}

Os ambientes automáticos de simulação são ferramentas excelentes para a simulação de modelos de forma rápida e eficiente. O Ambiente de simulação distribuída automático (ASDA) não possui um kernel dedicado à simulação de modelos de larga escala, o que o torna inviável para a simulação de modelos grandes, como um modelo de filas que representa a comunicação entre os milhares de mainframes de diversas empresas no mundo, ou ainda de um modelo que representa um cluster de servidores que sirvam a milhares de entidades no menor tempo possível.

O Scalable Simulation Framework (SSF) é uma API idealizada para a simulação de modelos de larga escala que se tornou um padrão público para a simulação destes tipos de modelo. O DaSSF contêm a implementação orientada a objetos (em C++) do SSF e é um kernel de simulação distribuída completo que utiliza a abordagem SRIP, implementando alguns algoritmos de sincronismo conservativos. Apesar da capacidade do DaSSF, construir um programa de simulação que utilize a API SSF não é uma tarefa trivial. O fato de o usuário fornecer um modelo de alto nível também não oferece flexibilidade, pois o kernel não disponibiliza um programa de simulação legível para que o usuário possa modificá-lo de acordo com suas necessidades.

Foi observando essas limitações que se viabilizou a inserção do DaSSF em um ambiente de simulação automático. Para isso, foi necessário que o usuário pudesse, a partir de um modelo escrito em uma linguagem de alto nível que o DaSSF suporte, desenvolver um programa de simulação que utilize o kernel para ser simulado e que ofereça ao usuário todos os benefícios de um ambiente de simulação automático, como visualização de relatórios, configuração do ambiente de simulação, edição e visualização do programa de simulação entre outros benefícios. 


\subsection{Contribuições do trabalho}

As contribuições deste trabalho de Mestrado são várias, destacando-se:

1. Flexibilização da utilização do Scalable Simulation Framework, inserindo-o num contexto de ambiente automático de simulação;

2. Uma possível e viável extensão do Ambiente de Simulação Distribuída Automático (ASDA) de forma que pudesse oferecer aos usuários a possibilidade de simular modelos de larga escala de forma eficiente e flexível;

3. Geração automática de um programa de simulação de modelos de larga escala, que utiliza a API SSF e o kernel de simulação de alto desempenho DaSSF

4. Abstração dos mecanismos internos do DaSSF para a sua utilização na construção de programas de simulação de modelos de larga escala.

\subsection{Produção intelectual parcial}

1) Jahnecke, A. N., Bruschi, S. M., “Towards large-scale simulations: A scalable simulation framework to ASDA”. Artigo aceito mas não publicado (English Short Papers Track), International Information and Telecommunication Technologies Symposium (I2TS 2005), Florianópolis, SC - Brasil, dez. 2005.

Além desse artigo, outros artigos vêm sendo escritos e submetidos a outros eventos promovidos pela comunidade e a pesquisa é de grande relevância, como por exemplo, Winter Simulation Conference (WSC) e Workshop on Parallel and Distributed Simulation (PADS), dado que a modelagem e simulação de sistemas de larga escala é um assunto bastante estudado.

\subsection{Trabalhos futuros propostos}

Além dos benefícios mencionados na seção anterior, este trabalho abre um leque de possíveis pesquisas, como por exemplo:

1. Amplificar o conceito de ambiente imersivo de simulação, através da interação direta do usuário com a simulação, como por exemplo, pausas na simulação, mudança de parâmetros e valores de atributos das entidades durante esta pausa, inserção ou 
extração de entidades durante a simulação, a fim de tornar possível a realização de otimização em modelos realizadas em tempo de execução, entre outros;

2. Utilização de linguagem XML no lugar da DML e criação de uma interface para a modelagem visual e que gera modelos em linguagem XML. Criação de um parser de modelos escritos na linguagem visual do ASDA para modelos em DML e XML;

3. Tornar o DaSSF ou um dos outros kernels de simulação baseados na API SSF como kernel padrão do ASDA e integrar totalmente o simulador ao ASDA;

4. Criação de outras classes de domínios específicos, como protocolos de comunicação, multiplexadores, entidades de redes de computadores (hosts, routers, switches, hubs etc.).

\subsection{Considerações finais}

O ASDA pode se tornar um ambiente mais completo após a inserção de um kernel de simulação de modelos de larga escala em seu contexto. O DaSSF se tornou uma ferramenta mais completa e seu leque de usuários foi ampliado após sua inserção num ambiente de simulação automático.

O número de ferramentas de simulação vem aumentando atualmente. A busca por um padrão de fato não cessa e esta pesquisa favorece à opção de unir duas ferramentas com conceitos diferentes. Podemos concluir que ambas as ferramentas discutidas nesta dissertação são necessárias à comunidade e a ferramenta resultante da pesquisa une os dois conceitos os quais realmente, após vários estudos, tendem a se convergir num só: um ambiente de simulação automático, para simulação distribuída ou não, tanto para modelos de larga escala quanto para modelos menores. 


\section{Referências Bibliográficas}

(Aiza, 2005) AIZA, T. S., Avaliação do Uso de Statecharts Estocásticos e Queuing Statecharts em um Ambiente de Simulação Automático - São Carlos, 2005. Dissertação (Mestrado em Ciências da Computação) - Instituto de Ciências Matemáticas e de Computação - Universidade de São Paulo.

(Bajaj et al., 1999) BAJAJ, L., BAGRODIA, R., MEYER, R., Case Study: Parallelizing a Sequential Simulation Model, In: Proceedings of the 13th Workshop on Parallel and Distributed Simulation - PADS ‘99, May 1-4, 1999 in Atlanta, Georgia

(Bagrodia et al., 1998) BAGRODIA, R.; MEYER, R.; TAKAI, M.; CHEN, Y.; ZENG, X.; MARTIN, J.; SONG, H., PARSEC: A Parallel Simulation Environment for Complex Systems, In: IEEE Computer, v.3, n.10, p.77-85, 1998.

(Banks, 1998) BANKS, J. Principles of Simulation. In: BANKS, J. Handbook of Simulation. Georgia, Atlanta: John Wiley \& Sons, Inc., p. 3-30, 1998.

(Banks \& Dai, 1997) BANKS, J., DAI, J., Simulation Studies of Multiclass Queueing Networks, In: IIE Transactions, v. 29, n. 3, pp 213-219, Mar, 1997

(Banks et al., 2001) J. BANKS, J. S. CARSON, II, B. L. NELSON, and D. M. NICOL. Discrete-event system simulation, 3rd Edition. Prentice Hall, Upper Saddle River, New Jersey, 2001.

(Blumofe et al., 1995) BLUMOFE, R. D., JOERG, C. F., LEISERSON, C. E., RANDALL, K. H., ZHOU, Y., Cilk: An efficient multithreaded runtime system, In: Proceedings of the $5^{\text {th }}$ ACM SIGPLAN Symposium on Principles and Practice of Parallel Programming (PPOPP'95), pags. 207-216, Jul. 1995.

(Bruschi, 2002) BRUSCHI, S. M., "ASDA - Um Ambiente de Simulação Distribuída Automático" São Carlos, 2002. Tese (Doutorado em Ciências da Computação e Matemática Computacional) - Instituto de Ciências Matemáticas e de Computação, Universidade de São Paulo.

(Bruschi, 2004) BRUSCHI, S. M., SANTANA, R. H. C, SANTANA, M. J. S., AIZA, T. S., ASDA: An Automatic Distributed Simulation Environment, In: Proceedings of Winter Simulation Conference 2004 (WSC04), Washington, DC, Dec, 2004

(Bryant, 1977) BRYANT, R.E. Simulation of Packet Communications Architecture Computer. Massachusetts : Massachusetts Institute of Technology, 1977 (Relatório Técnico 188 - MIT-LCS).

(Chandy \& Misra, 1979) CHANDY, K. M.; MISRA J. Distributed Simulation: A Case Study in Design and Verification of Distributed Programs. IEEE Transactions on Software Engineering, v.SE-5, n.5, p.440-452, 1979.

(Cowie, 1999) COWIE, J. H., "Scalable Simulation Framework API Reference Manual", V1.0, http://www.crhc.uiuc.edu/ jasonliu/projects/ssf/papers/ssfapi-manual.pdf 
(Cowie et al., 1999) COWIE, J., LIU, H., LIU, J., NICOL, D., OGIELSKI A., Towards Realistic Million-Node Internet Simulations, In: International Conference on Parallel and Distributed Processing Techniques and Applications (PDPTA'99), jun, 1999.

(Das, 1996) DAS, S. R. Adaptive Protocols for Parallel Discret Event Simulation . In: Proceedings of the 1996 Winter Simulation Conference (WSC'96), Coronado - USA. p. 186-193, December 8-11 1996.

(Ewing et al., 1999) EWING, G.C.; PAWLIKOWSKI, K.; MCNICKLE, D. Akaroa-2: Exploiting Network Computing by Distributing Stochastic Simulation. In: Proceeding of European Simulation Multiconference (ESM'99), Warson - Poland, p.175-181, 1999.

(Fracchia et al., 2003) FRACCHIA, R., GARETTO, M., LO CIGNO, R., A Queueing Network Model of Short-Lived TCP Flows with Mixed Wired and Wireless Access Links, In: IEEE QoSIP 2003 Workshop, Milano, Italy, February 24-26, 2003

(Francês, 2001) FRANCÊS, C. R. L. "Statecharts estocásticos e queueing statecharts: novas abordagens para avaliação de desempenho baseadas em especificação statecharts", 2001. Tese (Doutorado em Ciências da Computação e Matemática Computacional), Instituto de Ciências Matemáticas e de Computação, Universidade de São Paulo.

(Francês et al., 2005) FRANCÊS, C. R. L; OLIVEIRA E. L.; WEYL, J. C. A. C., SANTANA M. J. SANTANA, R. H. C, BRUSCHI, S. M., VIJAYKUMAR, N. L.; CARVALHO, S. V., Performance evaluation based on system modeling using Statecharts extensions, In: Simulation Modeling Practice and Theory, v. 13, n. 7, p. 584-618, 2005.

(Fujimoto, 1990) FUJIMOTO, R.M., Parallel Discrete Event Simulation, In: Communications of the ACM, v.33, n.10, p. 30-53, 1990.

(Fujimoto, 1993a) FUJIMOTO, R. M.,Parallel discrete event simulation: Will the field survive? In: ORSA Journal on Computing, 1993.

(Fujimoto, 1993b) FUJIMOTO, R. M.,Future directions in parallel simulation research. In: ORSA Journal on Computing, 1993.

(Fujimoto, 2000) FUJIMOTO, R. M. Parallel and Distributed Simulation Systems, John Wiley \& Sons, 2000.

(Heidelberger, 1988) HEIDELBERGER, P. Discrete Event Simulation and Parallel Processing: Statistical Properties. In: SIAM J. Stat. Comput, v.9, n.6, p.1114-1132, 1988.

(Jain, 1991) JAIN, R. The Art of Computer Systems Performance Analysis: Techniques for Experimental Design, Measurement, Simulation, and Modeling, Wiley- Interscience, New York, NY, April 1991.

(Jefferson, 1985) JEFFERSON, D. R. Virtual Time. In: ACM Transactions on Programming Languages and Systems, v.7, n.3, p.404-425, 1985.

(Kawabata, 2005) KAWABATA, C. L. O. Simulação Distribuída Utilizando Protocolos Independentes e Troca Dinâmica nos Processos Lógicos. São Carlos, 2005. Tese (Doutorado em Ciências da Computação e Matemática Computacional) - Instituto de Ciências Matemáticas e de Computação, Universidade de São Paulo. 
(Kumar et al., 2001) KUMAR, V., GRAMA, A., GUPTA, A., KARYPIS, G., Introduction to Parallel Computing, Addison-Wesley, 2001.

(Law \& Kelton, 1991) A. M. LAW AND W. D. KELTON. Simulation modeling and analysis, 3rd Edition. McGraw-Hill, New York, 1991.

(Lin, 1993) LIN, Y. B., Will parallel simulation research survive? In: ORSA Journal on Computing, 1993.

(Liu, 2003) LIU, J., Improvements in Conservative Parallel Simulation of Large Scale Models, Doctoral Thesis, University of Dartmouth, 2003.

(Liu \& Nicol, 2001) LIU, J., NICOL, D. M., "DaSSF 3.0 User's Manual", January 2001. http://www.crhc.uiuc.edu/ jasonliu/projects/ssf/papers/dassf-manual-3.1.ps.

(Liu et al., 2003) LIU, J., NICOL, D. M., LILJENSTAM, M., YAN, G., Simulation of large scale networks using SSF, In: Proceedings of Winter Simulation Conference (WSC03), New Orleans, LO, pp. 650-657, 2003

(Liljenstam et al., 2005) LILJENSTAM, M.; LIU, J.; NICOL, D.; YUAN, Y.; YAN, G.; GRIER, C. RINSE: the real-time immersive network simulation environment for network security exercises. In: Proceedings of the $19^{\text {th }}$ Workshop on Principles of Advanced and Distributed Simulation, PADS 2005. 2005. June 2005. p. $119-128$

(MacDougall, 1987) MACDOUGALL, M.H. Simulating Computer Systems Techniques and Tools. The MIT Press, 1987.

(Meng, 1999) MENG, X. Distributed Simulations - Issues and Implementations in Clusters of Workstations Environment. In: Computer Systems Science and Engineering, v.14, n.1, p.27-57, 1999.

(Misra, 1986) MISRA, J. Distributed Discrete-Event Simulation. In: Computer Surveys, v.18, n.1, p.39-65, 1986.

(Moreira, 2005) MOREIRA, E. M. Rollback Solidário: um novo protocolo otimista para simulação distribuída. São Carlos, 2005. Tese (Doutorado em Ciências da Computação e Matemática Computacional) - Instituto de Ciências Matemáticas e de Computação, Universidade de São Paulo.

(Morselli, 2000) MORSELLI, J. C. M. Junior, Um mecanismo para troca de protocolos de sincronização de simulação distribuída em tempos de execução. São Carlos, 2000. Tese (Doutorado em Ciências "Física Aplicada - opção: Física Computacional”) - Instituto de Física de São Carlos, Universidade de São Paulo.

(Nicol et al., 2003) NICOL, D. M., LIU, J., LILJENSTAM, M., YAN, G., "Simulation of large-scale networks using SSF", In: Proceedings of the 2003 Winter Simulation Conference, New Orleans, LA, December 7-10, 2003.

(Noronha \& Abu-Ghazaleh, 2002) NORONHA, R., ABU-GHAZALEH, N. B., Using Programmable NICs for Time Warp Optimization, International Parallel and Distributed Processing Symposium IPDPS'02, Ft. Lauderdale, FL, April 2002. 
(Noronha \& Abu-Ghazaleh, 2002a) NORONHA, R., ABU-GHAZALEH, N. B., Early Cancellation: An Active NIC optimization for Time Warp, Parallel and Distributed Simulation Workshop 2002, Washington, DC, May 2002.

(Ogielski, 1998) OGIELSKI, A. T, "Project S3: Scalable Modeling \& Simulations of Networks", Center for Discrete Mathematics \& Computer Science, out, 1998.

(Overeinder et al., 1991) OVEREINDER, B.; HERTZBERGER B.; SLOOT P. Parallel Discrete Event Simulation. In W.J. Withagen, editor, The Third Workshop Computer Systems, Faculty of Electrical Engineering, Eindhoven University, Eindhoven, The Netherlands, p. 19-30, May 1991.

(Pegden et al., 1995) PEGDEN, C.D.; SHANNON, R.E.; SADOWSKI, R.P., Introduction to Simulation using SIMAN. $2^{\text {nd }}$ ed., MacGraw-Hill International Editions, New York, 1995.

(Perumala et al, 1998) PERUMALA, K., OGIELSKI, A., FUJIMOTO, R., TeD - a language for modeling telecomunication networks, ACM SIGMETRICS, Performance Evaluation Review, 25(4):4-11, Março 1998.

(Reed et al., 1988) REED, D.A.; MALONY, A.D.; McCDREDIE, B.D. Parallel Discrete Event Simulation Using Shared Memory. IEEE Transactions on Software Engineering, v.14, n.4, 1988.

(Reynolds, 1993) REYNOLDS, P. F. , Jr. The silver bullet, ORSA Journal on Computing, 1993.

(Rodrigues, 2006) RODRIGUES, A. F. Inserção da Técnica de Modelagem Redes de Filas em um Ambiente de Simulação Distribuída Automático. São Carlos, 2006. Relatório Científica n. 2 - FAPESP.

(Soares, 1992) SOARES, L.F.G. Modelagem e Simulação Discreta de Sistemas, Editora Campus Ltda, 1992.

(Silva, 2000) SILVA, A. F. Modelos de redes de filas para sistemas computacionais distribuídos. Simulação x Métodos Analíticos. São Carlos, 2000. Dissertação (Mestrado em Ciências da Computação e Matemática Computacional) - Instituto de Ciências Matemáticas e de Computação, Universidade de São Paulo.

(Silva, 2006) SILVA, M. P. 2006. Particionamento de processos lógicos de simulação distribuída utilizando algoritmo genético. São Carlos, 2006. Dissertação (Mestrado em Ciências da Computação e Matemática Computacional) - Instituto de Ciências Matemáticas e de Computação, Universidade de São Paulo.

(Steinman, 1993) STEINMAN, J. S. Breathing Time Warp. In: 7th Workshop on Parallel and Distributed Simulation (PADS'93), California - USA. p. 109-118, 1993.

(Tanir \& Sevinc, 1994) TANIR, O.; SEVINC, S. Defining Requirements for a Standard Simulation Environment. IEEE Computer, p.28-34, February 1994.

(Tay \& Teo, 2001) TAY, S. C., TEO, Y.M., "Performance Optimization of Throttled TimeWarp Simulation", Proceedings 34th Annual Simulation Symposium (SS 2001), Seattle, WA, USA, 22-26 April 2001. 
(Tay et al., 1997) TAY S.; TEO, Y.M.; KONG, S.T. Speculative Parallel Simulation with an Adaptive Throttle Scheme. In: Proceeding of the $11^{\text {th }}$ Workshop on Parallel and Distributed Simulation (PADS'97), Lockenhaus - Austria, p.116-123, 1997.

(Thondugulam et al.,1998) THONDUGULAM, N. V., RAO, D. M., RADHAKRISHNAN, R., WILSEY, P., Unsynchronizes parallel discret event simulation, In: Proceedings of Winter Simulation Conference 1998 (WSC98), Washigton, DC, pp. 1563 - 1570, 1998.

(Unger \& Cleary, 1993) UNGER, B. W., CLEARY, J. G., "Practical parallel discrete event simulation", ORSA Journal on Computing, 5(3):242-244, 1993.

(White et al., 1975) WHITE, J. A., SCHMIDT, J. W., BENNET, G. K., “Analysis of Queueing Systems", Academic Press, New York. 


\section{Apêndice A}

\section{Arquivo cabeçalho da classe de domínio específico}

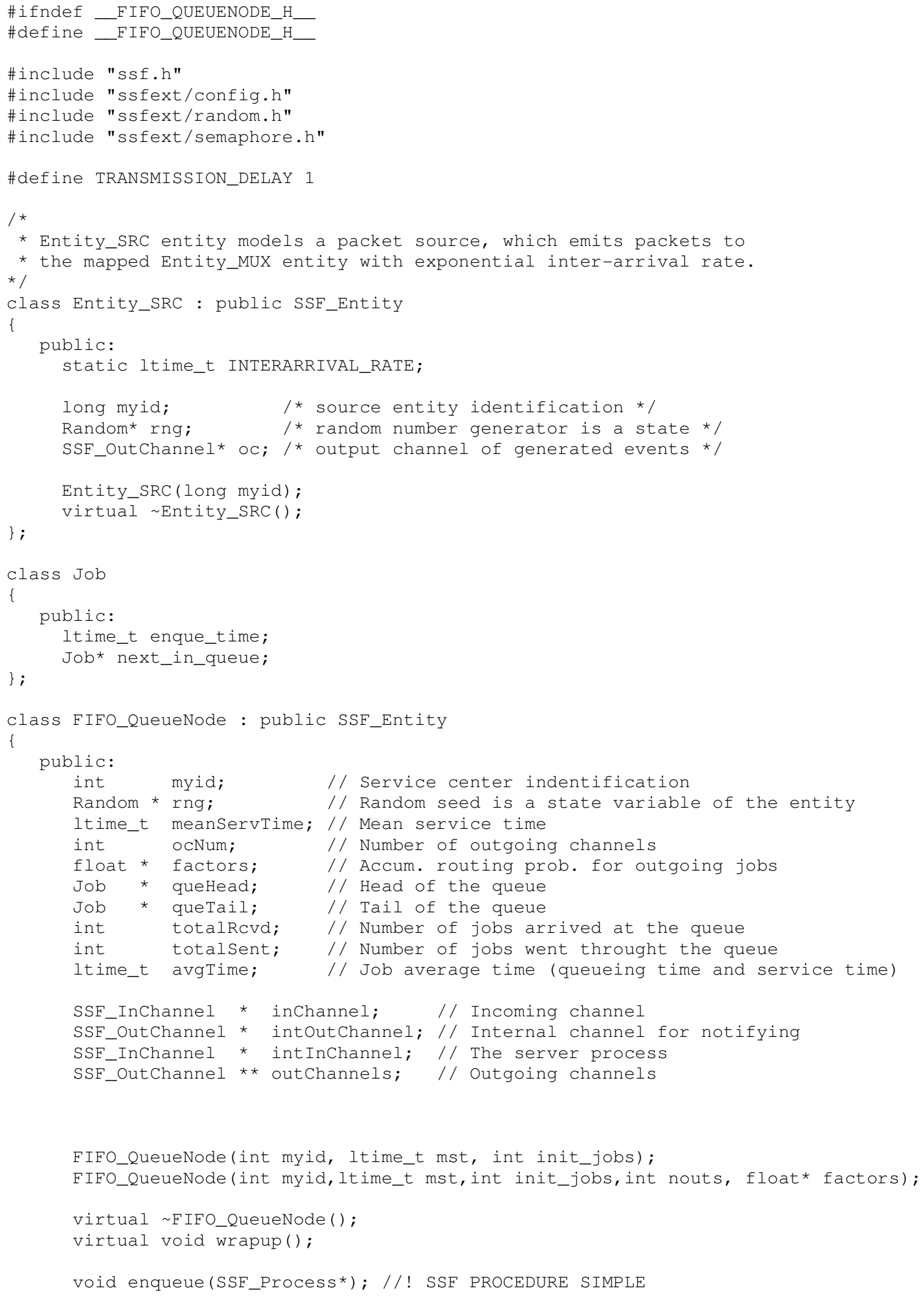


Void service(SSF_Process*); //! SSF PROCEDURE

void insert_init_jobs(int njobs);

\}$;$

\#endif /*_FIFO_QUEUENODE_H__ * / 


\section{Apêndice B}

\section{Arquivo de definição da classe de domínio específico}

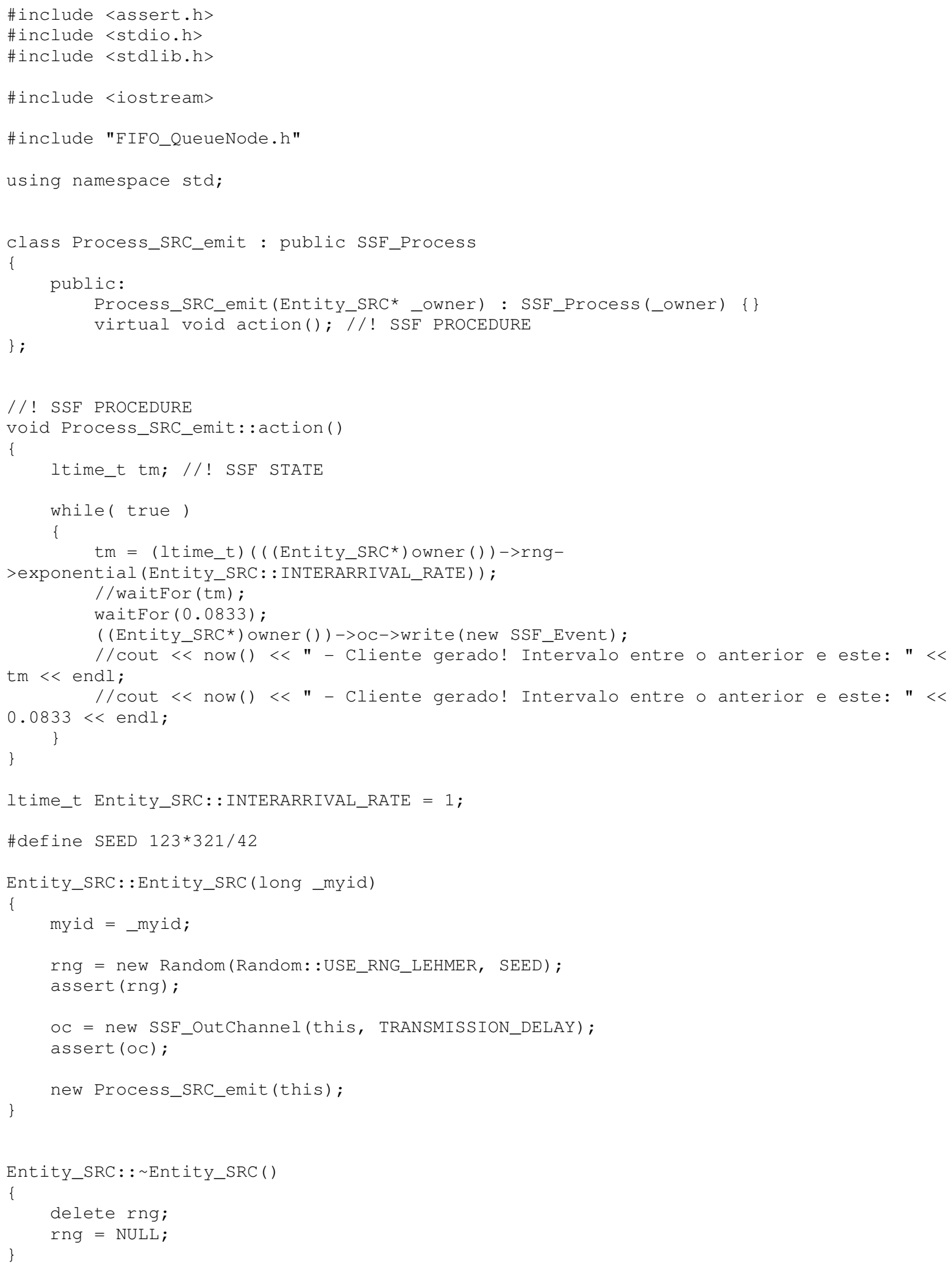




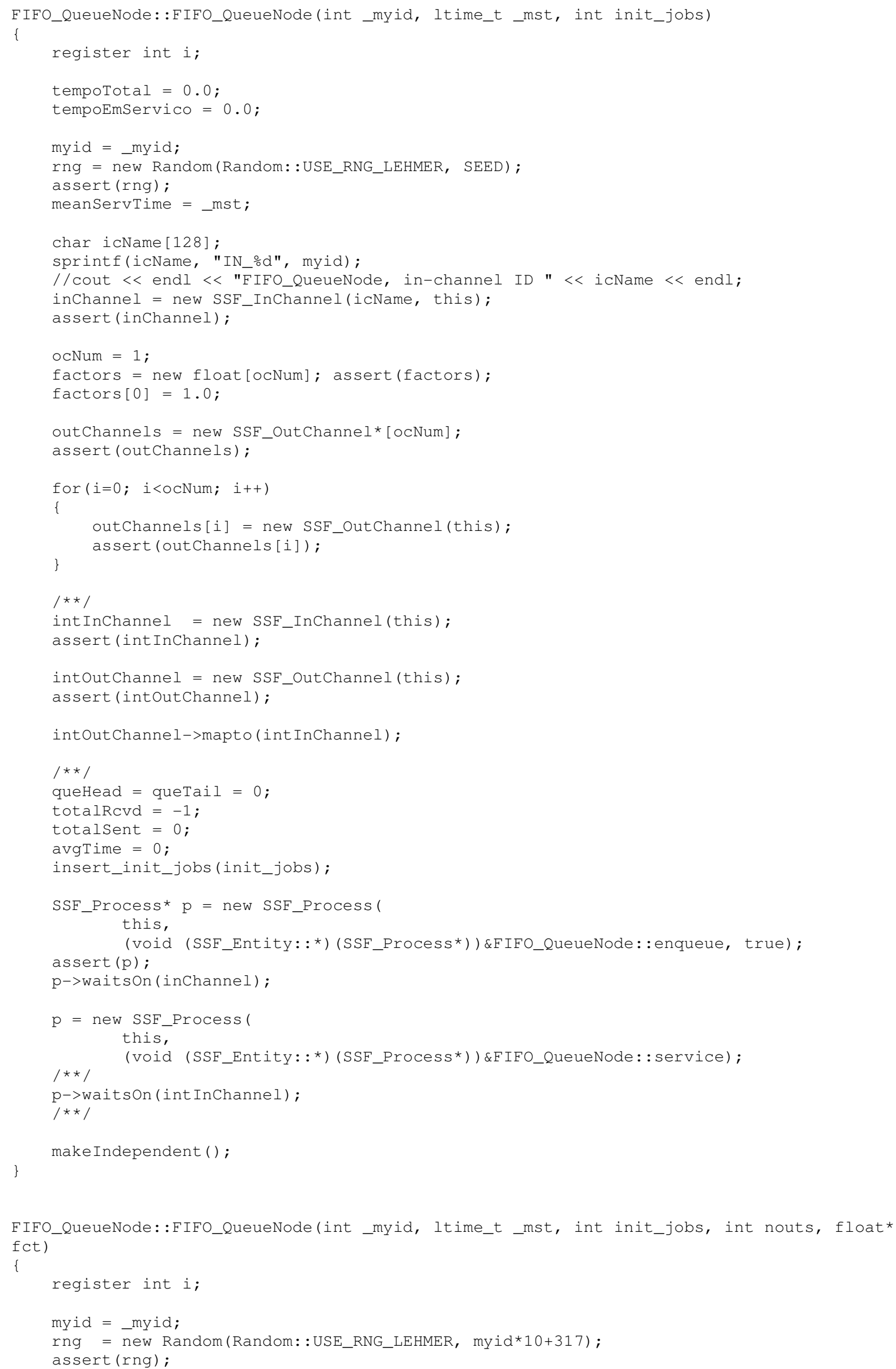




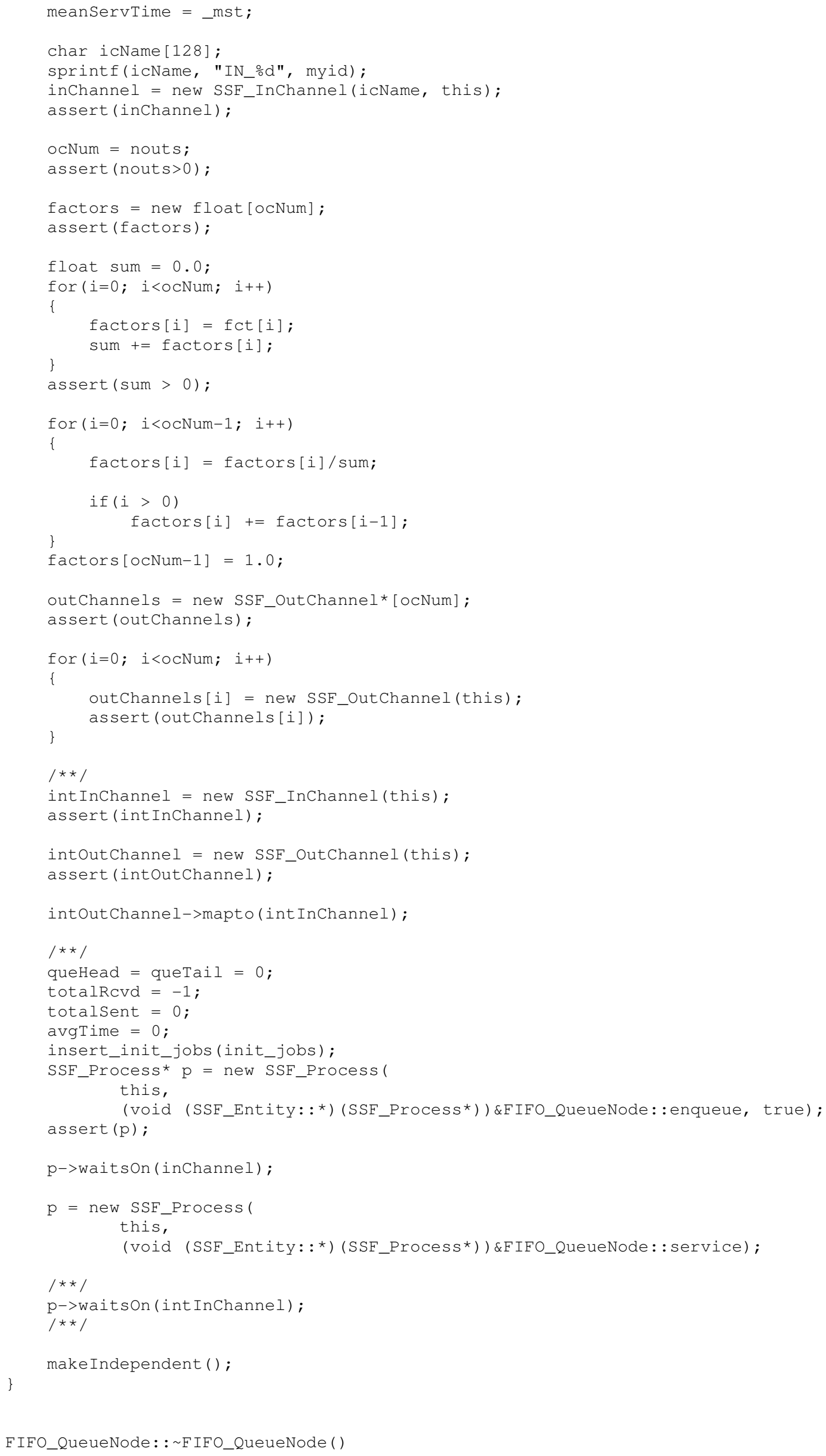




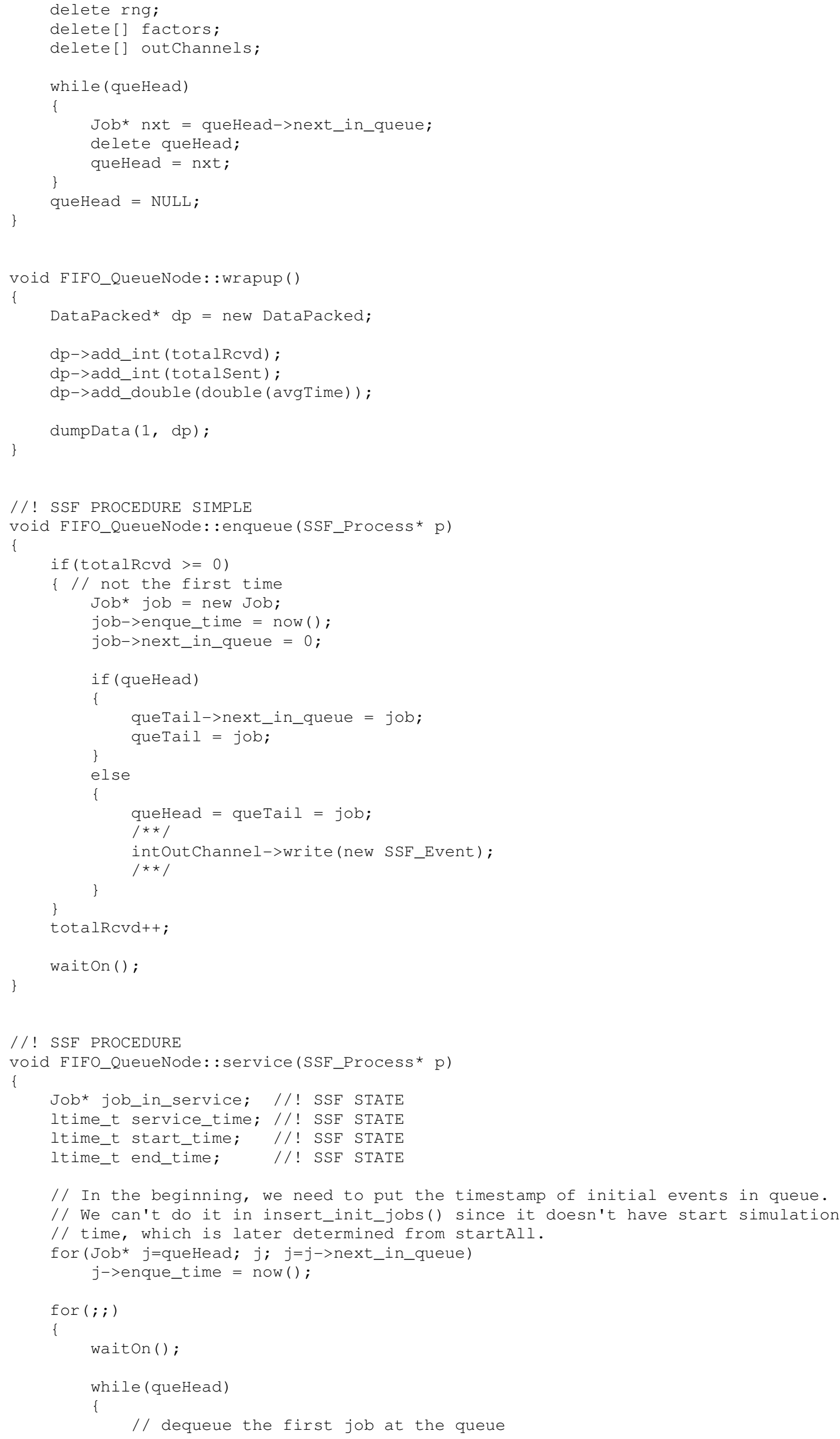




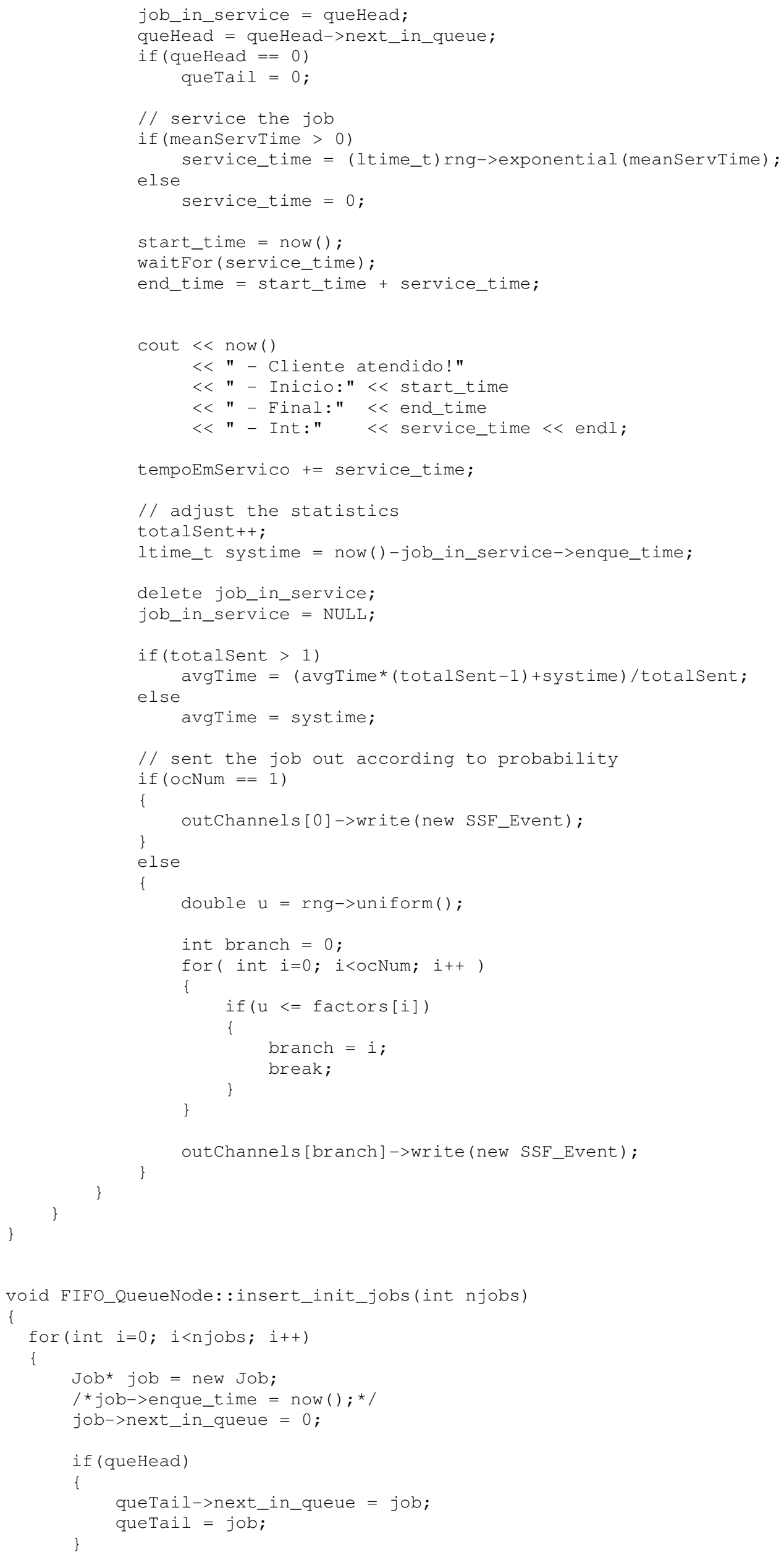




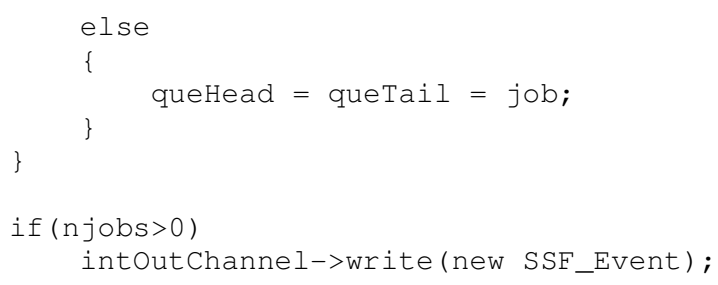




\section{Apêndice C}

\section{Arquivo de validação da classe de domínio específico - Sistema M/M/1}

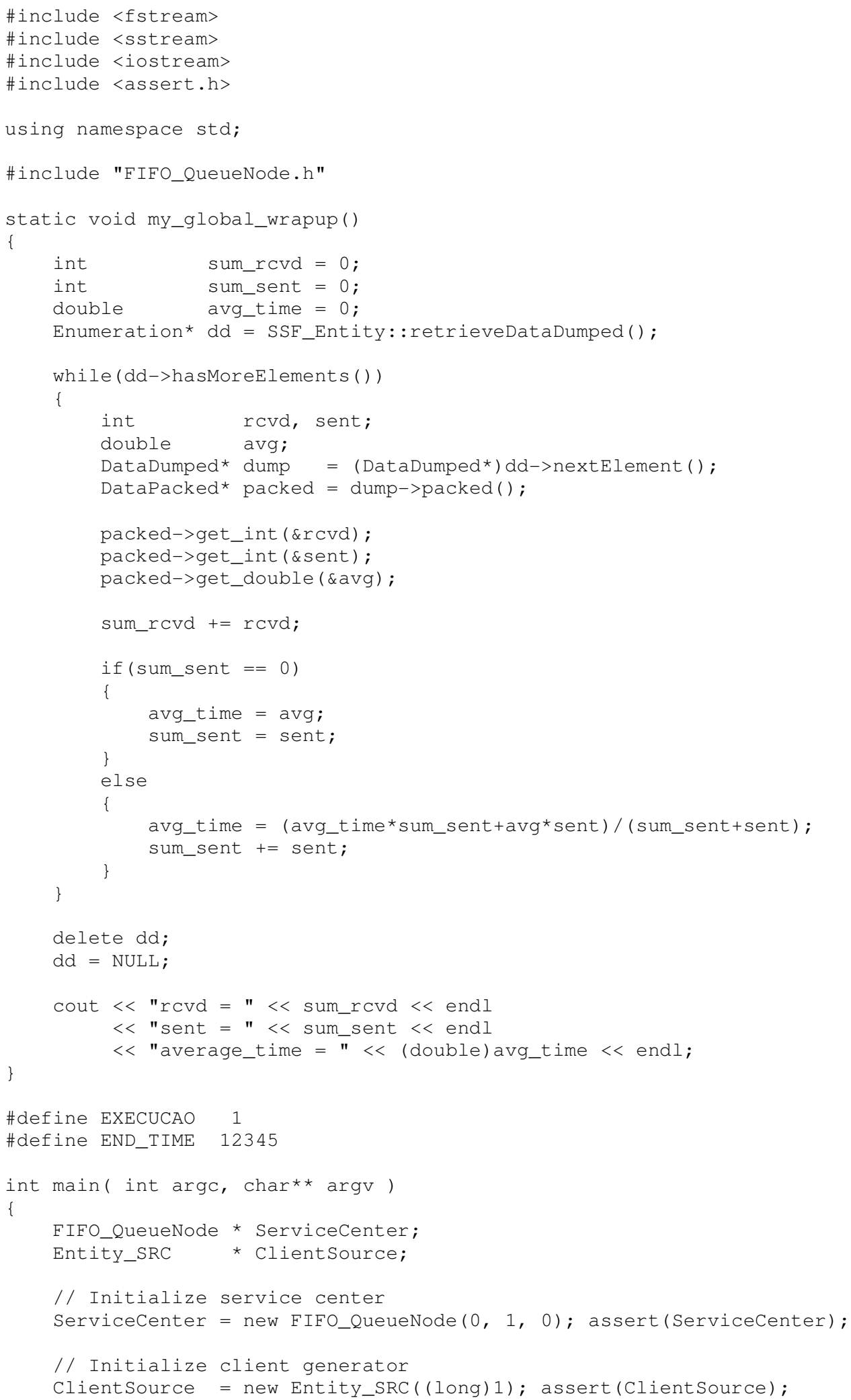


// Map source to service center's in channel

ClientSource->oc->mapto("IN_O");

// Put both entities in the same timeline

ClientSource->alignto (ServiceCenter);

/* The lines bellow will start the simulation */

SSF_Entity: :startAll (0.0, END_TIME);

SSF_Entity: :joinAll();

my_global_wrapup ( ) ;

return 0 ; 


\title{
Apêndice D
}

\section{Arquivo de modelagem de uma rede de computadores, em DML}

\author{
MODEL [ \\ /* Rede 1 */ \\ ENTITY [ID q00 INSTANCEOF "FIFO_QueueNode" PARAMS [FLOAT 1.0 INT 100 INT 1] ] \\ ENTITY [ID q01 INSTANCEOF "FIFO_QueueNode" PARAMS [FLOAT 1.0 INT 100 INT 1] ] \\ ENTITY [ID q02 INSTANCEOF "FIFO_QueueNode" PARAMS [FLOAT 1.0 INT 100 INT 1] ] \\ ENTITY [ID 903 INSTANCEOF "FIFO_QueueNode" PARAMS [FLOAT 1.0 INT 100 INT 1] ] \\ ENTITY [ID 904 INSTANCEOF "FIFO_QueueNode" PARAMS [FLOAT 1.0 INT 100 INT 1] ] \\ ENTITY [ID q05 INSTANCEOF "FIFO_QueueNode" PARAMS [FLOAT 1.0 INT 100 INT 1] ] \\ ENTITY [ID q06 INSTANCEOF "FIFO_QueueNode" PARAMS [FLOAT 1.0 INT 100 INT 1] ] \\ ENTITY [ID q07 INSTANCEOF "FIFO_QueueNode" PARAMS [FLOAT 1.0 INT 100 INT 1] ] \\ ENTITY [ID q08 INSTANCEOF "FIFO_QueUeNode" PARAMS [FLOAT 1.0 INT 100 INT 1] ] \\ ENTITY [ID q09 INSTANCEOF "FIFO_QueueNode" PARAMS [FLOAT 1.0 INT 100 INT 1] ]

\begin{tabular}{|c|c|c|c|c|c|c|c|c|c|c|}
\hline ENTITY & {$[I D$} & q10 & INSTANCEOF & "FIFO_QueueNode" & PARAMS & {$[F L O A T$} & 1.0 & INT & 100 & INT I] \\
\hline ENTITY & {$[I D$} & q11 & INSTANCEOF & "FIFO_QueueNode" & PARAMS & {$[F L O A T$} & 1.0 & INT & 100 & INT 1] \\
\hline ENTITY & {$[I D$} & 912 & INSTANCEOF & "FIFO_QueueNode" & PARAMS & [FLOAT & 1.0 & INT & 100 & INT 1] \\
\hline ENTITY & {$[I D$} & 913 & INSTANCEOF & "FIFO_QueueNode" & PARAMS & {$[F L O A T$} & 1.0 & INT & 100 & INT 1] \\
\hline ENTITY & {$[I D$} & q14 & INSTANCEOF & "FIFO_QueueNode" & PARAMS & {$[F L O A T$} & 1.0 & INT & 100 & INT 1] \\
\hline ENTITY & {$[I D$} & q15 & INSTANCEOF & "FIFO_QueueNode" & PARAMS & {$[F L O A T$} & 1.0 & INT & 100 & INT 1] \\
\hline ENTITY & {$[I D$} & 916 & INSTANCEOF & "FIFO_QueueNode" & PARAMS & [FLOAT & 1.0 & INT & 100 & INT 1] \\
\hline ENTITY & {$[I D$} & q17 & INSTANCEOF & "FIFO_QueueNode" & PARAMS & {$[F L O A T$} & 1.0 & INT & 100 & INT 1] \\
\hline ENTITY & {$[I D$} & 918 & INSTANCEOF & "FIFO_QueueNode" & PARAMS & {$[F L O A T$} & 1.0 & INT & 100 & INT 1] \\
\hline ENTITY & [ID & q19 & INSTANCEOF & "FIFO_QueueNode" & PARAMS & {$[F L O A T$} & 1.0 & $I N T$ & 100 & INT 1] \\
\hline
\end{tabular}




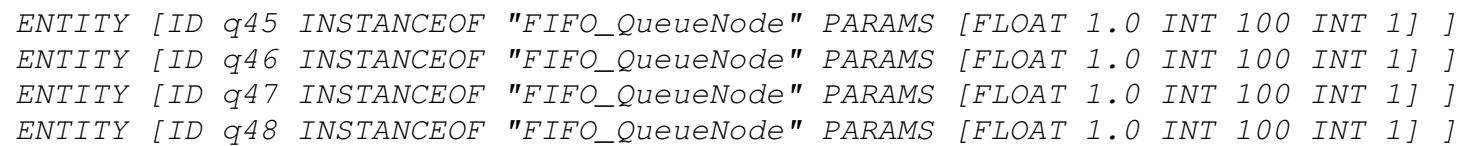

/* Channel mappings */

MAP [FROM qOO(OUT O) TO $q 40$ (IN) DELAY 1]

MAP [FROM Q01 (OUT O) TO $q 40$ (IN) DELAY 1]

MAP [FROM q02 (OUT O) TO 940 (IN) DELAY 1]

MAP [FROM q03(OUT O) TO 940 (IN) DELAY 1]

MAP [FROM q04(OUT O) TO 940 (IN) DELAY 1]

MAP [FROM q05 (OUT O) TO q40(IN) DELAY 1]

MAP [FROM q06(OUT O) TO $q 40$ (IN) DELAY 1]

MAP [FROM q07(OUT O) TO 940 (IN) DELAY 1]

MAP [FROM q08(OUT 0) TO $q 40$ (IN) DELAY 1]

MAP [FROM q09(OUT O) TO 940 (IN) DELAY 1]

MAP [FROM q10(OUT O) TO q4I(IN) DELAY 1]

MAP [FROM q11(OUT 0) TO $q 41$ (IN) DELAY 1]

MAP [FROM q12(OUT 0) TO q41(IN) DELAY 1]

MAP [FROM q13(OUT 0) TO 941 (IN) DELAY 1]

MAP [FROM q14(OUT O) TO $q 41$ (IN) DELAY 1]

MAP [FROM q15(OUT 0) TO q41(IN) DELAY 1]

MAP [FROM q16(OUT 0) TO 941 (IN) DELAY 1]

MAP [FROM q17(OUT 0) TO 941 (IN) DELAY 1]

MAP [FROM q18(OUT O) TO 941 (IN) DELAY 1]

MAP [FROM q19(OUT 0) TO q4I(IN) DELAY 1]

MAP [FROM q20(OUT 0) TO q42(IN) DELAY 1]

MAP [FROM q21(OUT O) TO 942 (IN) DELAY 1]

MAP [FROM q22(OUT 0) TO $q 42$ (IN) DELAY 1]

MAP [FROM q23(OUT 0) TO 942 (IN) DELAY 1]

MAP [FROM q24(OUT 0) TO $q 42$ (IN) DELAY 1]

MAP [FROM q25(OUT 0) TO q42(IN) DELAY 1]

MAP [FROM q26(OUT 0) TO 942 (IN) DELAY 1]

MAP [FROM q27(OUT 0) TO 942 (IN) DELAY 1]

MAP [FROM q28(OUT 0) TO 942 (IN) DELAY 1]

MAP [FROM q29(OUT 0) TO q42(IN) DELAY 1]

MAP [FROM q30(OUT 0) TO 943 (IN) DELAY 1]

$M A P$ [FROM 931(OUT 0) TO 943 (IN) DELAY 1]

MAP [FROM q32(OUT 0) TO q43(IN) DELAY 1]

MAP [FROM 933(OUT O) TO 943 (IN) DELAY 1]

MAP [FROM q34(OUT O) TO 943 (IN) DELAY 1]

MAP [FROM 935 (OUT O) TO 943 (IN) DELAY 1]

MAP [FROM q36(OUT O) TO 943 (IN) DELAY 1]

MAP [FROM q37(OUT 0) TO q43(IN) DELAY 1]

MAP [FROM q38(OUT 0) TO 943 (IN) DELAY 1]

MAP [FROM q39(OUT 0) TO 943 (IN) DELAY 1]

MAP [FROM q4O(OUT O) TO $q 44$ (IN) DELAY 1]

MAP [FROM q4I (OUT O) TO 944 (IN) DELAY 1]

MAP [FROM q42(OUT O) TO 944 (IN) DELAY 1]

MAP [FROM q43(OUT 0) TO 944 (IN) DELAY 1]

MAP [FROM q44(OUT O) TO 945 (IN) DELAY 1]

MAP [FROM 944 (OUT 1) TO $q 46$ (IN) DELAY 1]

MAP [FROM q44(OUT 2) TO 947 (IN) DELAY 1]

MAP [FROM q44(OUT 3) TO 948 (IN) DELAY 1]

MAP [FROM q45(OUT O) TO QOO(IN) DELAY 1]

MAP [FROM q45(OUT 0) TO GOI(IN) DELAY 1]

MAP [FROM q45(OUT 0) TO q02(IN) DELAY 1]

MAP [FROM q45(OUT 0) TO q03(IN) DELAY 1]

MAP [FROM q45(OUT 0) TO q04 (IN) DELAY 1]

MAP [FROM q45(OUT O) TO 905 (IN) DELAY 1]

MAP [FROM q45(OUT 0) TO 906 (IN) DELAY 1]

MAP [FROM q45(OUT 0) TO 907 (IN) DELAY 1]

MAP [FROM q45(OUT 0) TO q08(IN) DELAY 1]

MAP [FROM q45(OUT O) TO Q09(IN) DELAY 1]

MAP [FROM q45(OUT O) TO qIO(IN) DELAY 1] 
$M A P$
[FROM

MAP [FROM q46(OUT O) TO q0O(IN) DELAY 1]

MAP [FROM q46(OUT O) TO qOI (IN) DELAY 1]

MAP [FROM q46(OUT 0) TO q02 (IN) DELAY 1]

MAP [FROM q46(OUT 0) TO q03(IN) DELAY 1]

MAP [FROM q46(OUT 0) TO 904 (IN) DELAY 1]

MAP [FROM q46(OUT 0) TO q05 (IN) DELAY 1]

MAP [FROM q46(OUT 0) TO 906 (IN) DELAY 1]

MAP [FROM q46(OUT 0) TO q07(IN) DELAY 1]

MAP [FROM q46(OUT 0) TO q08(IN) DELAY 1]

MAP [FROM q46(OUT 0) TO q09(IN) DELAY 1]

MAP [FROM q46(OUT 0) TO q10(IN) DELAY 1]

MAP [FROM q46(OUT 0) TO 910 (IN) DELAY 1]

MAP [FROM q46(OUT 0) TO q11(IN) DELAY 1]

MAP [FROM q46(OUT O) TO 912 (IN) DELAY 1]

MAP [FROM q46(OUT O) TO q13(IN) DELAY 1]

MAP [FROM q46(OUT 0) TO 914 (IN) DELAY 1]

MAP [FROM q46(OUT 0) TO 915 (IN) DELAY 1]

MAP [FROM q46(OUT 0) TO q16(IN) DELAY 1]

MAP [FROM q46(OUT 0) TO q17(IN) DELAY 1]

MAP [FROM q46(OUT 0) TO $q 18$ (IN) DELAY 1]

MAP [FROM q46(OUT 0) TO 919(IN) DELAY 1]

MAP [FROM q46(OUT 0) TO q20(IN) DELAY 1]

MAP [FROM q46(OUT 0) TO $q 21$ (IN) DELAY 1]

MAP [FROM q46(OUT 0) TO q22(IN) DELAY 1]

MAP [FROM q46(OUT 0) TO 923 (IN) DELAY 1]

MAP [FROM q46(OUT O) TO 924 (IN) DELAY 1]

MAP [FROM q46(OUT 0) TO q25 (IN) DELAY 1]

MAP [FROM q46(OUT 0) TO q26(IN) DELAY 1]

MAP [FROM q46(OUT 0) TO q27(IN) DELAY 1]

MAP [FROM q46(OUT 0) TO $q 28$ (IN) DELAY 1]

MAP [FROM q46(OUT 0) TO q29(IN) DELAY 1]

MAP [FROM q46(OUT 0) TO q30(IN) DELAY 1]

MAP [FROM q46(OUT 0) TO q31 (IN) DELAY 1]

MAP [FROM q46(OUT 0) TO 932 (IN) DELAY 1]

MAP [FROM q46(OUT 0) TO 933 (IN) DELAY 1]

MAP [FROM q46(OUT O) TO 934 (IN) DELAY 1]

MAP [FROM q46(OUT 0) TO q35(IN) DELAY 1]

MAP [FROM q46(OUT O) TO 936 (IN) DELAY 1]

MAP [FROM q46(OUT 0) TO 937 (IN) DELAY 1] 
$M A P$ [FROM 946(OUT 0) TO 938 (IN) DELAY 1]

$M A P$ [FROM q46(OUT 0) TO q39(IN) DELAY 1]

\begin{tabular}{|c|c|c|c|c|c|c|}
\hline$M A P$ & [FROM & q47 (OUT & 0) & TO & q00 (IN) & DELAY 1] \\
\hline$M A P$ & [FROM & q47 IOUT & 0) & TO & q01 (IN) & $D E L A Y$ 1] \\
\hline IAP & [FROM & q47 (OUT & 0) & TO & q02 (IN) & $D E L A Y$ 1] \\
\hline$A A P$ & [FROM & 47 (OUT & 0) & TO & q03 (IN) & $D E L A Y$ 1] \\
\hline$A P$ & {$[F R O M$} & Q47 (OUT & 0) & TO & q04 (IN) & $D E L A Y$ \\
\hline$A P$ & [FROM & q47 (OUT & 0) & TO & $05(I N)$ & $D E L A Y$ \\
\hline & $O M$ & OUT & 0) & TO & $I N)$ & $\left.\begin{array}{ll}Y & 1\end{array}\right]$ \\
\hline & [FROM & 47 (OUT & 0) & TO & $(I N)$ & $D E L A Y$ 1] \\
\hline$A P$ & {$[F F$} & 47 (OUT & 0) & TO & IN) & DELAY 1] \\
\hline & [FROM & DUT & 0) & TO & IN) & $A Y$ l 1$]$ \\
\hline & & $U T$ & 0) & TO & & $\left.\begin{array}{ll}Y & 1\end{array}\right]$ \\
\hline & & $U T$ & 0) & TO & IN) & 1] \\
\hline$A P$ & {$[F H$} & $U T$ & 0) & TO & IN) & $D E$ \\
\hline$A P$ & [FROM & OUT & 0) & TO & $I N)$ & $A Y$ 1] \\
\hline & & $U T$ & 0) & TO & $I N)$ & $L A Y$ 1] \\
\hline$A P$ & {$[F$} & $U T$ & 0) & TO & $I N)$ & $D E L A Y$ 1] \\
\hline$A P$ & {$[F F$} & IOUT & 0) & TO & IN) & $D E L A Y$ 1] \\
\hline$A P$ & [FROM & lOUT & 0) & TO & $(I N)$ & $D E L A Y$ 1] \\
\hline & {$[F$} & $J T$ & 0) & TO & $I N)$ & $A Y$ 1] \\
\hline$A P$ & & & 0) & TO & & LAY 1] \\
\hline$I A P$ & [FROM & (OUT & 0) & TO & $(I N)$ & $D E L A Y$ 1] \\
\hline$A P$ & {$[F R$} & lOUT & 0) & TO & $(I N)$ & $D E L A Y$ 1] \\
\hline & {$[F]$} & $U T$ & 0) & TO & $I N)$ & {$[A Y$ 1] } \\
\hline$A P$ & & OUT & 0) & TO & & $D E L A Y$ 1] \\
\hline$A P$ & [FROM & 7 IOUT & 0) & TO & $(I N)$ & $D E L A Y$ 1] \\
\hline$M A P$ & [FROM & 94 & 0) & TO & IN) & DELAY 1] \\
\hline & & $T$ & 0) & TO & & DELAY \\
\hline$M A P$ & {$[F R O M$} & q47 (OUT & 0) & TO & $(I N)$ & DELAY 1] \\
\hline$M A P$ & [FROM & q47 IOUT & 0) & TO & $(I N)$ & $D E L A Y$ 1] \\
\hline$M A P$ & [FROM & 947 & 0) & TO & $(I N)$ & $D E L A Y$ 1] \\
\hline$M A P$ & {$[F F$} & $1 O U T$ & 0) & TO & $(I N)$ & DELAY 1] \\
\hline$M A P$ & {$[F R$} & q47 IOUT & 0) & TO & $(I N)$ & $D E L A Y$ 1] \\
\hline$M A P$ & [FROM & Q47 (OUT & 0) & TO & $(I N)$ & $D E L A Y$ 1] \\
\hline$M A P$ & [FROM & Q47 (OUT & 0) & TO & $(I N)$ & $D E L A Y$ 1] \\
\hline$M A P$ & {$[F R O M$} & q47 (OUT & 0) & TO & q33 (IN) & $D E L A Y$ 1] \\
\hline$M A P$ & [FROM & Q47 IOUT & 0) & TO & $(I N)$ & DELAY 1] \\
\hline$M A P$ & {$[F R O M$} & q47 (OUT & 0) & TO & q35 (IN) & DELAY 1] \\
\hline$M A P$ & [FROM & q47 (OUT & 0) & TO & $936(I N)$ & DELAY 1] \\
\hline$M A P$ & [FROM & q47 (OUT & 0) & TO & q37 (IN) & $D E L A Y$ 1] \\
\hline$M A P$ & [FROM & q47 (OUT & 0) & TO & q38 (IN) & DELAY 1] \\
\hline$M A P$ & [FROM & q47(OUT & 0) & TO & q39 (IN) & $D E L A Y$ 1] \\
\hline
\end{tabular}

MAP [FROM q48(OUT 0) TO q00 (IN) DELAY 1]

$M A P$ [FROM q48(OUT O) TO Q01 (IN) DELAY 1]

$M A P$ [FROM q48(OUT O) TO 902 (IN) DELAY 1]

$M A P$ [FROM q48(OUT 0) TO 903 (IN) DELAY 1]

MAP [FROM q48(OUT O) TO GO4 (IN) DELAY 1]

$M A P$ [FROM q48(OUT 0) TO 905 (IN) DELAY 1]

MAP [FROM q48(OUT 0) TO q06 (IN) DELAY 1]

$M A P$ [FROM q48(OUT 0) TO 907 (IN) DELAY 1]

$M A P$ [FROM q48(OUT 0) TO 908 (IN) DELAY 1]

$M A P$ [FROM q48(OUT O) TO 909 (IN) DELAY 1]

$M A P$ [FROM q48(OUT 0) TO q10 (IN) DELAY 1]

MAP [FROM q48(OUT 0) TO q10 (IN) DELAY 1]

$M A P$ [FROM q48(OUT 0) TO q11(IN) DELAY 1]

MAP [FROM q48(OUT 0) TO q12(IN) DELAY 1]

$M A P$ [FROM q48(OUT 0) TO q13(IN) DELAY 1]

MAP [FROM q48(OUT 0) TO q14(IN) DELAY 1]

$M A P$ [FROM q48(OUT 0) TO q15(IN) DELAY 1]

$M A P$ [FROM q48(OUT 0) TO q16(IN) DELAY 1]

$M A P$ [FROM q48(OUT 0) TO q17(IN) DELAY 1]

$M A P$ [FROM 948(OUT 0) TO q18(IN) DELAY 1]

MAP [FROM q48(OUT 0) TO q19(IN) DELAY 1]

MAP [FROM q48(OUT 0) TO q20(IN) DELAY 1]

MAP [FROM q48(OUT 0) TO q21 (IN) DELAY 1]

MAP [FROM q48(OUT 0) TO q22 (IN) DELAY 1] 


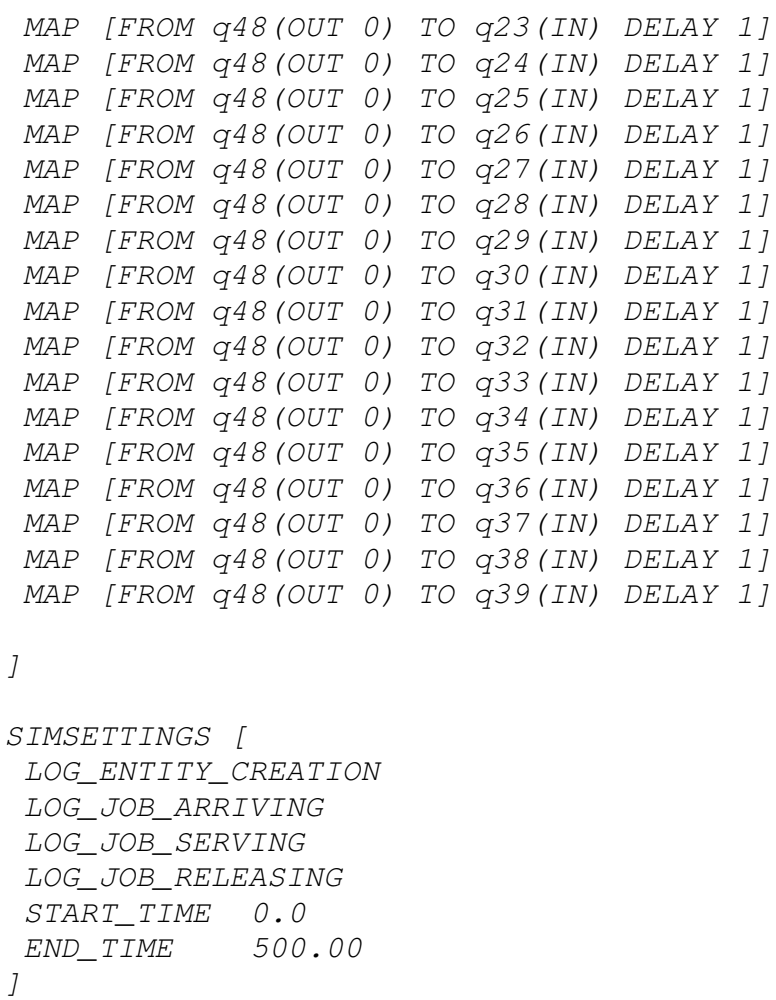

